THE INTERNATIONAL

REVIIEW OF RESEARCH IN

OPEN AND DISTANCE LEARNING

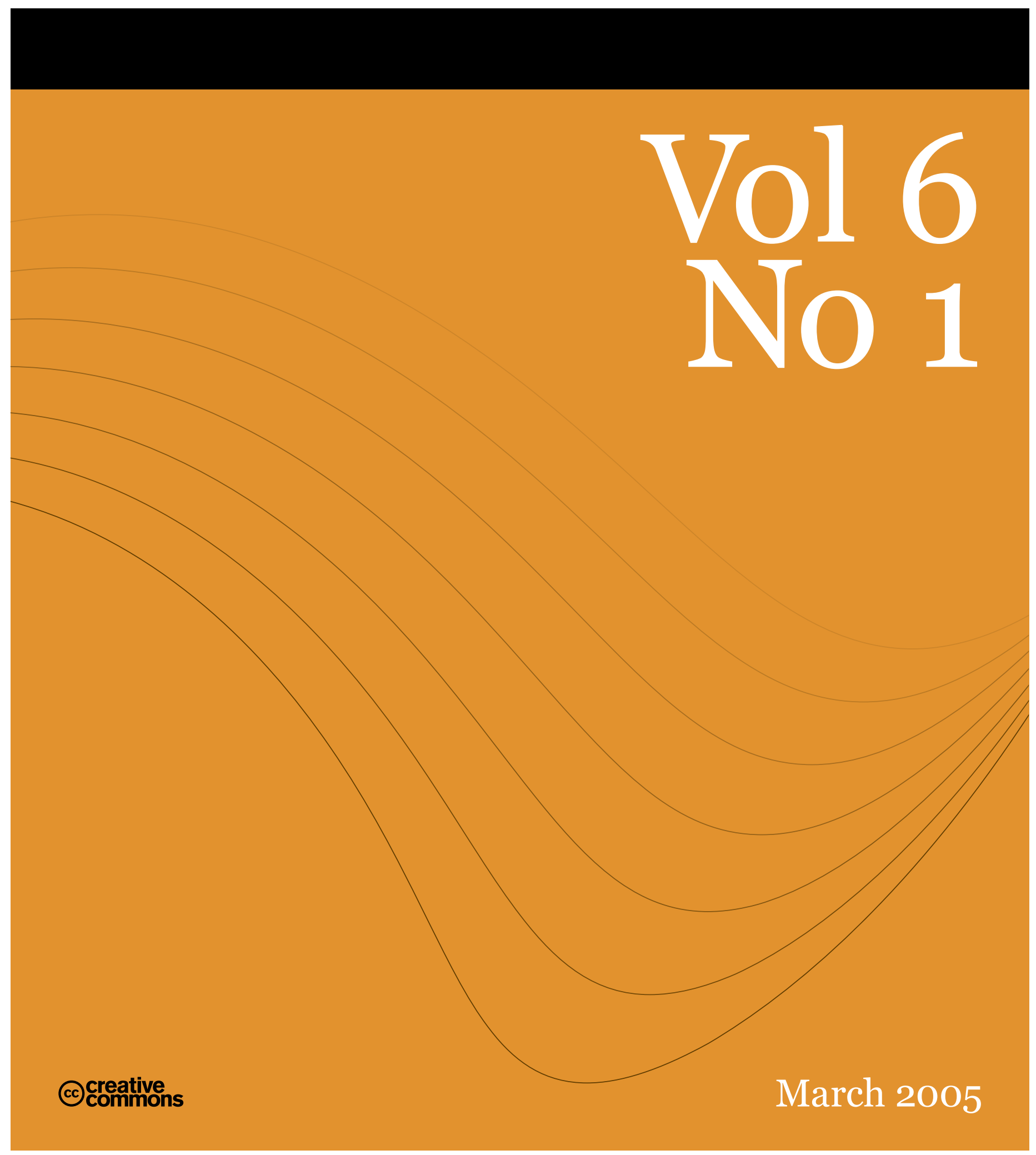


March - 2005

\title{
Guest Editors' Introduction to Special Theme Issue: Strategic Enterprises Down Under
}

\author{
Jeanne McConachie and Patrick Alan Danaher \\ Division of Teaching and Learning Services \\ Central Queensland University, Australia
}

\section{Background and Rationale}

Like all fields and forms of education, open and distance learning is complex, contextualized, and contingent (Harreveld and Danaher, in press; Nouwens, Erdinc and Danaher, 2004) - and is attended by a particular and peculiar ambivalence (see also Stronach and MacLure, 1997). On the one hand, open and distance learning is often accompanied by commentaries about access, equity, and social justice, whereby the empowering and libratory potential of learning in one's own place/ space and at one's own pace/ timescale is highlighted and lauded. On the other hand, open and distance learning is as subject as any other form of educational provision to the influence of forces associated with late capitalism and globalization, at least some of which are linked with the potential destruction of family, workplace, and community relationships and social capital (Rowan, Bartlett and Evans, 1997).

This enduring complexity and ambivalence are represented starkly in this first theme issue of the International Review of Research in Open and Distance Learning to be devoted to a single country, Australia. Strategic Enterprises Down Under: Engaging Drivers of Change in Australian Universities' Open and Distance Learning Provision presents six research-based and refereed studies of key issues pertaining to open and distance learning as it is enacted through a number of 'pressure points' in Australian contemporary universities. As we elaborate below, these pressure points resonate far beyond the geographical space of 'the land down under;' they are associated integrally with the reconfiguration and transformation throughout the Western world of the welfare state into an uncertain amalgam of corporate managerialism and economic rationalism, characterized by the principle of 'user pays,' post compulsory educational pathways, and the construction of learning as a good to be bought and sold (Danaher, Gale and Erben, 2000).

Within this broader context, this theme issue of the International Review of Research in Open and Distance Learning focuses on a topic in Australian universities' open and distance learning provision that is also of concern in most other countries. This topic is the multiple forms of engagement with the drivers of change underpinning such provision. These drivers are many and varied, and include concerns with benchmarking and standards; assuring and ensuring quality; the internationalization of both curriculum and competition; the commodification of knowledge; the massification of higher education; and the increasing reliance on non-government funding sources.

In many respects, the field of open and distance learning provides a lightning rod or a litmus test for the impact and implications of these drivers of change in the Australian university system. 
This field is subject to ongoing redefinitions as 'flexible learning' and 'online learning' enter the equation and push the boundaries between 'on-campus' and 'off-campus' learning and teaching. Competing - and ambivalent - claims are made about open and distance learning as widening equity of access to higher education and as replicating existing socio-cultural elites - as well as being more cost effective and more expensive than the face-to-face mode (Hülsmann, 2004, p. 34).

Managing these and other debates and tensions is no easy business. One potentially instructive approach to mapping the diversity and effectiveness of the management of open and distance learning in Australian contemporary universities is through the conceptual lens of the enterprise system. Enterprise systems "are packages of computer applications that support many, even most, aspects of a company's information needs” (McConachie, 2001, p. 194). Given the centrality of these enterprises to any university's sustainability - even survival - the challenges and opportunities involved in their efficient and strategic management might be argued to encapsulate the broader risks and potentialities of administering Australian universities' open and distance learning provision. As the articles in this issue demonstrate, the interplays between these challenges and opportunities and these risks and potentialities evoke tensions between centralized and decentralized decision-making, questions about which groups constitute universities' legitimate stakeholders, and debates about what universities in the early 21st century should be.

Within this framework, the authors of the articles in this issue address three key questions currently confronting open and distance learning in Australian universities:

1. What is the current 'state of play' of open and distance learning provision in Australian contemporary universities?

2. In what ways does that 'state of play' reflect and represent broader drivers of change in Australian higher education?

3. To what extent does the strategic management in Australian contemporary universities provide effective and efficient engagements with those drivers of change?

In seeking to address these questions, the issue is directed also at considering some of the wider implications of enterprise systems and drivers of change that extend beyond the Australian higher education sector. That is, these systems and drivers might well help to identify and articulate with equivalent principles, policies, and practices in open and distance learning in universities in other countries, where the strategic engagements with contemporary developments take on particular forms and specialized significance.

\section{Process and Structure}

Agreement 'in principle' to this theme issue having been garnered from the journal's Editor, the issue guest editors contacted a number of open and distance learning researchers in Australian universities, representing as many different states as possible. (In Australia, responsibility for higher education lies with the federal government, but state governments have input into particular higher education policies and programs.) The six refereed articles in this issue represent five universities in four states, with the respondents representing a sixth university in a fifth state.

In the first article, Rick Cummings, Rob Phillips, Rhondda Tilbrook, and Kate Lowe, all from the Teaching and Learning Centre at Murdoch University in Western Australia, advocate what they call a 'middle-out' approach to university decision-making and change management, an approach 
that they argue has important strengths in comparison with the more conventional 'top-down' and 'bottom-up' approaches. They illustrate this argument in terms of three cases of change management at Murdoch University:

- The Murdoch Online Mainstreaming project

- A new approach to the development of flexible learning units (courses)

- Mapping the alignment between unit (course) outcomes and graduate attributes

On the basis of these three cases, the authors analyze the three change management approaches in relation to six characteristics: leadership; champions; planning; purpose; institutional culture; and support. They contend that, while the 'middle-out' approach has several advantages, its long-term effectiveness depends on its eventual adoption into universities' formal and/or informal decisionmaking procedures.

In the second article, Ted Nunan from the Flexible Learning Centre at the University of South Australia examines the implications for open and distance learning provision of Australian higher education being constructed by the federal governments in terms of a (de)regulated market and competition for student places and funding. His analysis is framed around five specific features of markets:

- A defined field of production and consumption

- Competition among producers

- Consumers seeking identifiable products

- Price determination and monetary exchange between producers and consumers

- Providers and consumers operating according to how they perceive the market

Nunan concludes his examination by making a number of predictions about future forms of open and distance learning provision, particularly if Australian higher education markets become deregulated.

The third and fourth articles focus on different aspects of quality assurance and Australian university open and distance learning provision. In the third article, Ian Reid from the Flexible Learning Centre at the University of South Australia deploys critical discourse analysis to interrogate the submissions to the Australian Universities Quality Agency by two Australian universities: the University of Southern Queensland, a regional university with a transnational education focus; and the University of Adelaide, one of the traditional and prestigious 'sandstone' universities. Reid asserts that each institution's construction of the relationship between quality and open and distance learning reflects its respective decision-makers' assumptions about its particular location in the higher education marketplace.

In the fourth article, Alistair Inglis from the Centre for Staff Learning and Educational Development at Victoria University compares two frameworks for conceptualizing the quality of open and distance learning provision in Australian universities: the Quality Framework; and the Benchmarking Framework. The comparison is conducted in terms of four criteria: scope; institution type; framework structure; and intended applications. Inglis contends that the Benchmarking Framework is likely to be useful in comparing different universities' approaches 
to open and distance learning, while the Quality Framework is more helpful in assisting operational decision-making at the level of an individual organizational unit.

The fifth and sixth articles evaluate enterprise systems and open and distance learning provision at two Queensland regional universities with national and international outreach. In the fifth article, Alan Smith from the Distance and e-Learning Centre at the University of Southern Queensland reflects on a number of initiatives carried out by the university to engage proactively with sectoral imperatives for change. Focusing on change management processes associated with enterprise systems, Smith considers several examples of initiatives deploying such systems, including the e-University Project, the Generic Online Offline Delivery (GOOD) Project, and USQAssist. He argues that enterprise systems can articulate with a fifth generation model of distance education to facilitate effective and efficient change management.

In the sixth article, Jeanne McConachie, Patrick Alan Danaher, Jo Luck, and David Jones from the Division of Teaching and Learning Services and the Faculty of Informatics and Communication at Central Queensland University present a different view of enterprise systems. They use the distinction between teleological (centralized, purpose driven, and problem solving in orientation) and a teleological (decentralized, locally adopted, and flexible) approaches to systems development to analyze the results of an online survey completed by university staff members and students, particularly in relation to Blackboard as the university's officially designated course management system. This analysis is used in turn to identify broader tensions and struggles around institutional identity, and multiple possible approaches to linking such identity to engagements with change.

The respondents' text has been written by Michael Singh and Jinghe Han from the School of Education and Early Childhood Studies at the University of Western Sydney in New South Wales. Their response is presented in terms of the possible implications of the six articles for understanding the new labor relationships and technologies of Australian universities exporting degrees to meet the rapidly increasing international demand for higher education. One crucial corollary of universities operating in the higher education global marketplace is relentless pressures to cut costs and to boost profits, in order to ensure competitive market share and institutional survival. These pressures are met generally through a combination of deploying technological enterprise systems and intensifying work expectations of individuals and groups, with important implications for both quality assurance and university administration. Singh and Han conclude on a hopeful note, by observing the counter narratives to educational marketization and technological determinism that are evident in different sites and spaces in the higher education terrain.

\section{Implications and Significance}

Despite the focus in this issue of the International Review of Research in Open and Distance Learning on one country - Australia - and one sector - higher education - we hope that readers of the articles in the issue will observe many resonances and similarities with their own countries, sectors, and institutions. Such an outcome is important if the issue is to achieve one of its goals: to use the Australian context as a springboard for reflecting on broader questions about open and distance learning provision, enterprise systems, and drivers of change.

One index of these broader questions is the terms that were cross referenced across two or more of the articles. Some of these terms were as follows:

- Benchmarking 
- Blackboard and WebCT as specific course or learning management systems

- Drivers of change

- Markets

- Quality assurance

- Quality improvement

In themselves, each of these terms is likely to be relevant and significant to individual readers. What they have in common - the ongoing tension between government underfunding and surveillance, or between universities as sites of scholarship and as market competitors - is of concern to everyone with an interest in open and distance learning provision and with a commitment to maximizing the effectiveness, efficiency, and equity of such provision.

Another index of the broader international relevance of the articles in this issue is the responses that they provide to the three questions outlined earlier in this introduction:

1. What is the current 'state of play' of open and distance learning provision in Australian contemporary universities?

2. In what ways does that 'state of play' reflect and represent broader drivers of change in Australian higher education?

3. To what extent does the strategic management in Australian contemporary universities provide effective and efficient engagements with those drivers of change?

The articles demonstrate that, despite common pedagogical possibilities arising from current technological developments, those possibilities are enacted in different ways according to the particular institution in which they occur. Thus open and distance learning provision in Australian contemporary universities is as complex, diverse, and subject to multiple international, national, provincial or state, and local influences as in universities in any other country. This same point applies to the universities' engagements with the drivers of change: while many such drivers are common across universities and countries (for example, the massification of higher education, the commodification of knowledge, and the demise of the welfare state; see also Cookson, 2002, p. 1), individual universities' engagements with those drivers are as much localized as they are globalized in character.

So we end this guest editors' introduction to this special theme issue of the International Review of Research in Open and Distance Learning as we began it: on a note of ambivalence. The drivers of change identified above, and the strategic engagements with those drivers enacted by Australian contemporary universities, are in many cases positive and encouraging: for example, the massification of higher education is providing access to job opportunities and personal and professional development for many more individuals than was previously the case. At the same time, despite the diversity of localized engagements by individual universities, there is a worrying trend toward homogenization and standardization as those universities respond to demands to count, measure, and quantify such processes as quality assurance. It remains to be seen whether the challenges and opportunities highlighted in the articles in this issue, and the tensions and struggles that frame and constrain them, create strategic enterprises - whether 'down under' or elsewhere - that are empowering and liberatory or controlling and restrictive. 


\section{References}

Cookson, P. S. (2002). The Hybridization of Higher Education: Cross-national perspectives. International Review of Research in Open and Distance Learning, 2(2). Retrieved February 19, 2005 from: http://www.irrodl.org/content/v2.2/editorial.html

Danaher, P. A., Gale, T. C., and Erben, T. (2000). The Teacher Educator as (Re)Negotiated Professional: Critical incidents in steering between state and market in Australia. Journal of Education for Teaching, 26(1), 55 - 71.

Harreveld, R. E., and Danaher, P. A. (Eds.) (in press). Multiliteracies and Distance Education: Diversities and technologies in contemporary universities. Theme issue of the Malaysian Journal of Distance Education, 6(1).

Hülsmann, T. (2004). Guest editorial: Low cost distance education strategies: The use of appropriate information and communication technologies. International Review of Research in Open and Distance Learning, 5(1). Retrieved February 19, 2005 from: http://www.irrodl.org/content/v5.1/editorial.html

McConachie, J. (2001). Who benefits from exploratory business research? The effect of subcultures on the implementation of an enterprise system: An Australian regional university perspective. Queensland Journal of Educational Research, 17(2), 193 - 208.

Nouwens, F., Erdinc, Z., and Danaher, P. A. (Eds.) (2004). Evaluation in Open and Distance Education: Retrospects and prospects. Theme issue of the Turkish Online Journal of Distance Education, 5(3), 78.

Rowan, L. O., Bartlett, V. L., and Evans, T. D. (1997). Shifting Borders: Globalisation, localisation and open and distance education. Geelong, Vic: Deakin University Press.

Stronach, I. M., and MacLure, M. (1997). Educational Research Undone: The postmodern embrace. Buckingham, UK: Open University Press.

\section{Acknowledgments}

The editors are grateful to the contributing authors whose articles constitute an important contribution to scholarship about open and distance learning 'down under;' to Professor Michael Singh and Ms Jinghe Han for so effectively taking on the role of respondents to the articles; to Professor Terry Anderson and Ms Paula Smith for hospitably creating space for this theme issue in the International Review of Research in Open and Distance Learning and for invaluable support in making the theme issue a reality; to the anonymous referees whose detailed feedback on the articles helped to strengthen them; and to Mr Michael Secker who copyedited the originally submitted versions of the articles. 
March - 2005

\title{
Middle-Out Approaches to Reform of University Teaching and Learning: Champions striding between the "top-down" and "bottom-up" approaches
}

\author{
Rick Cummings, Rob Phillips, Rhondda Tilbrook, and Kate Lowe \\ Teaching and Learning Centre \\ Murdoch University \\ Perth, Australia
}

\begin{abstract}
In recent years, Australian universities have been driven by a diversity of external forces, including funding cuts, massification of higher education, and changing student demographics, to reform their relationship with students and improve teaching and learning, particularly for those studying off-campus or part-time. Many universities have responded to these forces either through formal strategic plans developed top-down by executive staff or through organic developments arising from staff in a bottom-up approach. By contrast, much of Murdoch University's response has been led by a small number of staff who have middle management responsibilities and who have championed the reform of key university functions, largely in spite of current policy or accepted practice. This paper argues that the 'middle-out' strategy has both a basis in change management theory and practice, and a number of strengths, including low risk, low cost, and high sustainability. Three linked examples of middle-out change management in teaching and learning at Murdoch University are described and the outcomes analyzed to demonstrate the benefits and pitfalls of this approach.
\end{abstract}

\section{Introduction}

What do we know about change in universities and how it is managed? Recent research, both in the higher education sector and in the broader corporate sector, has contributed significantly to our understanding of change in higher education (Hannan and Silver, 2000; Ramsden, 1998; Scott, 2003). The drivers leading to and processes of how universities manage change (see also McConachie and Danaher; Nunan; Reid; McConachie, Danaher, Luck, and Jones, this issue) are now better understood. In the area of teaching and learning, recent change within Australian universities has been driven by a number of forces, including Australian government initiatives, resulting in a plethora of reactions from institutions. The top-down (see Inglis, this issue) and bottom-up approaches to change management have been commonly used in universities (sometimes jointly), and are well documented (Anderson, Johnson, and Milligan, 1999; Bates, 1999; Miller, 1995). 
Middle-Out Approaches to Reform of University Teaching and Learning

Cummings, Phillips, Tilbrook, \& Lowe

Applying a Content, Context and Process Model of change management (Pettigrew and Whipp, 1991), this paper highlights six characteristics which distinguish between these two approaches to change management. Furthermore, the process of examining Murdoch University's change management strategy in teaching and learning against these characteristics, it was found that Murdoch University did not fit into either the top-down or bottom-up approaches to change, but rather a third approach focusing on middle management emerged, which we have termed the 'middle-out' approach. The paper identifies the ways in which the characteristics are manifest in three examples of change management in teaching and learning. The paper concludes by highlighting the way that the middle-out approach has influenced the strategic direction of the university.

Prior to exploring change management in teaching and learning in higher education, however, it is useful to summarize why change is such a critical topic in Australia's higher education system.

\section{Managing Change in Australian Universities}

In universities in Australia, as in most parts of the developed world, the rate and direction of change and the forces driving it are major concerns. Change is now a common process in universities, which are struggling to manage it - if they are managing it. The forces driving change are many and diverse and they are well documented. For example, "Globalisation, massification of higher education, a revolution in communications and the need for lifelong learning, leave Australian universities nowhere to hide from the winds of change” (Nelson, 2003, n.p.; see also Nunan, this issue).

Scott (2003) has summarized the influences for change created by these "winds” as:

- Rapid rise in competition

- $\quad$ Significant decrease in university funding from government sources

- Greater government scrutiny

- Growing consumer-rights movement in higher education

- Rapid spread of information and communications technology for university administration and as a delivery mechanism for higher education courses

One of the areas of greatest concern is the impact that the move to mass higher education in Australia will have on the quality of teaching and learning. The demographics of higher education in the western world have changed dramatically in the past two decades. Prior to the 1980s, higher education was for elite students and privileged five to ten per cent of the population who had the interest, motivation, and ability to learn largely on their own. However, higher education in most western developed countries is now clearly for the masses. In Australia, for example, the participation rate of 15-24 year olds rose from under 10 per cent in 1985 to over 18 per cent in 2001 (Australian Bureau of Statistics, 2003).

This growth has not only dramatically increased student numbers but also resulted in people with a broader range of academic ability taking part in higher education, causing concern that a proportion, perhaps a large proportion, will have greater difficulty in learning university level 
Middle-Out Approaches to Reform of University Teaching and Learning

Cummings, Phillips, Tilbrook, \& Lowe

material, particularly when presented through traditional lecture-based teaching. This has reinforced a requirement to improve teaching and learning processes to address the needs of a larger and more diverse student population. For example, as Laurillard argues, the success of lectures

... depends on the lecturer knowing very well the capabilities of the students, and on the students having very similar capabilities and prior knowledge. Lectures were defensible, perhaps, in the old university systems in which students were selected through standardised entrance examinations. Open access and modular courses make it most unlikely that a class of students will be sufficiently similar in background and capabilities to make lectures work as a principal teaching method (2002, p. 93).

The Australian Government's perception of how this will impact on the quality of teaching and learning is summarized in the following passage from the recent national review report:

Patterns of student enrollment and engagement in higher education have changed significantly. These developments have generated new expectations. Australia is actively positioning itself within an international 'knowledge-based economy,' which has placed new demands on higher education. The growth of the knowledge or digital economy has been accompanied by the promise of improved educational experiences through increased use of information and communication technologies, which many higher education institutions have readily adopted. The development of online learning poses both opportunities and challenges (Department of Education, Science, and Training, 2002, n.p.).

\section{National Approaches to Improving Teaching and Learning in Australia}

The Australian Government has been involved in efforts to improve the quality of teaching and learning in universities since 1990 through initiatives focused on project funding, including the Commonwealth Staff Development Fund (CSDF), the Committee for the Advancement of University Teaching (CAUT), the Committee for University Teaching and Staff Development (CUTSD), and the Australian Universities Teaching Committee (AUTC) (http://www.autc.gov.au/index.htm). After several years of reduced funding for teaching development, the government has recently allocated increased funding to establish the national Carrick Institute for Learning and Teaching in Higher Education.

Despite significant funding for projects aimed at improving teaching and learning, both in Australia and overseas, the success of these initiatives has been questioned (Alexander and McKenzie, 1998; Haywood, Anderson, Day, Land, Macleod, and Haywood, 1998), and there is little evidence of widespread improvements from national project funding. Johnston (1996) has argued that the project funding approach is flawed, because it relies on the 'dissemination' of outcomes, under the assumption that the dissemination of educational innovation occurs similarly to that of scientific innovation. She argues that this is an inappropriate model because, unlike scientific innovation, educational innovation is not a package which can be provided to staff to implement. Instead:

. . . learning to teach in new ways comes about from a more complex set of circumstances than applying new theoretical knowledge disseminated in formal 
Middle-Out Approaches to Reform of University Teaching and Learning

Cummings, Phillips, Tilbrook, \& Lowe

modes. This complex set of circumstances comprises: the establishment of a culture in which innovative teaching is expected and rewarded, and in which teams or departments rather than isolated individuals are the unit of change; the use of strategies which involve discussion, sharing of experiences, reflection and collaborative learning; and then the support of innovation through encouragement, recognition and resources (Johnston, 1996, p. 303).

The Australian initiatives identified above did succeed, however, in focusing greater attention on the need to improve teaching and learning in Australian universities, particularly in using technology, but largely failed to bring about substantial change in the sector (Department of Education, Science, and Training, 2002). For example, in a national review of professional development of university teachers, Dearn, Fraser, and Ryan (2002) found that the previous years of funding and attention had not replaced the disparate approach to professional development in universities by a more evidence-based approach. As a result, individual universities have had to take the lead in managing change in teaching and learning.

\section{Some Key Issues in Change Management in Universities}

An examination of the literature identifies a plethora of models of change management, including organizational models, soft systems models, and process flow models (see Iles and Sutherland, 2001, for a review of change management models). The Content, Context and Process Model (CCP) developed by Pettigrew and Whipp (1991) was found by the authors to be most relevant to teaching and learning in universities because it places change within a historical, cultural, economic, and political context, and it emphasizes the importance of interacting components. The main premise of this model is that successful change is a result of the interaction among the content or what of change (objectives, purpose, and goals); the process or how of change (implementation); and the organizational context of change (the internal and external environment). The model proposes the following eight interlinked factors as important in determining how successful a specific change will be:

1. Key people leading change (especially a multidisciplinary team)

2. Quality and coherence of local policy (analytic and process components)

3. Co-operative inter-organisational networks

4. Supportive organisational culture, including the managerial subculture

5. Moderate, predictable and long-term environmental pressure

6. Simplicity and clarity of goals and priorities

7. Positive patterns of managerial and staff relations

8. Fit between the change agenda and the locale (Pettigrew and Whipp as summarized by Iles by Sutherland, 2001, p. 32)

As indicated above, the two most common approaches to achieving change in universities are top-down and bottom-up (Anderson, Johnson, and Milligan, 1999; Bates, 1999; Miller, 1995). The top-down approach seeks to achieve change through the imposition of central policies, using 
Middle-Out Approaches to Reform of University Teaching and Learning

Cummings, Phillips, Tilbrook, \& Lowe

power-coercive strategies to effect change - that is, change is forced through strategic, financial, or industrial means (Miller, 1995). On the other hand, the bottom-up approach involves organic change arising from innovators and early adopters (Rogers, 1995), or through academics working individually or in groups, to manage the university through rational discussion and democratic decision-making processes (see also the teleological and ateleological systems discussed by McConachie, Danaher, Luck, and Jones, this issue). Longer term change management strategies often commence with one approach and evolve into the other.

With this framework in mind, the authors undertook a critical reflection on change management practices which had emerged in teaching and learning at Murdoch University over the last six years. As participant observers in this process, our observations and critical judgments were one source of data used in this study; however, other evidence was obtained from internal documents and evaluations of various initiatives in the overall change process. This analysis of change management processes at Murdoch University identified a possible third change management option, one led by middle managers, responding to demands from innovative members of the teaching staff but operating in the absence of strong and consistent leadership from either the senior executive or the academic policy-making body. This emergent model of change, termed the middle-out approach, is based both on critical analysis and on theoretical perspectives. It is the viability and usefulness of this third approach which is explored in the remainder of this paper.

As well as the CCP model discussed earlier, an additional theoretical perspective on change management of teaching and learning in universities was provided by McNaught, Phillips, Rossiter, and Winn (2000) in their national investigation of the adoption of computer facilitated learning resources in 28 Australian universities. McNaught and her colleagues concluded that across a range of universities three factors were critical: policy, culture, and support. Policy was identified with the top-down approach, including the degree of leadership, the existence of specific institutional policies, the extent to which these policies were aligned and congruent in a particular university, and the strategic processes such as grant schemes which flowed from policies.

Culture represents the bottom-up approach, comprising factors such as the extent of collaboration within institutions, the personal motivation of innovators, and characteristics of the institution such as staff rewards, teaching and learning models, and attitudes toward innovation.

The third component, support, comprises the range of institutional infrastructure designed to assist and facilitate the change process, such as the library and information technology services, professional development of staff, student support, educational design support, and information technology literacy support for staff and students. McNaught and her colleagues (2000) represented the three components as a Venn diagram, recognizing that where change takes place there is an overlap among the three components of policy, culture and support (see Figure 1). 
Figure 1. Simplified Model of the Factors Identified As Important in the Adoption of Changes in Teaching and Learning Practice (McNaught, Phillips, Rossiter, andWinn, 2000)

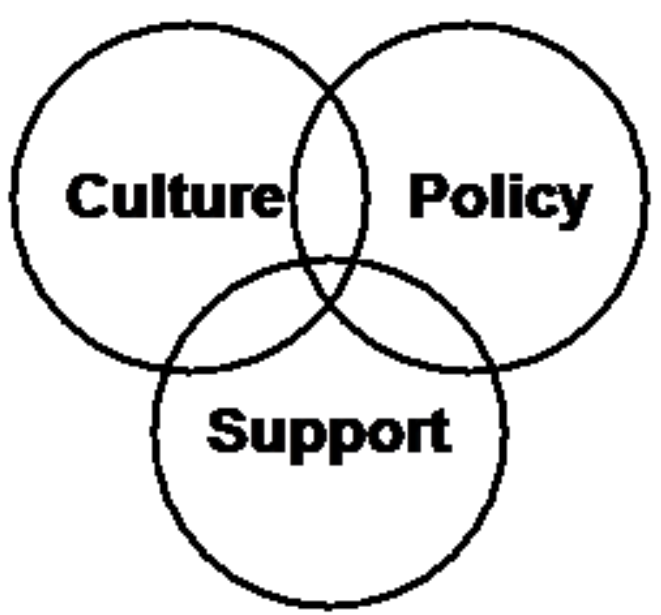

McNaught and her colleagues (2000) portrayed support as a reactive role, underpinning the main players in the change game - the university administration and the teachers at the chalkface. The experiences at Murdoch University, however, indicate that the support component can play a proactive rather than a passive role, driving change outward from the middle, through operational planning and project management, solving problems, and facilitating a connection between central vision and chalkface practice. The middle-out approach is therefore closely aligned with the support component in the diagram by McNaught and her colleagues.

The three approaches to change management in universities examined in this paper are not necessarily mutually exclusive even within a single change management event. However, it is argued that the three approaches have quite different characteristics and operate in distinctive institutional environments. Furthermore, an understanding of the middle-out approach may shed some light on recent change in Australian universities and provide possible lessons for future change. Three linked examples of middle-out change management at Murdoch University are presented in the next section, followed by a comparative analysis of the top-down, bottom-up, and middle-out approaches to change management in universities.

\section{Three Cases of Change Management in Teaching and Learning}

Murdoch University has been a dual mode university since its inception in 1975, with courses of study offered in both internal (on-campus) and external (distance) modes. The external study mode was based on the systems approach of the United Kingdom Open University, with printbased study guides, and readers supplemented by audiocassette tapes. Over time, the internal and external study modes evolved separately in many units (courses), with different study materials and unit coordinators. In responding to this unsustainable structure and the forces of change identified at the beginning of this article, three linked initiatives were undertaken at Murdoch University in the period 1995-2003 which impacted significantly on change in teaching and learning. These are described below in order to inform subsequent discussion of the emergent middle-out change management strategy and its comparison to the top-down and bottom-up approaches. 
Middle-Out Approaches to Reform of University Teaching and Learning

Cummings, Phillips, Tilbrook, \& Lowe

\section{Online and blended learning}

In 1995, Murdoch University started to explore the potential of online teaching through substantial grant funding which was distributed across the university, in a bottom-up approach, to individuals and small groups of academic staff who used them to develop a range of innovations in online teaching and learning, some of which were supported by an online template-based system through the Teaching and Learning Centre. The initial success of this initiative, coinciding with the hype of the dot-com era, encouraged the vice-chancellor in 1997 to brand the university as a virtual university, naming it Murdoch Online, and a new, online mode of enrollment was created. Unfortunately, this top-down vision was not matched by continued funding for either central resources or unit development,or by rewards for staff who adopted its fully online approach. As a result, staff, who were initially enthusiastic, lost heart at the workload involved in developing HTML pages themselves, with little evidence of support from the centre.

Staff in the Teaching and Learning Centre recognized that the online initiative, and the benefits which could flow from it, were under threat and convinced management to provide central funding to implement the WebCT learning management system (see also Smith; McConachie, Danaher, Luck and Jones, this issue). The Centre staff also undertook a number of support activities including software improvements linking the student record system to WebCT and developing templates and staff development activities to assist staff to manage their online coursework material. This project, termed the Murdoch Online Mainstreaming project, established online teaching and learning with a strong pedagogical emphasis, as a mission-critical activity of the university, providing uninterrupted access to online course materials for students, and empowering staff to have control over their own educational material. The initiative was successful and student uptake was high (Phillips, 2002), especially among on-campus students in what is commonly called blended learning.

\section{Flexible learning}

In 2001, the following two factors converged leading to a crisis within teaching and learning at Murdoch University:

- Three 'modes of delivery' (internal, external, and online) were found to be too inflexible to cope with the increased popularity of online learning, and the variety of ways in which students and their lecturers interacted with one another

- Funding cuts threatened the viability of external units taught independently to small numbers of students.

After considerable discussion and debate involving both the university's senior executive and Academic Council, a new approach to the design, development, and delivery of units was devised by a group of middle managers. The new approach was accepted in full by Academic Council and an implementation committee driven by middle management was established.

The flexible learning initiative reversed the previous strategy of delivering units of study to students in three modes, by proposing a flexible access approach, in which students could access the learning materials and teaching approaches in the way that best suited their needs (Phillips, Cummings, Lowe, and Jonas-Dwyer, in press). In the flexible access approach, a single set of unit materials is available to students face-to-face, in print, and online. This enabled the university to 
Middle-Out Approaches to Reform of University Teaching and Learning

Cummings, Phillips, Tilbrook, \& Lowe

make considerable savings in teaching costs and in the production of unit materials and reduced the need for unit coordinators to produce different materials for different student cohorts. Additionally, it enabled the university to make better strategic use of its information communication and technology infrastructure such as WebCT and iLecture, a system which digitally records face-to-face lectures and makes them available to students online in near real time. A pilot study of the new approach conducted in 2002 yielded positive results for both staff and students.

By 2003, the success of the pilot persuaded the senior executive to embed the flexible learning model into the university's new strategic plan and the implementation committee developed a plan for the conversion of all units to the new model by 2007. As at the middle of 2004, nearly 130 of a total of approximately 780 units have been converted. In addition, the university has agreed to fund the rollout of the digital recording system for lectures.

\section{Unit alignment and graduate attributes}

Over several years, Murdoch University identified and refined a set of graduate attributes - that is, generic academic and life skills which all students should be able to demonstrate on graduation. For these skills to be achieved, they have to be learnt at some stage of each degree program, and Academic Council required an audit to be done showing where each graduate attribute was learnt. This top-down approach was rejected by academics as meaningless managerialism.

However, the Teaching and Learning Centre, as a driver of middle-out change, recognized the opportunities of the auditing process to engage staff in reflection about the quality of their teaching practice and to facilitate wider curriculum change. Because the process of analyzing where graduate attributes were learnt was complex, a Web-based Graduate Attributes Mapping Program (GAMP) was developed (Lowe and Marshall, 2004) to simplify the mapping of graduate attributes to units of study and degree programs. On the completion of the mapping process, GAMP provides graphical and textual reports which clearly show where the graduate attributes are embedded in learning objectives, content topics, learning activities, and assessment. This information can then be aggregated across all the units in a specific degree program. At a glance, it is possible to see where attributes are addressed and whether there are significant gaps which need to be addressed.

The mapping process enabled educational designers in the Teaching and Learning Centre to encourage academics to reflect on their curriculum and to engage with them in improving it. In this way, a managerial chore was converted into a productive quality improvement activity (see also Inglis, this issue), with the potential to change the nature of e-learning provision at the university.

\section{The Longer Term Picture at Murdoch University}

Owing to the success of the initiatives outlined above and the appointment of a new pro-vicechancellor (Academic) with a strong strategic vision for teaching and learning, in 2004 the university amalgamated these three learning innovations into a single integrated and universitywide approach to curriculum change, called the School Development Process (SDP). The SDP (see http://www.tlc.murdoch.edu.au/schooldev/) is a whole-school approach to enhancing teaching and learning, coordinated by the Teaching and Learning Centre and based on systematic 
Middle-Out Approaches to Reform of University Teaching and Learning

Cummings, Phillips, Tilbrook, \& Lowe

data collection and information provision, curriculum planning, and curriculum renewal. The process brings together each school with the Teaching and Learning Centre in a range of curriculum renewal and development activities designed to improve the quality of units as well as contribute to the review which each school at Murdoch University undergoes every five years. The process works through an initial mapping of graduate attributes which creates a focus for curriculum review and is a catalyst for further teaching development. The renewal of curriculum then involves improved integration of graduate attributes, the conversion of units to the flexible model, and the use of blended approaches to learning where this is appropriate. To date, four of Murdoch University's 15 schools have undertaken the SDP and an evaluation of the process is currently underway.

\section{Comparison of the Three Approaches to Change Management}

The three change management approaches — top-down, bottom-up, and middle-out — are compared in this section by applying six characteristics of change management strategies identified in this study, and which were derived from the eight success factors identified in the Context, Content, and Process model. The links between the eight CCP success factors and the six characteristics used in this study are shown in Figure 2. The relevance of each of the six characteristics to the three approaches is discussed below with reference to the literature on change management.

Figure 2. Mapping of CCP Success Factors on Characteristics of Change

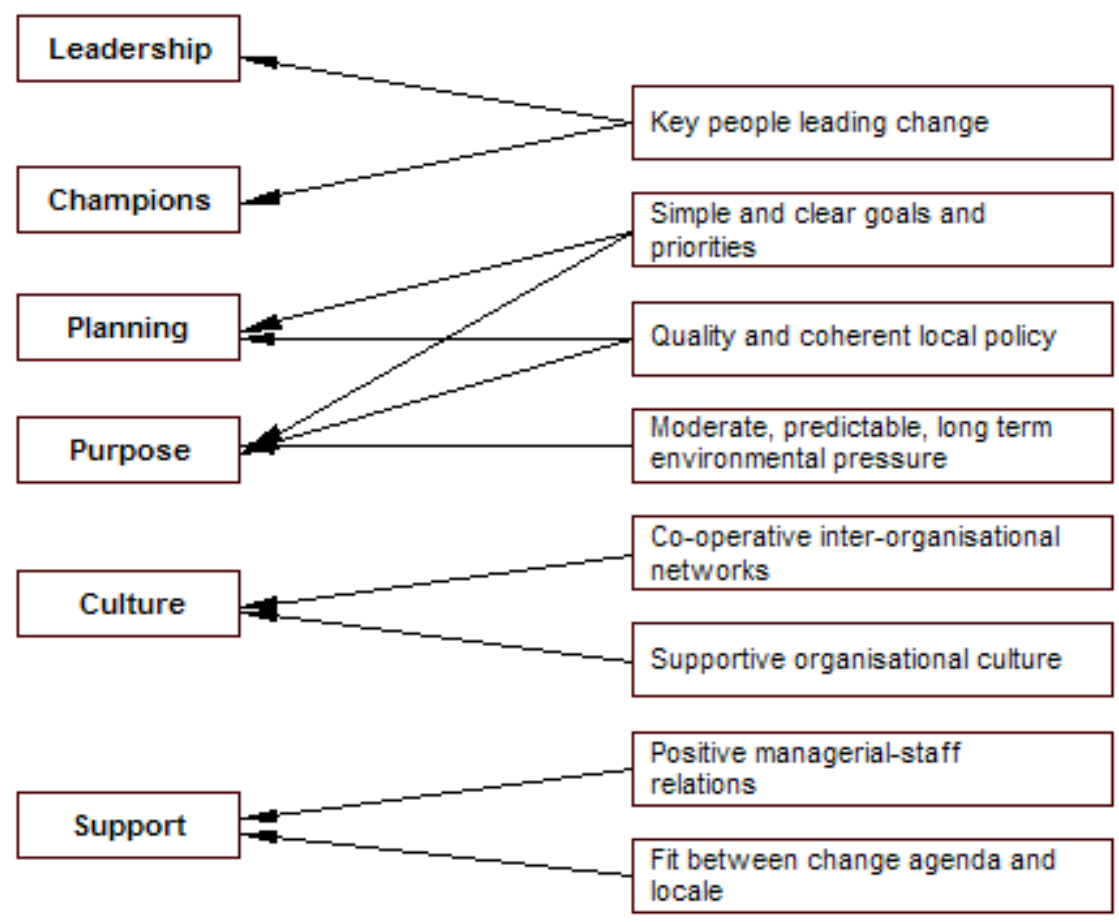


Middle-Out Approaches to Reform of University Teaching and Learning

Cummings, Phillips, Tilbrook, \& Lowe

\section{Leadership}

Leadership is a critical element in change management in universities and can be viewed alongside management as distinct but complementary elements in the change process (Ramsden, 1998). Leadership, in Ramsden's view, is about movement and change and has a long and rich history. It refers to individuals or small groups, is largely independent of positions, and relies on the skills of individuals, not formal power relationships. On the other hand, management is about 'doing things right' and is undertaken by people in formal positions responsible for planning, organizing, staffing, and budgeting. It is a relatively recent concept generated within the contemporary bureaucracy. In a similar vein, Kotter (1990) distinguishes between leaders who set direction, align people and groups, and motivate and inspire to create change, and managers who plan and budget, organize and staff, control, and solve problems in order to create order. To many staff, universities have sacrificed leadership in adopting a managerial approach to teaching and learning. In the top-down approach to change management, the leaders are senior management, using their management positions to drive change through organizational policies and restructures. In the bottom-up approach, leadership comes from individual staff who are personally inspired to make changes and to inspire others to follow their lead.

In the middle-out approach that we have observed at Murdoch University, middle managers became leaders and, through a combination of personal inspiration and policy based on emergent practice, have changed the university environment sufficiently to force both high level policy change and change in practice among teaching staff. Leadership in the middle-out approach is exhibited through problem solving and facilitation - that is, getting the job done and simplifying tasks required of those at the chalkface.

In the Murdoch University examples, the Teaching and Learning Centre provided leadership in addressing problems arising from excessive time demands on academic staff, lack of consistency in online materials, and an unsupported vision and lack of clear policy direction from senior management on the use of technology in teaching and learning. Middle managers in the Centre, the Library, and Information Technology Services, encouraged by the enthusiasm shown by a small number of early adopters but in the absence of a clear and sustainable vision from the top, provided leadership by devising a new unit model which improved flexibility for all students and permitted the university to continue to offer external enrollment, and by facilitating graduate attribute mapping within a clear pedagogical rationale.

\section{Change Champions}

Recent research into the nature of organizational change clearly shows the key role played by change champions (Clemmer, 2004; Scott, 2003). They are needed to provide the creative drive to overcome the bureaucratic response of "We've always done it this way," and to push against the inertia, passive resistance, or outright opposition that impedes most changes. A good champion is passionate about her or his cause or change.

In the top-down approach, champions are generally the senior management, promoting a strong change agenda for, in their view, the good, or even the survival, of the university. In the bottomup approach, individual staff members champion their own area of change, harnessing whatever resources they can garner individually and often using their own time to manage the change process. 
Middle-Out Approaches to Reform of University Teaching and Learning

Cummings, Phillips, Tilbrook, \& Lowe

In the middle-out approach, the champions are middle managers, midway between the senior staff champions in the top-down approach and the teaching staff champions in the bottom-up approach. Given their focus on problem solving and operational matters, and possessing some authority and resource to implement change, they are in a unique position to mediate between the more individualized interest of teaching staff and the broad strategic focus of senior staff. These champions may be staff in support units, such as Teaching and Learning Centers, Libraries, Quality Units, or Information Technology Services groups, who have sufficient autonomy and resources to establish change management projects within their sphere of responsibility, or where several managers are involved across a wider area of responsibility.

In the Murdoch University examples, the middle manager champions in support units took on a role separate from their normal management responsibilities to promote and implement change. They were representative on key decision-making groups, had strong links into schools, had responsibility for many of the university's central operations (learning management systems, information systems) and supervised staff with the expertise to make sustainable changes in these systems.

Often managers of central units are joined by the dean, a head of department, or a senior academic to form a team of champions. Alexander and McKenzie (1998) found that successful projects had a head of department who supported the project (sometimes with additional funds or resources), recognized its value to the department, and was committed to its implementation. This view has been supported by a more recent international survey by Collis and van der Wende (2002).

\section{Approach to Planning}

As Iles and Sutherland (2001) point out, change can be either planned (based on deliberate and reasoned actions) or emergent (apparently spontaneous and unplanned). Planned change is characteristic of the top-down approach and generally is managed by senior management through university wide strategic and operational plans, which, although sometimes developed in consultation with staff, are seldom operationalized by them, and even less often become the new modes of day-to-day practice. This is particularly true in teaching and learning, which are very individualized practices. By contrast, the bottom-up approach is characterized by emergent change in which centralized planning is replaced by a laissez faire, organic approach, along the lines of the Chinese proverb 'letting a thousand flowers bloom.' Change in this strategy tends to be patchy and localized. However, as Iles and Sutherland (2001) point out, emergent change can also be based on a set of implicit assumptions about the direction in which an organization should be moving, and these assumptions may dictate the direction of change, thus "shaping the change process by 'drift' rather than by design" (p. 14). This approach to planning characterizes the middle-out approach, in which middle managers react pragmatically to internal and external pressures but do so in a generally consistent direction. In this case, planning is important, but it is operational or opportunistic and aimed at solving a specific problem.

In the Murdoch University examples, a clear strategic direction or management plan for teaching and learning at Murdoch University was lacking, although a number of individual staff were experimenting with innovative approaches to using technology in their teaching. In responding to the needs expressed by leading teaching staff, middle managers applied operational planning through the Murdoch Online Mainstreaming project, reallocated recurrent funds to provide staff to assist academics, and set uptake targets which were achieved. Supported by a decision of 
Middle-Out Approaches to Reform of University Teaching and Learning

Cummings, Phillips, Tilbrook, \& Lowe

Academic Council, planning for the implementation of the flexible unit model was also largely operational, although once it was making headway it was incorporated into the university's strategic plan in 2003. Planning in the middle-out approach is a response to emergent needs and is aimed at addressing a specific problem rather than pursuing a strategic direction.

\section{Purpose for Change}

The underlying purpose is a critical factor in change management, as it provides the drivers for the change. However, one of the key elements of this characteristic is that different stakeholders will have different views of the purpose - that is, understanding why change is needed. The diversity of views is clear when one looks at why senior managers undertake change compared with individual teaching staff. The former, representing the top-down approach, are influenced by broad university drivers such as the university's financial situation, the prospect of new higher education student markets (see also Nunan; Reid; Inglis; Smith; McConachie, Danaher, Luck, and Jones, this issue), and the need for structural change in the university, whereas individual staff members, representing the bottom-up approach, are likely to be driven more by more specific factors such as managing increased workload, responding to student feedback, and personal interest in new technologies.

The purpose of a middle-out approach is neither policy-based nor rooted in individualism. Instead, it is problem-oriented, addressing questions such as "How can broadly based benefits be achieved?" and "How best can academics be supported in this change process?" The focus in the Murdoch University examples was on solving university-wide problems, such as ensuring an equivalent experience for students while retaining access for off-campus students in a tight financial environment, and providing a solution which would answer the strategic need to map graduate attributes through creating a tool which would have further benefits for academics wishing to enhance the quality of their units. The focus is initially on solving problems identified operationally but with the intention of creating changes in university policy and practice.

\section{Institutional Culture}

Research conducted on factors which lead to successful innovations and change has identified organizational culture as a critical factor. McNay (1995) outlines a typology of four cultures which operate in universities: collegium; bureaucracy; corporation; and enterprise. He argues that they all exist simultaneously in most universities but that the balance will vary considerably from university to university. Hannan and Silver (2000) propose the use of the concept of dominant culture to describe the balance within a particular university, emphasizing the importance of the dominant culture in universities in either enabling or inhibiting change agents and in the adoption of change.

More specifically, Alexander and McKenzie (1998) concluded, among other things, in a national study of change projects in teaching and learning in Australian universities that organizational culture was one of the factors which distinguished between successful and unsuccessful projects. Successful projects tended to be in universities where the promotion and tenure policies recognized teaching developments as a significant contribution to the university. Conversely, unsuccessful projects were usually found in institutions where these factors were missing.

Whereas there may be several cultures present in an organization, in top-down approaches to change management, the culture is usually bureaucratic, centralized, and directed, while by 
contrast the culture in the bottom-up approach is decentralized and individualistic, or sometimes collegial. In the middle-out approach, the institutional culture emphasizes collaboration, partnerships, negotiation, and distribution of authority. This culture is closer to the collegial culture of the bottom-up approach than to the managerial culture of the top-down approach. In fact, it could be called collegial, where collegial is interpreted as 'moving forward together', rather than 'every academic can do his or her own thing'. In the Murdoch University examples, the culture was team-based and collaborative, with middle managers and their staff working closely with academic staff who needed support, and with the tacit approval of senior staff who allowed the middle managers the space and flexibility to bring about change at an operational level. The middle-out change process has been the catalyst for a broader top-down approach, the School Development Process, discussed earlier.

\section{Support for Change}

Finally, change takes place within an organizational setting which continues to operate while the change is occurring. The extent and type of support, in the form of public statements, policy change, financial and resource support, and organizational restructure, are critical to the change management process. Top-down approaches usually provide funding support and focus on changing the infrastructure which supports teaching and learning - for example, changes in staffing, classrooms, etc. Bottom-up approaches focus on voluntary or casual assistants to help the individual staff members to carry out their individual change projects, and initiative is supported through project funding and sometimes reward structures.

In the middle-out approach, support shares many characteristics with the top-down approach. Support is provided by centrally funded bodies, which may provide project funding, professional development, and resources (people) for project development. By contrast with the top-down approach, however, the middle-out approach provides more targeted support, focused on solving specific, university-wide problems. Support of this type also encourages early adopting staff to take a limited risk in their teaching and learning innovations. Critically, support in the middle-out approach encompasses project management (Bates, 1999), both of individual projects and of initiatives designed to support systemic change. Each of the three initiatives outlined above was formally project managed, incorporated professional development, provided production support, and benefited from efficient information systems. Developing and testing these services on a limited number of units and staff enabled them to be developed at low cost and low risk and allowed changes to be made rapidly and with little effort.

\section{Summary of the Characteristics of Each Approach}

The six characteristics which distinguish approaches to change discussed above - leadership, champions, planning, purpose, institutional culture, and support - are summarized in the context of change in university teaching and learning in Table 1 (next page). 
Middle-Out Approaches to Reform of University Teaching and Learning

Cummings, Phillips, Tilbrook, \& Lowe

Table 1. Approaches to Innovation in Teaching and Learning

\begin{tabular}{|l|l|l||l|}
\hline \multicolumn{1}{|l|}{ Characteristic } & Top-down & Bottom-up & Middle-out \\
\hline Leadership & $\begin{array}{l}\text { Vision, } \\
\text { Directives }\end{array}$ & $\begin{array}{l}\text { Personal } \\
\text { inspiration }\end{array}$ & $\begin{array}{l}\text { Problem solving, Best } \\
\text { fit, Facilitation }\end{array}$ \\
\hline \hline Champions & $\begin{array}{l}\text { Senior } \\
\text { management }\end{array}$ & Individual staff & Middle managers \\
\hline Planning & Strategic & $\begin{array}{l}\text { Organic } \\
\text { Laissez faire }\end{array}$ & $\begin{array}{l}\text { Operational } \\
\text { Opportunistic }\end{array}$ \\
\hline Purpose & Policy & Self-interest & Problem-oriented \\
\hline $\begin{array}{l}\text { Institutional } \\
\text { culture }\end{array}$ & $\begin{array}{l}\text { Centralized, } \\
\text { Directed }\end{array}$ & $\begin{array}{l}\text { Decentralized, } \\
\text { Collegial }\end{array}$ & $\begin{array}{l}\text { Collaboration, } \\
\text { Negotiated }\end{array}$ \\
\hline \hline Support & $\begin{array}{l}\text { Funding, } \\
\text { Infrastructure }\end{array}$ & $\begin{array}{l}\text { Voluntary } \\
\text { assistants, One- } \\
\text { off innovations } \\
\text { funding }\end{array}$ & $\begin{array}{l}\text { Functional and } \\
\text { operational, including } \\
\text { low level funding, } \\
\text { project management, } \\
\text { professional } \\
\text { development }\end{array}$ \\
\hline
\end{tabular}

The top-down approach is characterized by leadership from the top, with the development of a university vision and associated strategic plans. The purpose of the change is related to policy, and this policy is championed by senior management. The institutional culture can be characterized as centralized and managerial, although large institutions may necessarily have a decentralized structure, and the motivation for change is extrinsic to those who actually effect the change. The support for change is provided through centrally allocated funding and the provision of the necessary infrastructure.

Similarly, in the bottom-up approach, leadership is provided by inspired and inspiring individuals seeking to solve a problem or to prevent one from arising, and thus the planning is organic or laissez faire (Bates, 1999). The purpose is the self-interest of the individuals or small groups as they struggle with the problem or issue. Generally, individuals or small group of champions, termed "Lone Rangers" by Bates (1999), arise to lead the search for the solution to the teaching and learning problem, and they work within a collegial and decentralized institutional culture. Without the formal support of the senior management, support is provided by voluntary or lowly paid assistants, characterized by Bates as the Lone Ranger's “Tonto.”

It is important to note that the top-down and bottom-up approaches are drivers for change, as well as change management strategies. Fullan (1994) and McNaught, Phillips, Rossiter, and Winn (2000) argue that successful change usually involves both approaches, with all stakeholders able to take ownership of the innovation.

The middle-out approach has some aspects of each of the other two approaches; for example, it has access to central support, has a university-wide focus, and operates collegially. It may also take place alongside other change management approaches. It is, however, markedly differentiated, in that it is very problem-oriented and operational. As shown above, the middle-out approach developed at Murdoch University, where there was a lack either of clear direction from 
Middle-Out Approaches to Reform of University Teaching and Learning

Cummings, Phillips, Tilbrook, \& Lowe

the top or of a consensus within the collegial agencies which drove teaching and learning policy. Within this gap, it fell to champions in middle management to identify the problem or the need for change, to develop the solutions, and to initiate the change.

\section{Discussion}

We have proposed in this paper that a third approach to change management in universities, middle-out, should be considered in addition to the traditional top-down and bottom-up approaches. We have applied a set of six characteristics of change management - leadership, champions, planning, purpose, institutional culture, and support - to the three approaches and found that they do vary considerably. The examples summarized above show how Murdoch University has used this approach to considerable benefit, resulting in significant whole of university change in teaching and learning.

The middle-out approach has demonstrated a number of benefits for Murdoch University. The innovations developed through this approach have been achieved at low cost and with low risks, because the approach tends to rely on the reallocation of existing resources for the initial development and involves a small number of staff and units. As such, mistakes had limited consequences and weaknesses could be corrected quickly and at relatively low cost. This approach also provided the opportunity to conduct formative evaluation studies on the early development, again at low cost. Finally, there was the opportunity to produce evidence of successful implementation and costed models of expansion when making the case for the wider adoption of the innovation. In tight financial times and without a clear strategic mandate, these 'runs on the board' and evidence-based financial models have proven highly persuasive. The evidence of success has also proved to be a strong motivating factor for other staff to adopt the innovation, whether or not it is formalized official policy.

There are of course risks and disadvantages in the middle-out approach. Without senior executive or strategic support, there is a real risk that an innovation, regardless of its merit, will not have the political support required for widespread adoption. There is also a need for the middle managers to have sufficient authority or power within the university to allocate the resources necessary for pilot projects. The capacity of the innovation to be developed and implemented, albeit only in a small way, using existing resources can also be used as evidence that it doesn't need additional resources allocated to it, so the wider implementation risks being underresourced. It is also unlikely that the broader university community will display the same readiness for change as the champions and other early adopters, and this may have implications for support and therefore costs. Finally, if the champions who develop and test the innovation do so with little, if any, additional support, they are prone to burnout from overwork and/ or lack of recognition.

\section{Conclusion}

The middle-out approach has been successfully used at Murdoch University in addressing problems which, for a variety of reasons, the two traditional approaches had not resolved. It developed at Murdoch University in an environment where there was a lack of clear direction from the top and where bottom-up innovation was faltering. Within this gap, it fell to middle management champions to identify the problem or the need for change, to develop the solutions, and to initiate the change. Lacking the support structure of senior management positions and sometimes acting independently of existing policy, these individuals showed leadership in moving well ahead of the rest of the university and developing new directions and ways of 
Middle-Out Approaches to Reform of University Teaching and Learning

Cummings, Phillips, Tilbrook, \& Lowe

working for others to follow. Not only do these individuals face the difficulties of operating in a policy vacuum and sometimes contrary to current policy, but they may also face direct and explicit opposition from others in the university, particularly those managing areas likely to be affected by the change if it is adopted.

The current forces of change impacting on teaching and learning in universities create environments in which middle-out approaches to innovation and change become a legitimate option. Universities, with the individualistic nature of their academic staff, the ability to change small elements (units or courses) without disrupting the larger environment, and the need for low risk and low cost change models, are appropriate environments for this approach. As discussed earlier, for broad implementation, initiatives need to have value for, and buy-in from, both the 'top' and the 'bottom'. In the examples described in this paper, the middle-out approach has clearly provided value to, and obtained buy-in from, rank and file academics, as well as convincing university senior management that proposed changes can be implemented successfully at low cost and with low risk, as is presently occurring in the School Development Process at Murdoch University.

It is unclear how widespread the middle-out approach is in Australian universities or overseas. There is anecdotal evidence that it has been tried and found useful elsewhere, but there is no systematic research to substantiate this. It would appear that the necessary conditions for it to work include:

- An institutional environment lacking in strong top down policies or formalized bottom-up change management strategies

- One or more critical university-wide problems which might be addressed by middle managers using operational, negotiated change management strategies

- Middle managers with sufficient autonomy, authority, and resources to undertake pilot projects

- Early adopting academic staff willing to participate in largely unfunded pilot projects

Finally, for middle-out change management approaches to work, they eventually need to have the change adopted by the university as a whole, either formally or informally. This requires an administration open to evidence-based proposals and willing to take on and to fund partially implemented changes. At present, this is not a common phenomenon in Australian universities.

\section{References}

Alexander, S., and McKenzie, J. (1998). An evaluation of information technology projects for university learning. Canberra, ACT: Committee for University Teaching and Staff Development and the Department of Employment, Education, Training, and Youth Affairs. Retrieved February 17, 2005 from: http://www.autc.gov.au/in/in_pu_cu_ex.htm

Anderson, D., Johnson, R., and Milligan, B. (1999). Strategic planning in Australian universities. Retrieved July 19, 2004 from: http://www.dest.gov.au/archive/highered/eippubs/991/report.pdf 
Middle-Out Approaches to Reform of University Teaching and Learning

Cummings, Phillips, Tilbrook, \& Lowe

Australian Bureau of Statistics. (2003). Education National Summary Tables: Australian social trends. Retrieved December 8, 2004 from: http://www.abs.gov.au/Ausstats/abs@.nsf/94713ad445ff1425ca25682000192af2/ bd9c7737a84700f0ca256bcd008272f8!OpenDocument

Bates, A. W. (1999). Managing Technological Change: Strategies for college and university leaders. San Francisco: Jossey-Bass.

Clemmer, J. (2004). Harnessing the energy of change champions. Retrieved November 20, 2004 from: http://www.clemmer.net/excerpts/harnes_change.shtml

Collis, B., and van der Wende, M. (2002). Models of Technology and Change in Higher Education: An international comparative survey on the current and future use of ICT in higher education. Enschede, The Netherlands: Centre for Higher Education Policy Studies, University of Twente. Retrieved July 19, 2004 from: http://www.utwente.nl/cheps/documenten/ictrapport.pdf

Department of Education, Science, and Training (2002). Striving for Quality: Learning, teaching and scholarship. Part of the Higher Education Review Process. Retrieved July 19, 2004 from:

http://www.backingaustraliasfuture.gov.au/publications/striving_for_quality/default.htm

Dearn, J., Fraser, K., and Ryan, Y. (2002). Investigation into the Provision of Professional Development for University Teaching in Australia: A discussion paper. Canberra, ACT: Commonwealth of Australia.

Fullan, M. G. (1994). Why centralized and decentralized strategies are both essential. Retrieved 30 June, 2004 from: http://www.ed.gov/pubs/EdReformStudies/SysReforms/fullan2.html

Hannan, A., and Silver, H. (2000). Innovating in Higher Education: Teaching, learning and institutional culture. London: The Society for Research into Higher Education and Open University Press.

Haywood, J., Anderson, C., Day, K., Land, R., Macleod, H., and Haywood, D. (1998). Use of TLTP materials in UK higher education. Edinburgh. United Kingdom: Learning Technology Research Group, University of Edinburgh. Retrieved July 19, 2004 from: http://www.flp.ed.ac.uk/LTRG/TLTP.html

Iles, V., and Sutherland, K. (2001). Organisational Change. London: National Coordinating Center for Service Delivery and Organisational Research and Development.

Johnston, S. (1996). Questioning the concept of 'dissemination' in the process of university teaching innovation. Teaching in Higher Education, 1(3), 295 - 304.

Kotter, J. P. (1990). A Force for Change: How leadership differs from management. New York: Free Press.

Laurillard, D. M. (2002). Rethinking University Teaching: A conversational framework for the effective use of learning technologies (2nd ed.) London: Routledge. 
Lowe, K., and Marshall, L. (2004). Plotting Renewal: Pushing curriculum boundaries using a Web-based graduate attribute mapping tool. In R. Atkinson, C. McBeath, D. JonasDwyer, and R. Phillips (Eds.) Beyond the Comfort Zone: Proceedings of the 21st ASCILITE Conference, December 5-8 (p. 548-557). Perth, Australia: Australian Society for Computers in Learning in Tertiary Education. Retrieved December 15, 2004 from: http://www.ascilite.org.au/conferences/perth04/procs/lowe-k.html

McNaught, C., Phillips, R., Rossiter, D., and Winn, J. (2000). Developing a framework for a useable and useful inventory of computer-facilitated learning and support materials in Australian universities (Evaluations and Investigations Program). Canberra, ACT: Department of Employment, Training, and Youth Affairs. Retrieved July 19, 2004 from: http://www.dest.gov.au/highered/eippubs1999.htm

McNay, I. (1995). From the Collegial Academy to the Corporate Enterprise: The changing cultures of universities in the changing university? London: The Society for Research into Higher Education and Open University Press.

Miller, H. D. R. (1995). The management of change in universities. London: The Society for Research into Higher Education and Open University Press.

Nelson, B. (2003). Our Universities: Backing Australia's future. Australian Government. Department of Education, Science and Training. Retrieved July19, 2004 from: http://www.backingaustraliasfuture.gov.au/ministers message.htm

Pettigrew, A., and Whipp, R. (1991). Managing change for competitive success. Oxford, UK.: Blackwell.

Phillips, R. A. (2002). Issues Surrounding the Widespread Adoption of Learning Management Systems: An Australian case study. In A. J. Kallenberg and M. J. van de Ven (Eds.) Proceedings of the "New educational benefits of ICT in higher education" conference (p. 246-252). Rotterdam, The Netherlands: Erasmus Plus.

Phillips, R. A., Cummings, R., Lowe, K., and Jonas-Dwyer, D. (in press). Rethinking Flexible Learning in a Distributed Learning Environment: A university-wide initiative. Educational Media International.

Ramsden, P. (1998). Learning to lead in higher education. London: Routledge.

Rogers, E. M. (1995). Diffusion of innovations (4th ed.). New York: Free Press.

Scott, G. (2003, November/ December). Effective change management in higher education. Educause Review, 64 - 80. 
March - 2005

\title{
Markets, Distance Education, and Australian Higher Education
}

\author{
Ted Nunan \\ Flexible Learning Centre \\ University of South Australia \\ Adelaide, Australia
}

\begin{abstract}
The paper argues that the Australian university system is unstable. There will be significant change as government implements its reform agenda and even more radical change if it moves to new deregulation. The role of distance education in university education needs to be analyzed against this 'market' agenda of government in terms of characteristics of markets and market behavior. After a scan of the current role, the paper looks at two scenarios (regulated and deregulated) for distance education in university teaching and learning in Australia.
\end{abstract}

Keywords: educational markets; distance education; flexible delivery; competition

\section{Introduction}

Australian higher education is about to be changed by a government 'reform agenda' that establishes a market (see also Cummings, Phillips, Tilbrook, and Lowe; Reid; Inglis; Smith; McConachie, Danaher, Luck, and Jones, this issue) for educational goods and services and regulates competition within that market. The starting point of the reform agenda has been the privatization of the university system through government underfunding of operating costs. To survive, universities need to earn income from private capital. For the past ten years the Australian system has been propped up with education export earnings.

The changes underway within Australia are consistent with trends in Western education systems. Gibbons (2004), for example, identifies three principal elements of the new context in which universities operate: "a rightward shift in political thinking; an intensification of competition brought about, in part, by globalisation;" and "a more central role for knowledge in generating the innovations that are needed to meet the risks associated with the intensification of competition." This 'rightward shift' and 'globalisation' have led the Australian government to rely upon competition as the force that will shape the demand for and the provision of education.

This paper looks at distance education as it is changed by, and operates within, educational markets in Australia. It contends that directions and developments in distance education depend increasingly upon market forces and that an analysis of these forces is essential to understanding current changes and possible futures. 
The situation within Australian university education is unstable. A brief scan of current developments in university education and the role of distance education within it are provided before two change scenarios are examined. The first is a form of regulated market proposed by government and outlined in Our Universities: Backing Australia's Future (Nelson, 2003; see also Cummings, Phillips, Tilbrook, and Lowe, this issue), and the second involves a radical 'paradigm change' to open the market to what are currently in Australia non-university providers. The need to address the possibility of radical change is a feature of analysis of the Australian system by writers such as Simon Marginson (2003, 2004) and Glyn Davis (2004).

\section{Australian Higher Education: The current situation with regard to distance education}

Within Australia, there has been little movement in the provision of distance education with institutions that traditionally cater for external students maintaining their market share of the domestic market. The figures for the top six providers (taken from the Department of Education, Science, and Training statistics on all students by state, institution, mode of attendance, type of attendance, and gender for 2003/ 2002) show minor fluctuations in student numbers: 27,474/ 28,871:13,909/ 13,955: 12,307/ 14,126: 9,390/ 9,676: 6,850/ 7,238: 18,737/ 18,446. These fluctuations are against a backdrop of an 8 percent overall growth in full-time distance education students, an 8.8 percent growth in full-time multi-modal students, and a 5 percent growth in internal full-time students for 2003 compared with 2002.

The 'no or limited growth' scenario for domestic external students has meant that distance education is of little strategic interest to institutions in their quest to gain income through new markets or by gaining a greater share of existing markets. There is, however, strategic interest in maintaining market shares of domestic internal students by ensuring that study arrangements are convenient and enable students to 'earn and learn.' Many institutions have therefore added to their existing 'design configuration' (the mix of technology, administrative arrangements, and people) (Gibbons, 2004) to develop more flexible delivery approaches (Nunan, 2000), while at the same time maintaining face-to-face as the predominant mode. This has meant the provision of parts of a program by distance or online education or at the very least the use of distance teaching techniques within courses or programs.

In Australia, the enrollment category of mixed mode records instances where students use a mix of internal and external studies. This provides a measure of flexibility at a macro level as it enables student choice about how frequently they will need to attend at a campus. The use of micro in-course mechanisms of introducing flexibility using distance education or online teaching and learning techniques is much more difficult to measure as three categories have been identified (Web supplemented, Web dependent, and fully online) and institutional and national figures are not available.

The provision of mixed mode attendance within a program has seen major changes in demand and provision. In New South Wales, changes between the 2002 and 2003 mode of attendance patterns show that the total of part- and full-time external and multi-modal students went from 28,699 to 58,785 - an increase of some 105 percent. Closer inspection of the figures reveals that the changes represent a number of universities providing external mode within multi-modal attendance - for example, Macquarie University for 2002 had 79 and 895 full- and part-time external with 350 and 160 full- and part-time multi-modal students, while for 2003 the corresponding figures were 78, 742, 291, and 3,465; the figures for the University of New South Wales were 254, 1531, 0, and 0 for 2002 and 212, 858, 0, and 5,420 for 2003. Institutions with 
existing external delivery capacity have used this to provide more flexible arrangements for studying programs at their institutions.

New forms of 'distance education' have become integrated into the delivery processes of universities as 'flexible delivery'. Universities are undergoing a paradigm shift with regard to the provision of teaching and learning - their first decision is more likely to be what type of variant of fifth generation intelligent flexible learning (Taylor, 1999, 2001; see also Reid; Smith, this issue) is needed, rather than whether either traditional internal face-to-face or distance teaching should be used. Indeed, the changes to distance education are such that it is arguable whether it is useful to consider it as a distinctive and organizational entity (King, 2003).

Distance education has but a small and tangential role to play in the main game for Australian higher education, which is generating income from international enrollments. Currently international students make up nearly one in four of all Australian university students and contribute AUS \$5 billion to the system. There are predictions for further expansion. Vidovich (2004) comments upon this situation, noting that Australian universities:

... are heavily into the 'business' of international marketing, and this emphasis is set in a context of reduced Commonwealth Government funding, creating pressures for universities to actively seek private sources of income, especially from overseas (p. 344).

So important has been this source of funds to the economic survival of particular institutions that within them the national and local have become driven by the global.

Conventional distance education has not been part of exporting education. Where students are taught in their home country the model has been largely one of an Australian satellite campus or of 'education centers' through partner institutions. However, the products of distance education in the form of printed course guides and their resources often play a role in defining the syllabus of the area and in assuring the quality of the face-to-face teaching and learning experiences provided by a partner institution. This use of distance teaching materials in conjunction with local tutors enables the capacity to reach wider in-country markets and has assisted in gaining income for some institutions.

\section{The Australian Higher Education Market: Charting the changes ahead}

I move now to look at the changes that will come with the regulated market arrangements announced by government and speculate upon the possible impact of changes that would flow from a deregulated market.

In terms of a regulated market, Marginson (2004) summarizes the agenda set out in Our Universities: Backing Australia's Future (Nelson, 2003) in the following terms:

... [It] establishes full fees, supported by a voucher-like income contingent loans scheme on the Friedman model for up to $35 \%$ of students in undergraduate courses. For other students, it allows universities to vary their Higher Education Contribution Scheme (HECS) charges as they see fit, up to 25 percent higher than the present standard HECS rates, or down to zero, so that the places would 
be funded just by the government grant. Thus the HECS, which was originally intended as a standard payback charge to defray costs with a minimum economic impact on the student, begins to look more like a market price. The Nelson program also extends the new tuition loans (aptly named FEE-HELP) to universities in the private sector, which makes the private higher education sector economically viable for the first time (p. 6).

Marginson believes that such changes will constitute a "key moment" for the higher education system, as it will be "the first time that the full scale Hayek-Friedman model has been implemented into undergraduate education in Australia, and one of the first times in the world." For postgraduate research and coursework studies, market conditions had already been established as the start of a program of competition and pricing.

A deregulated market will be formed if the Australian government changes its definition of the term 'university' and allows 'teaching only' institutions to award university degrees. Currently in Australia a university must conduct teaching and engage with "the creation of new knowledge through research, and original creative endeavour" (Ministerial Council on Education, Employment, Training, and Youth Affairs, 2000, n.p.). Davis (2004) argues that deregulation will create a new range of private and public teaching only institutions and open the Australian system to education exporters from other countries. This creates new market conditions never before experienced within Australia with 'teaching shops,' Internet providers, satellite campuses, and other 'design configurations' competing for a share of the market for university degrees. The future directions and uses of 'distance education' in Australia depend upon whether deregulation takes place or not.

Before I move to speculate upon futures for distance education, it is useful to identify broad directions for distance education that are consequent upon markets and market behaviors. A useful starting point in the analysis of markets is provided by Marginson (2003):

Markets incorporate five distinct features: a defined field of production and consumption: competition between producers; identifiable products (commodities); prices and monetary exchange between producers and consumers; and the human behaviours and values - entrepreneurship and minimisation in production, utility-maximisation in consumption, contractual relations and so on - consistent with economic self interest. Real life education systems normally incorporate some but not all of these features of markets in a developed form. Higher education systems typically consist of a set of producer institutions ('the market') that together participate in several interlocking markets based on distinct products: undergraduate education, research degrees, research and consultancy, other services (p. 7).

The next section of the paper takes these five features of markets and comments upon the operation of distance education with regard to each of the features.

\section{What Role for Distance Education in a Market Driven System?}

Much of the analysis of the future of distance education has been by educationists who tend to highlight particular drivers of change (see also McConachie and Danaher; Cummings, Phillips, Tilbrook, and Lowe; Reid; McConachie, Danaher, Luck, and Jones, this issue). For example, much is written about the unprecedented demand for higher education, the capacities of new 
technologies that are being used to deliver education, and new methodologies that accompany such technologies. Analysis of this situation results in conclusions such as "competition in education on an international and national basis will become the principal determinant of the success or failure of institutions” (Turoff, 1998, n.p.), or that the confluence of these forces will see e-learning in the form of online delivery as a potential solution to the situation. Bonk (2004), for example, writes about the Perfect E-Storm (from emerging technology, enormous learner demand, enhanced pedagogy, and erased budgets) and sees technology as a solution for maintaining quality and achieving more with less. Twigg (2003) sees improving quality, reducing costs, and meeting demand connected with radical changes in institutional practices. She contends:

Currently in higher education, both on campus and online, we individualize faculty practice (that is, we allow individual faculty members great latitude in course development and delivery) and standardize the student learning experience (that is, we treat all students in a course as if their learning needs, interests, and abilities were the same). Instead, we need to do just the opposite: individualize student learning and standardize faculty practice (n.p.).

These works provide insights into facets of the situation and often take normative positions based on a number of social values. There are few analyses that bring together features of markets and put the position that it is market behavior in response to a set of conditions that shapes possible choices for action. The notion that educational purposes and directions are a function of Adam Smith's 'invisible hand' which operates in ways consistent with economic self-interest is not an attractive one for educationists.

In what follows the concept of a market, its features, and its behaviors provide an integrative framework for analysis. The five distinct features cited by Marginson (2003) are taken in turn.

\section{Markets Have a Defined Field of Production and Consumption}

Technically, any university can define the field of production that it wishes to exploit or specialize in, provided that it alone can confer the degree. While the end-point 'field of production' is a degree, the mechanisms to achieve this for consumers can involve producing other products. In the case of distance education, such products are course guides and readers, assessment tasks, and specific services associated with external studies. In Australia, consumption of such products has been mainly for postgraduate coursework or professional upgrading degrees.

The conventional role for distance education has been to provide external studies toward recognized degrees for those consumers who could not, or chose not to, attend the institution. There have been various attempts to define cost relationships between such production and consumption, and conclusions vary according to how costs are attributed, the richness of the services supplied including those that use communications technology, the costs of the teaching and marking, and whether the activities maximize economies of scale. Hülsmann (1999) reports that, on a cost per student basis in five industrialized countries, distance education institutions can operate at between 25 and 50 percent of the cost per student in a conventional university.

The move to mixed mode studies has seen a different pattern of consumption where distance education is used by internal students as a convenience - it allows students to earn and learn by managing time to suit their particular circumstances. This move to 'convenience' for internal students means that design configurations will need to use distance or online techniques and 
consumer expectations will drive institutions to compete with regard to flexibility in the provision of studies. This will lead to considerations of costs of introducing flexibility and cost benefit analysis by institutions. Particular educational products and services products may be outsourced using partnership arrangements in efforts to gain a quality or cost advantage.

Consequently, distance education processes and products may provide the key to being able to take greater market share (of either or both internal and external students) in an area by 'tailoring' costs and prices to undercut competitors. Cutting costs can be by combinations of outsourcing and disaggregation of course delivery arrangements.

\section{Markets have Competition among Producers}

Market competition involves forces such as the threat of new entrants, the bargaining power of customers, the bargaining power of suppliers, the threat of substitute products or services (where applicable), and the jockeying among current contestants (Porter, 1991). Institutions need both to defend against these forces and to influence them in their favor. The regulated system uses the notion of a government sponsored 'learning entitlement' for students to 'spend' among suppliers, while a deregulated system would have a complex price point and other market competition behaviors.

The threat of new producers entering the market for coursework taught degrees is a consequence of the radical deregulation option that may be taken up by government. In Australia the brake upon private capital entering the market is that awarding a university degree can be done only by institutions that satisfy conditions about teaching and research infrastructure and research activity - with this brake removed, 'free trade' in the provision of teaching services will radically change the institutional landscape. If teaching only private producers are given the capacity to award degrees, their 'institutional costs' are likely to be less than those of conventional universities and this could provide a price point advantage in a deregulated market.

Distance education and online delivery processes bring a different form of competition among producers. While 'branding' (see the next subsection) is a function of institutional standing, it can also be a function of teaching and learning excellence made highly visible through distance and online teaching materials. Competition for consumers is made possible as the consumption of superior teaching is a relatively simple matter of changing to a different address on the Internet or the postal address of a new university. Also, it is likely that such competition will be protected by competition 'rules' and students will be able to trade their 'academic currency' (learning entitlement) against a new course from another institution as they search for better subsidies, lower cost courses, higher quality services, better brand names, and so on. Providers of distance education will work to make course switching easier in an attempt to increase demand for their courses or parts of their programs. That is, the market will include parts of a degree program as well as the degree itself.

Distance education providers will balance the 'poaching' and 'loyalty' factors according to their market position and marketing skills. An institution would wish to encourage 'loyalty,' so that students undertake all courses of a degree at that institution, and at the same time maximize 'poaching,' so that students who start a degree elsewhere transfer to the institution. Encouraging 'loyalty' by giving subsidies (by designing 'frequent flyer point' schemes for recruiting others or a sliding scale of subsidization of student costs depending on 'customer loyalty factors') and 'poaching' (making sure that your brand name has high employment or professional advancement 
value and making it available for students who complete one third or more of your degree) will increasingly be used as competition for students becomes greater.

Distance education (and online delivery processes) can be used to create different forms of competition among producers within the market. Given the trend to convenience through mixed mode studies, there will be pressure on institutions to deal with loyalty and poaching, especially where program rules allow the substitution of studies from another institution. Some of the transfer arrangements will be managed through groups of institutions forming cartels (but operating within competition guidelines), so that students will have the advantage of wider choice but from within a managed set of alternatives.

\section{Consumers in a Market Seek Identifiable Products}

Educational markets are distinctive, in that consumers cannot get a complete picture of what they are purchasing as they are yet to experience the teaching and learning opportunities that they will be undertaking. This means that consumers purchase a 'brand' and if the brand does not meet their expectations they seek to transfer among institutions.

While the visibility of the teaching and learning products gives signals to consumers about the standing of the producer, it is the teaching and the support for learners, not the information per se, that differentiate an institution from others. This places service to students as the key factor in a mature market. There will be a short-term valuing of resources and platform advantages by consumers, but these will be significant in the long term only where they are an integral part of a service culture of learning and supporting learning. Consequently, some suppliers are willing to make the information in their courses open and available to all, based on the belief that only they can provide the level of service to match the information product, thereby realizing its value.

Distance education suppliers will increasingly focus upon the service requirements of external students and sharpen this focus to the specific requirements of niche markets. As with banking and other service sector institutions, the mix of online and face-to-face service for students with teaching and learning will be central to the competitive standing of an educational institution. Attempts to identify the service components (through student charters, service agreements, and the like) will become part of the information about delivery processes and will influence consumer choice. Distance teaching materials and student support arrangements will be increasingly used to define services available to internal students.

\section{Markets Facilitate Price Determination and Monetary Exchange between Producers and Consumers}

Value for money can be a direct function of lower tuition charges, better and newer communication technologies, and other services, and through lower opportunity costs (that is, achieving a degree in a shorter time). Subsidies provide more to students for each dollar that they spend at a particular institution. Price points for tuition charges are important in markets, and institutions may work to provide a 'stripped down' version of the teaching and learning experience in an effort to gain market share. Writing about changes in the United States system, Levine and Sun (2002) note:

The bottom line is that today's older adult students are bringing their consumer attitudes to higher education. They seek four things from their colleges - 
convenience, service, high quality and low cost. They will not pay for activities and services they do not use, for hiring faculty to offer elective courses they will not take, for buildings such as a chapel or student union that they will not frequent. They are asking for a stripped down version of high[er] education, absent of extras (n.p.).

Government intends that price signals will become clearer through a loan and repayment via taxation mechanisms and the student learning entitlement. A key initiative here is to have secure, Web-based access via a unique student identity number that will set out the bank style 'education account' of remaining entitlement and charges. Consumers will have information that will enable them to compare options and choices about charges arising from their future studies, and this is seen as part of the infrastructure that is necessary to develop a national market in higher education.

There will be great pressure upon distance education providers to decide whether to maintain parity of esteem between distance courses and face-to face courses by having the same price point for both or to have a cost differentiation which reflects particular economies that can come from using distance education techniques and technologies. Another way of looking at this situation is to decide whether there is market advantage in having reduced distance education costs cross subsidizing face-to-face delivery costs.

\section{Market Behaviors Result from Operating According to Perceptions of the Market}

Both providers and consumers operate according to their perceptions of the market. Because information about a degree is generally cast in terms of 'producer specifications' (its content, the type of teaching that is received, the rules and regulations associated with achieving the degree), judgments about the product are often made on the basis of producer or input characteristics (for example, staff qualifications and research output, producer processes and quality systems, selectivity of students). This is often termed 'institutional reputation' or 'brand.'

For distance education, quality course materials, service culture, and identifiable subsidization will interact in ways that produce market advantage. Selectivity for distance education is not attained through the exclusion of students - instead, the quality of a course or program provided by distance education is less about who interacts with the individual as a student and more about the total nature of the student experience. With formal education, part of the purchase is about 'whom you sit with' in lectures and tutorials; for distance institutions a market signal for quality comes from the type of service culture that surrounds the student experience. For distance education, value for money becomes a key factor in the selection of an institution, program, and course.

Value for money and perceptions of it can flow from economies of scale, which can bring lower student charges and subsidized services in key areas such as ease of registration and credit transfer, telecommunications, and library services. Personalized experiences can be maintained where large enrollments are broken down into smaller 'activity groups' linked to an institutional 'tutor' so that advantages of small group 'membership' can be retained. The provision of comprehensive course materials within the tuition costs can be a major advantage, as it reduces the costs associated with the purchase of texts, travel to libraries, and other communications charges. Institutions will exploit 'value for money' subsidies that impact upon consumer perception and satisfaction with the institution and their experience of studies. 
Institutions will be engaged in careful analysis of the relationship between fixed and variable costs when attempting to exploit economies of scale and a mix of service provision that involves technology. It is commonly agreed that the cost structure of distance education is one of high initial fixed costs with low variable costs, but that the latter are altered by the choice of delivery medium. Any strategy that requires significant technical support for students or allows greater access by students to academics will, in a developed country, cause variable costs to increase and may disrupt the economies of scale derived from other areas. More importantly, a balance between fixed and variable costs will impact upon consumer perceptions, and institutions will be engaged in greater monitoring of student satisfaction about their study experiences.

To use distance education in a market, it will be necessary to have both economies of scale within institutional infrastructures (that is, special delivery arrangements for large numbers of distance education students catered for by the institution) and programs that have 'scalable delivery processes' to generate good profit margins. Institutions that position themselves to students as a mix of 'clicks and bricks' and market their student service-oriented culture will reap long-term benefits. Getting the right mix of technology and services for external, internal, and international students, and capturing this within the institutional brand, will be essential in a competitive market.

\section{Conclusion: The future of distance education in Australian higher education}

This paper has argued that 'distance education' will be reduced to its economic purposes defined by market conditions of supply, demand, and competition. The current major providers of distance education in Australia with 10,000 or more students are likely to make strategic gains in the longer term and through their focus upon recruiting staff who are skilled in distance education/ online technologies to gain greater shares of a relatively small and stable market.

The trend toward using distance education techniques to improve the flexibility in delivering teaching and learning will continue, and this will be through both mixed mode enrollments and the use of online approaches within courses. If Australia moves to mass higher education targets of 50 percent of the secondary school population, this trend for catering for 'earner learners' will intensify, and with price differentiation becoming a factor influencing student choice there will be growing pressure on institutions to compete in the provision of flexible learning. This competition will mean that institutions will increasingly focus upon analyzing the costs of providing this flexibility and evaluating whether such costs are warranted given the market share that results. Universities will focus upon business cases for new programs, and cost models for different levels of delivery will have center stage in program approvals processes.

If the market is deregulated and a new range of providers is able to confer university degrees, there will be niche providers working to undercut traditional universities in high demand, high profit areas such as executive management, specialist computer science, and law. Free trade arrangements open the potential for imports and exports in education that respond to global demand and global cost and price structures - for example, distance teaching universities such as the University of Phoenix might seek to establish a presence in Australia and provide 'shop face' facilities for outsourcing elements of their delivery processes.

Because of the unstable condition of Australian higher education, the future for distance education is not easy to predict. Gibbons (2004) identifies static and dynamic competition: static competition works within the current 'design configuration,' while dynamic competition attempts 
to foreshadow the next 'design configuration' that will arise through changes in technology and other market conditions. Australian university education is undergoing reorganization, and current 'design configurations' are moving to feature flexibility. Dynamic competition may come into play with deregulation, and radical and new design configurations will be necessary - the familiar forms of organizations and ways of working may be overturned, with a greater emphasis upon responding to competition for private capital in new markets based upon free trade deals.

Australian universities would be well advised to consider both static and dynamic competition by at least maintaining their existing capacities in distance education, as it represents a reservoir of skills and infrastructure arrangements that can be used to make adjustments to delivery processes to suit future changes to education markets.

\section{References}

Bonk, C. (2004). The Perfect e-Storm: Emerging technology, enormous learner demand, enhanced pedagogy, and erased budgets, Part 1. The Observatory on Borderless Higher Education, 23.

Davis, G. (2004). Tiers or Tears? The regulation of Australian higher education. The Inaugural Melbourne Politics Lecture. November. Department of Political Science, University of Melbourne: Australia.

Gibbons, M. (2004). Innovation in a New Context. Paper presented at the general conference of the Organisation for Economic Co-operation and Development Institute for Management in Higher Education. September 13-15. Paris, France.

Hülsmann, T. (1999). The costs of distance education. In K. Harry and H. Perraton (Eds.) Education Through Open and Distance Learning. Vol. 1 (p. 72-84). London: Routledge and the Commonwealth of Learning.

King, B. (2003). Has Distance Education a Future? Keynote address: Cambridge Conference on Open and Distance Education, September 26-28. Maddingly Hall, Cambridge: UK.

Levine, A., and Sun, J. C. (2002). Barriers to Distance Education. Washington, DC.: American Council on Education Center for Policy Analysis.

Marginson, S. (2004). They Make a Desolation and They Call it F. A. Hayek: Australian universities on the brink of the Nelson reforms. Australian Book Review, 260. 28 - 35.

Marginson, S. (2003). Markets in Higher Education: National and global competition. Radford Lecture presented at the New Zealand Association for Research in Education/ Australian Association for Research in Education joint conference, November 29 December 3. Auckland, New Zealand.

Ministerial Council on Education, Employment, Training, and Youth Affairs (2000). National protocols for higher education approval processes. Protocol 1: Criteria and processes for recognising universities. Retrieved February 23, 2005 from:

http://www.dest.gov.au/highered/mceetya_cop.htm 
Nelson, B. (2003). Our Universities: Backing Australia's future. Canberra, ACT: Commonwealth of Australia.

Nunan, T. (2000). Exploring the concept of flexibility. In V. Jakupec and J. Garrick (Eds.) Flexible Learning, Human Resource and Organisational Development: Putting theory to work (p. 47-66). London: Routledge.

Porter, M. E. (1991). Michael Porter on competition and strategy. Harvard Business Review, 90079.

Taylor, J. (2001). Fifth generation distance education. e-Journal of Instructional Science and Technology, 4(1). Retrieved February 23, 2005 from:

http//www.detya.gov.au/highered/hes.htm

Taylor, J. (1999). The Death of Distance: The birth of the global higher education economy. $e$ Journal of Instructional Science and Technology, 3(1), 6 - 11.

Turoff, M. (1998). Education, Commerce and Communications: The era of competition. Association for the Advancement of Computing in Education. Retrieved February 23, 2004 from: http://eies.njit.edu/\%7Eturoff/Papers/webnettalk/webnettalk.htm

Twigg, C. (2003). Improving Learning and Reducing Costs: New models for online learning, Educause Review, 38(5), 28 - 38. Retrieved February 23, from:

http://www.educause.edu/pub/er/erm03/erm035.asp

Vidovich, L. (2004). Global-national-local dynamics in policy processes: A case of 'quality' policy in higher education. British Journal of Sociology of Education, 25(3), 341 - 354. 
March - 2005

\title{
Quality Assurance, Open and Distance Learning, and Australian Universities
}

\author{
Ian C. Reid \\ Flexible Learning Centre, University of South Australia \\ Adelaide, Australia
}

\begin{abstract}
Open and distance education has integrated quality assurance processes since its inception. Recently, the increased use of distance teaching systems, technologies, and pedagogies by universities without a distance education heritage has enabled them to provide flexible learning opportunities. They have done this in addition to, or instead of, face-to-face instruction, yet the practice of quality assurance processes as a fundamental component of distance education provision has not necessarily followed these changes.

This paper considers the relationship between notions of quality assurance and open and distance education, between quality assurance and higher education more broadly, and between quality assurance and the implementation of recent quality audits in Australian universities. The paper compares quality portfolios submitted to the Australian Universities Quality Agency by two universities, one involved in distance education, the other not involved. This comparison demonstrates that the relationship is variable, and suggests that reasons for this have more to do with business drivers than with educational rationales.
\end{abstract}

Keywords: distance education; quality assurance; online learning; e-learning; audit; higher education

\section{Introduction}

Following the expansion of enrollments in Australian universities in the 1980s, the federal government decided that the public purse could no longer fund universities at the same per student levels, and the Higher Education Contribution Scheme (HECS) scheme was introduced in 1989 as an additional taxation on students and funding source for universities. This 'user pays' principle supported the government's efficiency aims and allowed it to use its battery of statistics to demonstrate per student costs and benefits, gradually reconstructing the student/ consumer (Baldwin and James, 2000). As students began again to experience paying for higher education through HECS, and were provided with more choices in an expanded market (see also Cummings, Phillips, Tilbrook and Lowe; Nunan; Inglis; Smith; and McConachie, Danaher, Luck and Jones, this issue), the issue of quality was more rigorously pursued, with the establishment of the Committee for Quality Assurance in Higher Education in 1991. This instigated external audits of universities in 1993-1995, with universities ranked according to particular criteria and rewarded financially as a result (Committee for Quality Assurance in Higher Education, 1995). This process was clearly unpopular with those who 'lost' in this competition, and, from its 
conclusion in 1995 to the establishment of the Australian Universities Quality Agency (AUQA) in 2001, there was a policy vacuum relating to quality, notwithstanding guidelines and frameworks regarding benchmarking (see also Inglis, this issue) and quality (Inglis, Ling and Joosten, 1999; McKinnon, Walker and Davis, 2000). Having given universities increased independence from government funding sources and regulation, and encouraging them to grow as commercial entities, the government had also expanded the role of quality assurance (see also Inglis; and McConachie, Danaher, Luck and Jones, this issue) in order to provide comfort to anyone who should seek to question whether Australian universities are providing 'quality.' AUQA allows the government to 'steer at a distance' (Knight, 1994; Marceau, 1993; Marginson, 1997) more effectively, borrowing from its experiences in other areas of government activity (Gashler, 1994) and the use of the technique internationally (Kickert, 1991) to apply it to the operations of Australian universities (Vidovich, 2002).

Notwithstanding the long history of distance education in Australia (Smith, 1984), one of the policy developments that occurred over this period was the establishment in 1988 of Distance Education Centers in seven universities to act as resources and service centers to the Australian higher education system. This was seen as a means by which isolated and 'second chance' students could access higher education. The federal funding of these centers was shortlived, ending in 1994 because of policy developments and changes in technology that reduced the need for universities to rely on a specialist center. The existence of these Distance Education Centers in Australian higher education provided an impetus for a reconceptualization of quality (Calder, 1994) by introducing notions of quality of commodities (through correspondence packages) and quality of service (through student service centers) and a focus on educational production and delivery as a 'Fordist' process (Evans and Nation, 1989). A further option for 'second chance' learners was the establishment of Open Learning Australia as a distance provider acting as a broker for existing institutions and providing courses to students without the usual high school prerequisites (King, 1992). It is fair to say, however, that distance education did not greatly influence mainstream policy debates during this period, particularly those related to quality assurance.

\section{Australian Universities}

There are currently 38 universities which receive federal funding for teaching in Australia, including the private Australian Catholic University and Notre Dame University. Bond University is another private university, but it does not receive funding for teaching. Each of these universities has its own particular character and role within the educational market (Marginson and Considine, 2000). It must be recognized that these universities, now cast as independent enterprises in an educational marketplace, are not equals:

The market in higher education is no level playing field. Institutions do not compete on the same terms. All else being equal, strong institutions with the greatest capacity to compete tend to become stronger over time relative to other institutions - unless government intervenes to even up the competition, for example by distributing funding on the basis of inter-institutional equity, or a planned division of labour (Marginson and Considine, 2000, p. 188-189).

Given this, one would expect that universities' representations of themselves, and of the quality of what they do, would be different depending on the particular role that they play in this market and the particular 'niches' that they wish to pursue. Since distance education technologies can enable engagements with new markets, their use can create new definitions of quality within universities. 
This paper aims to tease out the changing relationships between distance education and quality assurance. It does so by comparing two Australian universities, with respect to their submissions to the AUQA audit process. It focuses upon their use of distance education methods and rationales in that process, and upon their particular locations in the Australian educational market. I have chosen the University of Southern Queensland (USQ) and the University of Adelaide for this purpose, owing to the differences in their use of distance education technologies, as described below. I now give a brief sketch of each institution's market positioning as 'Enterprise Universities' (Marginson and Considine, 2000), followed by an analysis of the primary text that each produced as a part of the audit process that each underwent.

USQ (see also Smith, this issue) has a significant history of distance education and has won a number of awards for its distance education delivery, including an institutional award from the International Council of Distance Education (ICDE). Described by Marginson and Considine (2000) as one of the "flexible learning specialists" (p. 226), and as a "New University" (p. 190), USQ has significant distance delivery to students both in Australia and in transnational settings.

The University of Adelaide is one of the original state-based "sandstone" universities (Marginson and Considine, 2000, p. 190), with very little tradition of distance delivery. Having a history that dates back to its establishment as a cultural pillar of a British colony, it is a high prestige institution with elite disciplines such as medicine and law. Like all universities, it has expanded its use of online technologies within teaching and learning.

Despite the divergent histories of these two institutions, each employs online technologies for the purpose of delivery. I have chosen this aspect of delivery for particular emphasis in my analysis below, since it is an aspect of open and distance education in which they are involved (even though Adelaide is not significantly engaged in distance education per se), and because it is laid down as an object of interest in AUQA's audit manual (Woodhouse, 2001).

\section{The Research Framework for the Study}

In this study, I focused on the primary texts produced by each university for the AUQA audit process, namely the performance portfolio document that each institution submitted to AUQA, which I call "the submission.” These texts were publicly available from the universities' websites. In order to analyze these texts to discern the dialogical relationships between distance education and quality assurance in the case of the two universities, I employed the theory and methods of critical discourse analysis (Chouliaraki and Fairclough, 1999; Fairclough, 1992, 1995, 2001, 2003; Fairclough and Wodak, 1997; Janks, 1997; Luke, 1995; van Dijk, 1993, 1997; Wodak and Meyer, 2001). This approach to the study of social policy has been applied to a wide range of situations, including those of political platforms (Fairclough, 2000), management texts (Chiapello and Fairclough, 2002), and university discourse (Fairclough, 1993). In accordance with this research tradition, I take the language of these texts to be both "socially shaped and socially constitutive" (Fairclough, 1993, p. 134), and I aim to read them in a socially critical way in order to link these "discursive practices, events and texts" to " . . . wider social and cultural structures, relations and processes ...” (Fairclough, 1993, p. 135). This approach allows us:

. . . to connect each individual social event with the larger patterns of social relationships that persist from one event to the next. We need to be able to relate discourse, the words and deeds of the here-and-now, to the Discourses, the social habits of speech and action in the community as a whole (Lemke, 1995, p. 20, emphasis in original). 
For this study, particular interest was paid to the discourses of distance education, as represented by online delivery, and of quality assurance, and these discourses were then related to the Discourses of society as a whole. For example, I aimed to track some of the links between the practices, events, and texts described within these discourses and wider social and cultural forces, such as those constructing Australian universities as entrepreneurial businesses in an educational marketplace. It is these particular social forces, crystallizing in what Marginson and Considine (2000) call the "Enterprise University," which were of particular interest.

While there have been numerous policy developments in the area of quality assurance and online delivery (see for example: the international survey by Parker, 2004; the development work by the Sloan Consortium in the United States, such as Moore, 2002; and the European SEEQUEL project summarized by Johns, Baker, and Williams, 2004), these have focused on instrumental approaches, providing practical advice to practitioners, and thematic analyses of these approaches. My interest in this study, rather, was in the wider social forces at play in such policy developments as described above. In order to study the development of policy positions about quality in online delivery within the critical discourse framework, it is thus necessary to consider two discourse formations, which do not interrelate greatly at present, but which are likely to influence each other more so in the future.

The first arises from the discourses around online delivery in universities, which I will call the online discourse formation. This modernist discourse formation attempts to demonstrate the educational and institutional advantages of the Internet for the delivery of education. Online technologies have emerged as one of the key mechanisms by which universities have aimed both to modernize their internal operations, through the use of computer-based administrative systems, and to improve the efficiency and effectiveness of their teaching, understood within the massification paradigm (Scott, 1995) as an effective way to reach more students more cost effectively. These are some of the ways that online technologies are being used to enable universities to gain a place at the education marketplace table, broadening their reach, increasing their visibility, and commercializing their operations. For distance educators, the advantages of online technologies are usually portrayed as adding increased interactivity, for example through the use of online discussion methods, to past delivery techniques (Inglis, Ling, and Joosten, 1999; King, 2001; Meyer, 2002; Rumble, 2001; Salmon, 2003; Taylor, 2001). For teachers of oncampus students, online technologies are promoted as providing increased flexibility and richness to students' educational experiences, freeing them from attendance at particular places and times (Bottomley, 2000; Nunan, 2000).

The second discourse formation is that of quality in university education, which I will call the quality discourse formation. Quality assurance processes aim to provide guarantees, not necessarily of quality per se, but rather of the carrying out of the atomized processes by which particular 'products' are claimed to be produced. Thus it creates languages and activities that prescribe and proscribe, while all the time maintaining the supposed 'independence' of the organizational unit under its gaze: the university. Implicit in these policy positions is an idealized notion of what a university is, and consequently of what a good university is. Within this, 'quality assurance' is seen as a way to ensure that universities can demonstrate that they have appropriate measures in place to satisfy their 'stakeholders' that the education that they provide is of a satisfactory standard, or of a comparable standard to that of other universities (Harman, 2001; Kemp, 1999; Pond, 2002; Salter and Tapper, 2000; Twigg, 2001; Woodhouse, 1999). This is a discourse of control and accountability, where educational outcomes are seen as important commodities to be measured and promoted (Rhodes and Sporn, 2002; Vidovich, 2002).

I turn now to analyze two texts from within the quality discourse formation: the AUQA submissions from two Australian universities. These analyses consider the nature of the online 
discourse formations within them, and from this juxtaposition identify the ways in which the language of these texts is both "socially shaped and socially constitutive" (Fairclough, 1993, p. 134).

\section{The USQ AUQA Submission}

The submission by USQ to AUQA (University of Southern Queensland, 2002) is a 52 page full color document with numerous charts and diagrams. The report has an attractive cover similar to a promotional brochure, featuring a horizontal montage of images of students. The images are, from left to right, of two students using computers in a library, a student in academic dress holding a parchment, two images of students operating technical equipment, a group of students chatting casually outside the Wide Bay Campus, and a group in period dress who appear to be acting in a play. All of the students appear to be young and some have an Asian appearance. Males and females are about equally represented. It is a bright, inclusive, and international image.

USQ's institutional commitment to online methods in its operations is emphasized throughout its submission. For example, one of the "Key Institutional Priorities" listed in the submission is the:

Completion of a totally integrated e-infrastructure, including outcomes from the GOOD and BETTER projects, object-oriented personally configured website(s), the three modules of the PeopleSoft system, USQAssist (including full roll-out of the RightNow CRM system), an upgraded USQConnect with new (WebCT) learning management platform and appropriate access portals ... (p. 10).

This remarkable list of information technology projects creates an impression of innovation and technological competence. The USQ text places a large emphasis on online technologies in describing its future directions and its current quality claims. With a range of acronyms and 'brands,' an online environment is constructed that claims to provide a range of high tech solutions. What is not clear, however, is what problems these solutions address. Rather, they are cast as evidence of a progressive and innovative university. By invoking these information technology projects, the text projects USQ into the higher education landscape as a leader in the use of online technologies.

USQ's submission also spends a great deal of its available space describing its teaching and learning environment. In particular, Section 4.3, "Flexible Modes of Delivery," comprises 21 of its 52 pages. It makes strong claims for leadership in this area and places technology at the heart of its innovation by claiming that it is developing a new "generation" of distance education technologies (Taylor, 2001):

Many universities are just beginning to implement fourth generation distance education initiatives. USQ is actively engaged in creating the fifth generation based on the further development and judicious application of new technologies (University of Southern Queensland, 2002, p. 26).

It is interesting how the USQ text makes quality claims with respect to this online environment, considering the fact that the use of online technologies at the time was so new. It is difficult to claim established educational quality in an area where the means of teaching are so rapidly developing and changing, and when quality is often associated with experience developed over a long period of time. So instead of arguing for online quality, the submission argues for quality through the " . . . pivotal role of the Distance Education Centre as the focus for the instructional design expertise and research, production and distribution of distance learning materials ...” (p. 
8). This claim is justified through the acknowledgment of international distance education awards won by USQ, such as the ICDE award of excellence mentioned above, and noted on the university's homepage at the time of the audit. The role of the Distance Education Center and the materials that it produces are a key rhetorical tool in the USQ text's quality claims. Indeed, its surveys of user feedback from the early 1980s on the quality of the materials and services of the center are relied on in the portfolio, which as the AUQA panel noted "... pre-dates most online technological advances (about which USQ collates impressive usage statistics) . . .” (Australian Universities Quality Agency, 2002, p. 14). So there is a disjunction between the rhetoric of online technologies being fundamental to the operation of USQ on the one hand, and their absence from the quality discourse on the other.

\section{The University of Adelaide AUQA Submission}

The University of Adelaide submission to AUQA (University of Adelaide, 2002) is a 90 page document with a color cover featuring the university's two logos. The cover of the submission thus represents the university in a professional genre, using the symbols of brand marketing. It is a sombre and mature image. The submission itself is a drawing together of information to present a case for quality across the university. One device by which this is achieved is by making a general claim, followed by examples which have desirable facets of a systematic process, but which are not coordinated. For example, in the area of learning support the submission makes a general claim about quality:

Academic areas provide a wide range of learning support. An extensive system of course advice, with its blend of pastoral care, information on administrative practices and assistance with program choice [,] is a notable strength of the University ... (p. 37).

The report then supports this claim with examples from disparate areas of the institution:

Some schools have appointed their own discipline specific advisors (eg. Electrical and Electronic Engineering), whose role includes monitoring students at risk (eg., Chemistry). Others have taken this further by appointing a Student Learning Support Coordinator to advise on study skills and monitor assignment requirements (eg., AGSB) ... (p. 37)

This section goes on and lists a total of seven areas which have examples of 'good practice,' listed as undifferentiated examples. It is as if discipline specific advisers all monitor students at risk, advise on study skills, monitor assignments, etc., yet this is clearly not the case. The way in which they are listed as examples allows a reading of them as facets of one process. There is an elision from one example to the next, without qualification, as if each was another instance of a homogeneous process, even though the actual activities being spoken of (and the people involved) are quite different. The attempt here is to imply that examples are exemplars of quality. In this way, the submission gathers evidence from the university's disparate operations into a document that attempts to present a coherence that may not necessarily exist within the institution. In a sandstone institution (Marginson and Considine, 2000) which is made up of strong faculty groupings, where the central management is not strong, this is a way to demonstrate that corporate processes for quality assurance exist. Such an institution's quality text must argue that quality in its many parts make up a quality whole, if it is to mount an argument regarding quality assurance processes at the institutional level. 
The submission spends only 12 pages on teaching and learning - the same space given to "Governance and Leadership" - and acknowledges that the university needs to improve in teaching and learning:

The University has made a strategic commitment to raise learning and teaching to a level of excellence on a par with its research performance (p. 31).

The means by which learning and teaching performance could be equated with research performance (two quite different endeavors) are not described. Nor is the claim about research quality substantiated in this part of the document, although claims are made about this in an earlier section, and the reader is assumed to have been convinced by this. Consider the bases on which the claim for research quality is made:

The University of Adelaide is one of Australia's leading research institutions. It has a long tradition of producing high quality research that is attuned to the economic and social needs of South Australia, Australia and the international community. It receives significant levels of government, industry and other external funding, reflecting its relevance and importance in the current research climate. In striving for quality research outcomes, the University of Adelaide has put significant resources into supporting its higher degree research (HDR) students (p. 21).

Concepts of 'tradition,' international standing, and resourcing are appealed to here, but these bases are not relevant to their teaching and learning improvements since, as already acknowledged, such things are not present for teaching and learning. There are some serious problems with the comparison between research and teaching and learning quality. Take, for example, the valuing of input resources in the above description of research excellence. In this argument for quality in research, the attention given to inputs, such as grant income and resourcing for support for research students, is presented as an indicator of quality. Yet this argument cannot be used in claiming quality in teaching and learning, since it is acknowledged that funding for teaching grants has been reduced because of financial constraints (p. 36).

In any case, the submission makes it clear that the university's current strengths lie in research rather than in teaching and learning. The University of Adelaide submission uses achievements in one area of its operations, namely research, and reflects their glory onto another - teaching and learning. Yet the arguments used to justify claims for quality research do not hold up for teaching and learning. The submission glosses over this logical anomaly by a range of strategies, as summarized above.

Continuing the low key theme of teaching and learning in the submission is the section on "Educational technologies:"

The University has not been quick to embrace the opportunities afforded by new educational technologies, proceeding with caution and modest expectations. Its emphasis has been less on the opportunities they provide for distance education, and more on their potential for improving teaching efficiency for staff and learning flexibility for students (p. 36).

Here online technologies are associated with the language of reluctance and slowness, displaying "caution" and "modest expectations." This is an unusual collocation. It is rare to see information technologies associated with slowness and caution, rather than 'real time' and rapid change. This 
language of reticence and prudence is then associated with notions of "teaching efficiency." The catchcries of online technologies, flexible delivery, and the like are circumscribed here with considerable mollifications. They are cast as a means of providing "learning flexibility for students," but the journey toward that destination is a slow and careful one. In this way, teaching innovation with technology can be seen to be progressing in a managed and cautious way, making the changes fit easily within the quality assurance discourse of the audit submission, where changes must be planned, managed, measured, evaluated, and - eventually - audited. There is also a clear tension between "teaching efficiency for staff" and "learning flexibility" for students - this latter concept fitting more easily within the online discourse.

But the tensions do not end there. The submission goes on to indicate that online methods are in conflict with the university's culture, when it points out one of the conclusions of the selfassessment focus groups that it held with staff prior to the audit:

Of particular concern is the mismatch between many of the University's policies and procedures on the one hand, and the requirements of a centrally administered learning management system on the other. These will require urgent attention (p. 36).

Here "centrally administered" online delivery sits uncomfortably in an institution like the University of Adelaide with decentralized control. The use of distance education technologies is not a central plank of its strategy, but something which is developing slowly. Claims for online development are cast in the future tense, while management commitments are placed in the past tense. Online learning is not mentioned explicitly in the submission's description of the institution's quality assurance processes.

\section{The Universities' Locations in the Market}

The University of Adelaide's AUQA submission indicates that online delivery is not important in its market positioning. It is satisfied to rely on its reputation and its research performance as its main market advantage:

In a University with a formidable research culture, the emphasis given to learning and teaching over the last decade has been a significant achievement . . . The University maintains its market dominance in highscoring school-leavers, including those completing the International Baccalaureate. This continuous quality intake of students is achieved through multiple approaches: the marketing of the University's reputation, effective undergraduate student recruitment strategies, student load planning processes and rigorous admissions policies. Minimum TER [Tertiary Entrance Rank] cut-off scores for bachelor programs maintain high entry standards while providing students with realistic expectations of success (University of Adelaide, 2002, p. 32).

Hence online technologies figure within the list of a range of activities carried out by the institution, without taking a central place within its market strategy. Online delivery is not relied upon. The quality assurance of teaching and learning is described with the language of caution and slowness. These markers of quality in the educational marketplace are ignored in favor of other 'selling points.' The university's sandstone reputation and dominance of the high achieving school leaver market describe dominance in the market. By contrast with the University of Adelaide, the USQ text uses online technologies as a key rhetorical tool to market the university to the educational marketplace, but does not use them significantly for quality assurance 
purposes. Rather, when the discourses of quality assurance are required, more safe and traditional data are presented from traditional distance education methods and processes.

\section{Conclusion}

This paper, in comparing the AUQA audit submissions of two Australian universities delivering distance education, has described links between their depiction of quality, through these delivery mechanisms, and their institutional locations in the educational marketplace. This initial analysis suggests that the logics used in their quality claims have more to do with business drivers (see also McConachie and Danaher; Cummings, Phillips, Tilbrook and Lowe; Nunan; and McConachie, Danaher, Luck and Jones, this issue) than with educational rationales. The function of quality audit, to assure the quality of a national 'brand' of Australian university education, is best served by traditional, bounded, and well known data. This came from the Fordist processes of traditional distance education in the case of the USQ submission text, and from descriptions of quality inputs in the case of the University of Adelaide text. On the other hand, the marketing function of quality audit was provided by the USQ text through the use of future-focused images of online delivery tools and technologies; while the University of Adelaide text appealed to traditional reputations.

For USQ, as a new university, based in the Queensland rural center of Toowoomba, and with a heritage as a College of Advanced Education, the online world presents it with an opportunity that it must grasp if it is to grow - the overriding imperative of the Enterprise University (Marginson and Considine, 2000). Less encumbered by slow and traditional academic cultures, new universities have an outward-looking stance that makes them ". . . precariously free to reinvent themselves . . ." (p. 202). The University of Adelaide, as a sandstone university with a traditional background, can assume that it possesses elite "positional goods" (Hirsch, 1976; Marginson and Considine, 2000). As such, it can incorporate the online world into its operations without substantially changing its assumed superiority. It can do what its fellow sandstones have done, namely to “. . . appropriate modernism, layering it into their academic traditions" (Marginson and Considine, 2000, p. 199). The particular location of each institution in the market may have a decisive influence on the use made of distance education methods in its respective arguments for quality educational provision.

\section{References}

Australian Universities Quality Agency. (2002). Report of the Audit of University of Southern Queensland. Melbourne: Australian Universities Quality Agency.

Baldwin, G., and James, R. (2000). The market in Australian higher education and the concept of student as informed consumer. Journal of Higher Education Policy and Management, 22(2), $139-148$.

Bottomley, J. (2000). Reconfiguring institutional strategies for flexible learning and delivery. In V. Jakupec and J. Garrick (Eds.) Flexible Learning, Human Resource and Organisational Development: Putting theory to work (p. 87-106). London: Routledge.

Calder, J. (1994). Programme Evaluation and Quality. London: Kogan Page.

Chiapello, E., and Fairclough, N. (2002). Understanding the New Management Ideology: A transdisciplinary contribution from critical discourse analysis and new sociology of capitalism. Discourse \& Society, 13(2), 185 - 208. 
Chouliaraki, L., and Fairclough, N. (1999). Discourse in Late Modernity: Rethinking critical discourse analysis. Edinburgh: Edinburgh University Press.

Committee for Quality Assurance in Higher Education. (1995). A report on Good Practice in Higher Education. Canberra, ACT: Australian Government Publishing Service.

Dijk, T. A. van (1997). Discourse Studies: A multidisciplinary introduction. London: Sage.

Dijk, T. A. van (1993). Principles of critical discourse analysis. Discourse \& Society, 4(2), 249 283.

Evans, T. D., and Nation, D. (1989). Critical Reflections on Distance Education. London and New York: Falmer Press.

Fairclough, N. (2003). Analysing Discourse: Textual analysis for social research. London: Routledge.

Fairclough, N. (2001). Critical discourse analysis as a method in social scientific research. In R. Wodak and M. Meyer (Eds.) Methods of Critical Discourse Analysis (p. 121-138). London: Sage.

Fairclough, N. (2000). New Labour, New Language? London: Routledge.

Fairclough, N. (1995). Critical Discourse Analysis. New York: Longman.

Fairclough, N. (1993). Critical Discourse Analysis and the Marketization of Public Discourse: The universities. Discourse \& Society, 4(2), 133 - 168.

Fairclough, N. (1992). Discourse and Social Change. Cambridge, UK.: Polity Press.

Fairclough, N., and Wodak, R. (1997). Critical discourse analysis. In T. A. van Dijk (Ed.) Discourse as Social Interaction Vol. 2 (p. 258-284). London: Sage.

Gashler, P. (1994). Government as Catalyst: Steering rather than rowing, governing rather than implementing. Bulletin of Public Administration, 77, 64 - 66.

Harman, G. (2001). The Politics of Quality Assurance: The Australian quality assurance program for higher education, 1993-1995. Australian Journal of Education, 45(2), 168 - 182.

Hirsch, F. (1976). Social Limits to Growth. Cambridge, MA.: Harvard University Press.

Inglis, A., Ling, P., and Joosten, V. (1999). Delivering Digitally: Managing the transition to the knowledge media. London: Kogan Page.

Janks, H. (1997). Critical discourse analysis as a research tool. Discourse, 18(3), 49 - 62.

Johns, K., Baker, K. D., and Williams, S. A. (2004). SEEQUEL Conceptual Framework. Reading, UK.: University Of Reading. 
Kemp, D. (1999). Quality Assured: A new Australian quality assurance framework for university education. Retrieved February 14, 2005 from:

http://www.dest.gov.au/archive/ministers/kemp/dec99/ks101299.htm

Kickert, W. (1991). Steering at a Distance: A new paradigm of public governance in Dutch higher education. Colchester, UK.: University of Essex.

King, B. (2001). Managing the changing nature of distance and open education at institutional level. Open Learning, 16(1), 47 - 60.

King, B. (1992). The Open Learning Initiative: New directions for higher education. Australian Journal of Educational Technology, 8(2), 85 - 98.

Knight, J. (1994). Steering at what distance? The political economy of equity, diversity and quality in the August 1993 higher education budget statement. Australian Universities Review, 37(2).

Lemke, J. L. (1995). Textual Politics: Discourse and social dynamics. London: Taylor \& Francis.

Luke, A. (1995). Text and Discourse in Education: An introduction to critical discourse analysis. In M. W. Apple (Ed.) Review of Research in Education 21, (p. 3-48). Washington, DC.: American Educational Research Association.

Marceau, J. (1993). Steering from a Distance: International trends in the financing and governance of higher education. Canberra, ACT: Australian Government Publishing Service.

Marginson, S. (1997). Steering from a Distance: Power relations in Australian higher education. Higher Education, 34, 63 - 80.

Marginson, S., and Considine, M. (2000). The Enterprise University: Power, governance and reinvention in Australia. New York: Cambridge University Press.

McKinnon, K. R., Walker, S. H., and Davis, D. (2000). Benchmarking: A manual for Australian Universities. Canberra, ACT: Department of Education, Training and Youth Affairs.

Meyer, K. A. (2002). Quality in Distance Education: Focus on on-line learning. San Francisco: Jossey-Bass.

Moore, J. C. (2002). Elements of quality: The Sloan-C framework. Needham, MA.: The Sloan Consortium.

Nunan, T. (2000). Exploring the Concept of Flexibility. In V. Jakupec and J. Garrick (Eds.) Flexible Learning, Human Resource and Organisational Development: Putting theory to work (p. 47-66). London: Routledge.

Parker, N. K. (2004). The quality dilemma in online education. In T. Anderson and F. Elloumi (Eds.) Theory and Practice of Online Learning (p. 385-421). Alberta, Canada: Athabasca University Press. Retrieved February 14, 2005 from: http://cde.athabascau.ca/online book/ch16.html 
Pond, W. K. (2002). Twenty-first Century Education and Training: Implications for quality assurance. Internet and Higher Education, 4, 185 - 192.

Rhodes, G., and Sporn, B. (2002). Quality Assurance in Europe and the US: Professional and political economic framing of higher education policy. Higher Education, 32 (3), 355 390.

Rumble, G. (2001). Re-inventing Distance Education, 1971-2001. International Journal of Lifelong Education, 20(1-2), 31 - 43.

Salmon, G. (2003). E-moderating: The key to teaching and learning online. London: RoutledgeFalmer.

Salter, B., and Tapper, T. (2000). The Politics of Governance in Higher Education: The case of quality assurance. Political Studies, 48(1), 66 - 87.

Scott, P. (1995). The Meanings of Mass Higher Education. Buckingham, UK: Society for Research into Higher Education.

Smith, K. (1984). Diversity Down Under in Distance Education. Toowoomba, QLD.: Darling Downs Institute Press.

Taylor, J. (2001). Fifth Generation Distance Education. Canberra, ACT: Department of Education, Science and Training.

Twigg, C. (2001). Quality assurance for whom? Troy, NY.: Center for Academic Transformation.

University of Adelaide. (2002). Performance portfolio July 2002. Adelaide, Australia: Author.

University of Southern Queensland. (2002). USQ portfolio. Toowoomba, QLD.: Author.

Vidovich, L. (2002). Quality assurance in Australian higher education: Globalisation and 'steering at a distance.' Higher Education, 43(3), 391 - 408.

Wodak, R., and Meyer, M. (2001). Methods of Critical Discourse Analysis. London: Sage.

Woodhouse, D. (2001). Australian Universities Quality Agency: Audit manual (version 0). Canberra, ACT: Department of Education, Science and Training.

Woodhouse, D. (1999). Quality and quality assurance. In J. Knight and H. de Wit (Eds.) Quality and Internationalisation in Higher Education (p. 29-40). Paris: Organisation for Economic Co-operation and Development.

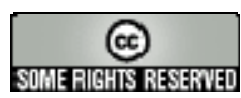


March - 2005

\title{
Quality Improvement, Quality Assurance, and Benchmarking: Comparing two frameworks for managing quality processes in open and distance learning
}

\author{
Alistair Inglis \\ Centre for Staff Learning and Educational Development, Victoria University \\ Melbourne, Australia
}

\begin{abstract}
Managing quality processes become critically important for higher education institutions generally, but especially for institutions involved in open and distance learning. In Australia, managers of centers responsible for open and distance learning have identified two frameworks that potentially offer ways of conceiving of the application of quality processes: the Quality Framework published in Inglis, Ling, and Joosten (1999); and the Benchmarking Framework published in McKinnon, Walker, and Davis (2000). However, managers who have been considering applying one or other framework within their institutional contexts have had to face the issue of how they should choose between, or combine the use, of these frameworks. Part of their dilemma lies in distinguishing among the related functions of quality improvement, quality assurance, and benchmarking. This article compares the frameworks in terms of their scope, institutional application, structures, and method of application, and then considers what implications the similarities and differences between the frameworks have for their use.
\end{abstract}

\section{Introduction}

Quality has become a matter of major importance for higher education institutions generally, but particularly so for institutions involved in open and distance learning (ODL) (Higher Education Council, 1997; Twigg, 2000; Western Cooperative for Educational Telecommucations, 2003). The origins of the quality movement within distance education in Australia can be traced back at least to the study by Nunan and Calvert (1992) and even before that to the work of the Standing Committee on External Studies in the mid 1980s. The Open and Distance Learning Association of Australia chose quality as the theme of its biennial forum in 1991 (Atkinson, McBeath and Meacham, 1991). At about the same time, the Australian government, through the National Board of Employment, Education, and Training, funded a study of costs and quality in on- and offcampus resource-based learning (Jevons and Northcott, 1994).

Within the broader higher education sector, the interest in quality originated from previously established movements overseas as it did from the debate taking place within distance education. The establishment of the Australian Universities Quality Agency (AUQA) to manage institutional quality audits within universities was influenced mainly by developments in the United Kingdom, 
mainland Europe, and the United States, and by the prior establishment of a similar agency in New Zealand (Vidovich, 2002).

The issue of quality impinges on the work of universities in a number of ways. For example, in order to protect their critical market (see also Cummings, Phillips, Tilbrook and Lowe; Nunan; Reid; Smith; McConachie, Danaher, Jones and Luck, this issue) in overseas education, universities have wanted to ensure that the standard of the educational products that they have been offering matches the standard of what they are offering onshore. Universities are also keen to establish how they compare with one other, or at least with other similar universities, even if they are not always keen to make such comparisons public.

The growing concern with quality in higher education has led institutions to look for ways of managing quality processes. In recent times, the focus of attention has turned to quality processes in the context of the online delivery of programs. This in turn has led to various attempts to develop frameworks for conceptualizing and structuring these processes. In Australia, the Quality Improvement Framework described in Inglis, Ling, and Joosten (1999) and the Benchmarking Framework described in McKinnon, Walker, and Davis (2000) have offered alternative ways of supporting quality processes in relation to teaching and learning in higher education. Staff in a number of universities have been looking into how each of these frameworks may be used to manage quality processes within distance, open, and flexible learning, including online learning. As a result, the author has received a number of enquiries seeking advice on how the two frameworks should be viewed in relation to each other. From the fact that these enquiries were being received, it seemed that comparison of the frameworks might be useful at this point of time. Furthermore, it was felt that if such a comparison were to be attempted by one of those involved in the development of one or other of the frameworks it might be regarded as all the more useful.

This article therefore attempts to compare the two frameworks from the point of view of the practitioner in ODL who wants to make a choice between the two. It couches this comparison in terms of four factors: the scope of the frameworks; the type(s) of institution to which they are meant to be applied; the structures of the frameworks; and the ways in which the frameworks are intended to be used. Based on this comparison, it then considers the implications of the similarities and differences between the frameworks for their use in managing quality processes in ODL.

\section{Distinguishing Among Quality Processes}

In the literature related to quality in higher education, three terms commonly appear: benchmarking, quality assurance, and quality improvement. These terms refer to distinct yet closely related functions. Judgments about quality are comparative and what distinguish among these three functions are the types of comparisons that are made.

\section{Benchmarking}

'Benchmarking' (see also Reid, this issue) is a term that is now widely used within the quality arena. Benchmarking involves comparing a set of products or services against the best that can be found within the relevant industry sector.

The European Benchmarking Code of Conduct defines benchmarking as being "the process of identifying and learning from Good Practices in other organizations" (The European Federation 
Comparing Two Frameworks for Managing Quality Processes in Open and Distance Learning

Inglis

of Quality Management, n.d., p. 1). The Public Sector Benchmarking Service in the United Kingdom describes benchmarking as involving:

Regularly comparing aspects of performance (functions or processes) with best practitioners, identifying gaps in performance, seeking fresh approaches to bring about improvements in performance, following through with implementing improvements, and following up by monitoring progress and reviewing the benefits. (Public Sector Benchmarking Service, n.p.)

O’Reagain and Keegan (2000) have described the four steps involved in benchmarking as: 1) understanding in detail one's own processes; 2) analyzing the processes of others; 3) comparing your own performance with that of others analyzed; and 4) implementing the steps needed to close the performance gap. However, as often happens when a term comes into everyday use, some of the original precision of its meaning is lost. Within the higher education sector in Australia, the term 'benchmarking' is now sometimes used to refer to processes that are more concerned with the other quality functions.

In the area of distance education, various sets of guidelines have been produced to support good practice (Twigg, 2001). Having reviewed the literature on guidelines, the Institute for Higher Education Policy produced a set of 24 benchmarks by which success in the online delivery of programs could be judged (Phipps and Merisotis, 2000).

\section{Quality Assurance}

Quality Assurance (see also Inglis and McConachie, Danaher, Luck and Jones, this issue) is a process oriented to guaranteeing that the quality of a product or a service meets some predetermined standard. Quality assurance makes no assumptions about the quality of competing products or services. In practice, however, quality assurance standards would be expected to reflect norms for the relevant industry. The process of quality assurance therefore compares the quality of a product or service with a minimum standard set either by the producer or provider or by some external government or industry standards authority. By rights, this standard should bear some relationship to best practice, but this is not a necessary condition. The aim in quality assurance is to ensure that a product or service is fit for the market.

\section{Quality Improvement}

Quality Improvement (see also Cummings, Phillips, Tilbrook and Lowe, this issue) is concerned with raising the quality of a product or service. The type of comparison that is made when engaged in quality improvement is between the current standard of a product or service and the standard being aimed for. Quality improvement is concerned with comparing the quality of what is about to be produced with the quality of what has been produced in the past. Quality improvement is therefore primarily concerned with self rather than with others. Processes focused on quality improvement are also focused more on specific aspects of an organizational unit's performance than on overall performance. It is usually the case that constraints dictate that efforts at improvement need to be targeted at areas of greatest need.

\section{Quality in Open and Distance Learning}

ODL differs in numerous respects from the practices employed in face-to-face education and the practices employed in online ODL differ from those involved in more traditional forms of ODL. 
The ways in which quality comparisons are made need not only to recognize that these differences exist, but also to take them into account when the processes for judging quality are designed. It is not appropriate to judge the quality of programs offered online by the same criteria as those used to judge the quality of programs offered face-to-face or by print-based distance education, even though in overall terms some comparability among differing offerings of the same program in different modes may be sought. By the same token, however, it is important to recognize that there is a high degree of commonality. The overall design of a course and its assessment are likely to be unaffected by the mode, and many of the same resource materials will be used in different modes. Where differences are likely to be most pronounced will be in the area of delivery of the program and in student support.

\section{What Is Meant by a "Framework?"}

What are being compared in this paper are what have been described as two "frameworks." Each framework also has associated instructions and examples, and both frameworks are each embedded in larger documents. The frameworks themselves, however, are the focus of interest here. It is therefore useful to begin by clarifying what is meant in this context by a framework.

A framework is generally something that provides form and a degree of rigidity. The framework of a building gives the building its structural integrity. The types of frameworks being described here are intended to bring structure to processes to which they are applied. They are intended to assist institutions to organize the processes that are being used in the area of quality management. They don't completely prescribe quality processes, but they channel processes in particular directions that accord with best practice.

While it is possible for both of the frameworks compared to be used for quality improvement, quality assurance, and benchmarking, for the purposes of clarity the framework described in McKinnon, Walker, and Davis (2000) will, from here on, be referred to as the "Benchmarking Framework," while the framework described in Inglis, Ling, and Joosten (2002) will be referred to as the "Quality Improvement Framework." Benchmarking and quality improvement are the processes to which the respective frameworks are most suited. This does not mean, however, that they cannot be applied to the other quality processes. This issue is discussed in more detail below.

\section{Origins of the Frameworks}

The Benchmarking and the Quality Improvement Frameworks were both the products of government-funded projects. Although developed within a year of each other, they were produced completely independently. The ways in which each of the projects arose differed considerably, and the nature of the differences had a major impact on what was produced in each case.

\section{Origins of the Benchmarking Framework}

The Benchmarking Framework was developed to provide a tool that could be used by universities to:

- Ascertain performance trends and initiate self-improvement

- Enable groups of universities to compare their performance 
Comparing Two Frameworks for Managing Quality Processes in Open and Distance Learning

Inglis

- Enable universities to ascertain their competitive [positions] (McKinnon, Walker, and Davis, p. 1)

Work on the development of the Benchmarking Framework was undertaken over 18 months in 1998 and 1999, and the Framework was published in February 2000. The development of the Framework involved senior executive staff in 33 Australian universities at the level of vicechancellor, deputy vice-chancellor, pro-vice Chancellor, or deputy principal/ registrar. During the Framework's development, discussions were held with staff of the Commonwealth Higher Education Management Service. The Framework was published in Benchmarking: A Manual for Australian Universities (McKinnon, Walker and Davis, 2000), which can be downloaded from the Department of Education, Science, and Training (DEST) website (http://www.dest.gov.au/archive/highered/otherpub/Execsumbench.htm). This document will be referred to as "the Manual."

\section{Origins of the Quality Improvement Framework}

The Quality Improvement Framework originated from a project that was undertaken in order to provide expert advice to the National Board of Employment, Education, and Training on the issues of quality, cost, and access in resource-based learning by taking advantage of he new learning technologies. The project was commissioned on behalf of the Higher Education Council. The project had a number of goals, one of which was the development of a framework for considering issues of quality in resource-based learning, including issues associated with equity of access.

Following the project's completion, the main findings together with the Framework were published by the Higher Education Council in a booklet entitled Quality in Resource Based Learning (Higher Education Council, 1997). However, a more extensive explanation of the Framework and its use was subsequently provided in the book Delivering Digitally: Managing the Transition to the Knowledge Media (Inglis, Ling and Joosten, 1999). In the original booklet, the Framework was presented in isolation and referred to simply as a "Quality Framework." In Delivering Digitally, however, further material was added explaining how to apply the Framework within an institutional setting and providing an example of an application of the Framework. Delivering Digitally was initially published in a hardback edition. Within a year, however, it was reprinted as a paperback edition, and a second paperback edition has subsequently been published (Inglis, Ling and Joosten, 2002). In the second edition, the chapter that presents the Framework has been considerably revised. The focus of this chapter has been shifted more toward quality improvement and the explanation of the use of the Framework was expanded and some changes were made to the Framework itself. For these reasons, it is recommended that this is the edition to which readers should now refer.

A number of universities have displayed interest in applying the Framework to their quality processes, either by using the Framework directly or by adapting aspects of the Framework. The Framework informed the development of quality assurance and quality improvement policies and processes at RMIT University where it was originally developed. It is currently being used at the University of Tasmania and the University of Melbourne. A workshop session on the Framework's use for quality improvement was presented at the October 2003 meeting of the Australasian Council of Open, Distance and E-Learning. Internationally, it has been reported that the Framework has been used at the University of Lund (Wigforss and Badersten, 2000a, 2000b). 
Comparing Two Frameworks for Managing Quality Processes in Open and Distance Learning

Inglis

\section{Locating Each Framework in Relation to the Three Types of Quality Processes}

From what has been said about the origins of the two frameworks, it can be appreciated that the purposes for which they were developed were somewhat different. The framework described in McKinnon, Walker, and Davis (2000) was principally intended for use in comparing institutions. The framework described in Inglis, Ling, and Joosten (2002) was intended more for use in managing quality processes within institutions. These differences are then reflected in the structures of the respective frameworks, and the ways in which it is suggested that they be used. More will be said about those differences below. It is important not to make too strong a point of the difference in orientation. McKinnon, Walker and Davis (2000) point out that one of the uses to which the Benchmarking Framework can be put is identifying aspects of a university's operations that could merit improvement. It is equally possible to use the Quality Improvement Framework for the purpose of comparing the performance of different types of institutions. Using either of the frameworks for quality assurance will require the setting of minimum performance standards, but that is obviously also a possibility. The difference in orientation is therefore one of relative alignment with the three quality processes, and the differences in alignment stem from the origins of the respective frameworks. The Benchmarking Framework was devised for the purpose of enabling institutions to compare themselves with other institutions with which they are competing for students, funding, and staff. The Quality Framework was devised for the purpose of enabling staff within institutions to institutionalize a quality improvement ethos.

\section{Comparing the Frameworks}

Frameworks of the type described here can be compared on the basis of a variety of factors. The purpose of this comparison is to provide some assistance in making choice decisions and therefore the frameworks will be compared on the basis of four factors, reflecting the major points of difference that are likely to affect such decisions:

- $\quad$ Scope (the areas of application that they cover)

- $\quad$ Type(s) of institution to which they are intended to be applied

- Structures of the Frameworks

- The ways in which they are meant to be applied

\section{Scope of the Frameworks}

One of the most immediately obvious differences between the two frameworks relates to their scope. The Benchmarking Framework was intended to enable universities to make comparisons across the full range of institutional functions. As well as encompassing aspects of teaching and learning, this framework therefore also deals with other aspects of a university's role - notably research and community engagement. The Quality Improvement Framework, on the other hand, was specifically developed to contribute to the delivery of education and training programs that rely on the use of new learning technologies. This framework is therefore centered on those aspects of an educational institution's operations that are concerned with teaching, program delivery, and student support. 
Comparing Two Frameworks for Managing Quality Processes in Open and Distance Learning

Inglis

In comparing the frameworks in relation to their scope, one finds areas of commonality as well as areas of marked difference. The Benchmarking Framework encompasses the area of teaching and learning that the Quality Improvement Framework has as its main focus. However, it covers a lot more besides. For staff specifically involved with teaching and learning, both frameworks therefore have something to offer. However, areas of overlap that lie outside those that are immediately obvious should not be overlooked. For example, although the Quality Improvement Framework focuses specifically on education and training delivery, it also deals with functions such as information technology infrastructure support, student learning support, and even institutional leadership. The Benchmarking Framework, for its part, has included benchmarks for Finance and Physical Infrastructure that overlap with Principle 1 of the Quality Improvement Framework dealing with the planning and management of resources and benchmarks for student support that overlap with Principle 10 of the Quality Improvement Framework dealing with the needs of learners.

\section{Institution type}

While the Benchmarking Framework is broader in scope than the Quality Improvement Framework, the Benchmarking Framework is designed for application to a much narrower range of institutions. The Benchmarking Framework is intended specifically for application to universities, and this is strongly reflected in the elements of the framework. As the authors point out, universities vary widely in terms of their missions, size, and focus but nevertheless have many features in common that set them apart from other types of educational institutions (McKinnon, Walker and Davis, 2000, p. 1). The Benchmarking Framework takes into account these characteristics of universities. The Quality Improvement Framework was devised for use in higher education but as it is presented in Inglis, Ling, and Joosten (2002) may be applied to any organization delivering education and/ or training programs relying on the new learning technologies. It could also be applied to vocational education and training providers, professional associations providing courses using new learning technologies, and commercial training centers. Where one can expect to find commonality between the frameworks therefore is in their application to universities.

\section{The structures of the Frameworks}

The most important differences between the frameworks relate to the ways in which the elements are conceptualized. These differences have, in turn, an important bearing on the ways in which the Frameworks are used as well as on the purposes for which they are used.

Structure of the Benchmarking Framework. The Benchmarking Framework comprises a series of 67 benchmarks, of which 25 have been designated as a core subset. As the Manual explains, the purpose of defining the core set was to provide a more manageable set of indicators to monitor on a regular basis, and the Manual goes into considerable detail in explaining the rationale for selection of the core subset and the implications of the benchmarks selected.

The complete set of benchmarks covers the range of a university's operations. They are grouped into nine areas:

1. Governance, Planning and Management

2. External Impact 
3. Finance and Physical Infrastructure

4. Learning and Teaching

5. Student Support

6. Research

7. Library and Information Services

8. Internationalization

9. Staff

There are a number of aspects of the Benchmarking Framework that make the structure of the Framework difficult to grasp initially. First, the numbering of the individual benchmarks is according to the chapters of the Manual in which the indicators are placed. As a consequence, the numbering starts at 3.1 rather than 1.1. Secondly, the definitions of the individual benchmarks contain several components, but the purpose of these components and the ways in which it is intended that these should be used is not fully described. In most cases, the purpose and use are fairly obvious. This is not always the case, however. For example, the Levels component provides a criterion by which to judge an institution's practices but the status and origins of the criterion are not explained.

Structure of the Quality Improvement Framework. The Quality Improvement Framework is organized around 10 key principles. These principles are meant to encompass the range of functions involved in supporting online delivery:

1. Informed planning and management of resources

2. Sustained committed leadership

3. Improving access for all clients, incorporating equity, and promoting cultural diversity

4. Understanding the requirements of the learner and reflecting stakeholder requirements

5. Design, development, and implementation of programs for effective and active learning

6. Creating confident and committed staff with new competencies

7. Managing and maintaining the technical infrastructure

8. Evaluating for continuous improvement

9. Provision of effective and efficient administrative services

10. Supporting the needs of learners

Associated with each of the principles is a set of best practice indicators. The indicators provide criteria for demonstrating whether the principles are being applied. 
Application of the Framework also involves the development of checklists and evidence guides that are then the tools that are used in the field. The Quality Improvement Framework can therefore be thought of as a conceptual structure for guiding quality processes rather than as an evaluative instrument.

\section{Applying the frameworks}

The way in which it is anticipated that each of the frameworks will be used is reflected in their respective structures, as well as in the types of advice and assistance that are provided to users.

Using the Benchmarking Framework involves contextualizing it to the situation to which it is being applied by selecting the set of benchmarks that will be used. For each benchmark, a number of elements are defined: the area of institutional operations to which the benchmark applies, the type of element (that is, lagging, leading, learning), the rationale for the benchmark, good practice, and the levels of performance.

This use of the Benchmarking Framework is assisted by the provision of graduated indicators that enable an institution to evaluate - in a rather basic fashion, it must be admitted - how well an institution scores against a particular benchmark.

The Manual provides only a modest amount of guidance on the ways in which the Framework should be used. As has already been noted, the three general areas of application are pointed out. However, the procedures that should be followed when the Framework is used in any of these ways are not described. It is therefore left very much up to the user. This appears to be a significant shortcoming, given that any significant variation on the way that the Framework is used from institution to institution could greatly affect the validity of any comparisons that might be drawn.

The Quality Improvement Framework also needs to be contextualized to the institutional situation, but this is accomplished somewhat differently. The Framework must be contextualized in two ways: firstly, in relation to the functions for which the particular organizational unit is responsible; and secondly, in relation to current institutional priorities. Because the Framework has been designed to be all-encompassing in the sense of identifying the range of functions that need to be supported by an education or training provider, whereas organizational units are typically responsible for only a subset of functions, each organizational unit needs to identify the principles and best practice indicators that are applicable to its role. Also, because most organizational units do not have the resources to work across all fronts at once, the Framework also needs to be contextualized to the priorities. This will involve identifying those principles and indicators that are the focus of attention for the immediate future. The implication of this second step is that the Framework will need to be recontextualized at regular intervals.

The instrument that is used in the field is therefore not the Quality Improvement Framework itself, but the checklists that are derived from the Framework. As institutional priorities will change from year to year, these checklists will likewise change over time.

\section{Choosing between the Frameworks}

The purpose of erecting a conceptual structure is to guide thinking within a particular field of practice, which, in turn, may then guide action. It is appropriate, therefore, to consider the ways in 
which each of the Frameworks is able to guide the thinking of teaching and administration about the practice of ODL.

The type of question that a head of a center of ODL is likely to want to ask in relation to the possible application of the frameworks to a particular situation is: "Which Framework should I be using and how should I be using it?”

From what has been said, it can be seen that the main differences between the frameworks lie in their scope, structures, and domains of application rather than in their intended functions. Both frameworks are capable of performing more or less the same functions within universities in relation to ODL. However, the ways in which the frameworks are designed to be used makes them more suited to some purposes than to others. When comparing the frameworks for the purpose of choosing between them it is therefore more profitable to begin by asking, "For what purposes is the framework being chosen?" than "Which framework best suits a particular function?”

If the principal aim is to compare one's own institution with others, then, depending on the level at which the comparison is being made, either framework could suffice. However, the Benchmarking Framework will support a more general comparison, while the Quality Improvement Framework will allow the comparison to be made at an operational level. On the other hand, if the principal aim is to provide a means of managing quality processes, then the Quality Improvement Framework will provide a more flexible and adaptable vehicle for achieving this aim.

The Benchmarking Framework has benefited from the extensive consultation with senior university administrators, both in Australia and overseas, that went into the construction of its benchmarks. However, the same characteristics that recommend it for making comparisons among institutions at the same time diminish its value for managing quality improvement processes within institutions at the operational level. What it gains in general application, it loses in adaptability to the needs of operational units. The Quality Improvement Framework, on the other hand, is designed to adapt to the characteristics of institutions at all levels. Because the checklists and evidence guides are highly variable, the Quality Improvement Framework is able to be adapted to a wide range of institutional types and organizational structures. It can also easily take into account the stage of development of an organization. The more detailed explanation of the ways in which it can be used may be another factor that attracts those who have not had previous experience of introducing quality processes within educational institutions.

\section{Maintaining the currency of the Frameworks}

An inherent aspect of the concept of best practice is that what constitutes best practice will change over time. Maintaining a commitment to best practice entails looking for opportunities and avenues for improvement and the effect of the drive for improvement will be to raise the benchmarks over time. This is particularly likely to be the case in the area of flexible and elearning, where changes in technology will offer opportunities to raise the quality of delivery and support services while at the same time lowering costs.

The Quality Improvement Framework was developed in the context that existed at the time. It is possible that the Framework may not be able to accommodate fully developments that take place in what practitioners in ODL regard as best practice. No criteria exist at the present time by which to judge how long a framework of this type might remain current. However, given the level of 
abstraction at which the framework has been specified, it is to be expected that the framework will date much more slowly than the practices to which it refers.

The currency of the Benchmarking Framework will also be subject to change over time. It has already been pointed out that the originators of the Framework have themselves foreshadowed the need for further development. Indeed, the function of benchmarking, which, as explained earlier, draws a comparison with the best of current practice, involves adjusting to the benchmarks to take into account improvements in practice. A recent study, however, that began with the objectives of adding new elements covering student admission practices and student complaints procedures to the benchmarking framework and of reviewing benchmarking generally among universities found that the manual developed by McKinnon, Walker, and Davis (2002) was not seen by universities as a useful benchmarking tool and concluded that the manual "does not offer a solution to benchmarking in an increasingly 'involve me' evaluation world”(Garlick and Pryor, 2004, p. viii). The findings of this study underscore the importance of one of the recurring themes in the literature relating to the application of quality processes: that systems and frameworks must be not only conceptually sound but also acceptable to stakeholders in the process.

\section{The Dark Side of the Introduction of Quality Processes}

There has been an implication in what has been said that the results produced by the application of quality processes are invariably desirable. In the ideal world, that may be so, but in the real world we usually fall considerably short of that for which we aim. In falling short of the ideal, we run the risk that the consequences of the intervention may be more problematic than the issues that the intervention is designed to address. This, in addition to the fact that the system needed to implement the quality processes itself, carries a cost. This cost is reflected particularly in the time of staff involved in the processes.

One of the adverse consequences of the application of quality frameworks can be that attention is focused on certain aspects of programs (those identified in the framework), to the neglect of other aspects that may nevertheless be regarded as being of importance. To the extent that this happens, it could be considered a reflection of a deficiency in the design of a framework. The difficulty of achieving an ideal design, however, must nevertheless be recognized.

An issue of greater concern is that the introduction of the use of quality frameworks may in certain circumstances have a stultifying effect on innovation. The corollary of increasing the value placed on certain specified activities is that the value placed on other activities that are not identified will be diminished. The way in which the use of quality frameworks has been applied is therefore likely to have a significant impact on the willingness of staff to break with existing conventions.

Finally, as Garlick and Pryor (2004) point out, the top-down imposition (see also Cummings, Phillips, Tilbrook and Lowe, this issue) of indicators on an institution is likely to lead to staff members responding to the letter rather than to the intent of the process, thus undermining the purpose of the activity.

\section{Conclusion}

Both the Benchmarking and the Quality Improvement Frameworks represent potentially useful tools for managing quality processes. From this comparison, however, it is apparent that the applications for which each is suited are somewhat different. The suitability of the frameworks 
for different purposes lies not just in the structures of the frameworks, but also in their degree of abstraction, the ways in which they are intended to be used, and their adaptability to different contexts.

For comparing the overall performance of universities in the area of ODL, the Benchmarking Framework has some applications. However, when it comes to making operational decisions in relation to the management of individual organizational units, the Quality Improvement Framework is likely to be found more useful. The reasons for this lie not just in the fact that this was the purpose for which the framework was primarily developed, but also because it is more adaptable to individual contexts.

\section{References}

Atkinson, R., McBeath, C., and Meacham, D. (1991). Quality in Distance Education: ASPESA Forum 91. Bathurst, NSW.: Australian and South Pacific External Studies Association.

The European Federation of Quality Management (n.d.). The European benchmarking code of conduct. Retrieved June 28, 2004 from: http://www.benchmarking.gov.uk/ content/documents/codeofconduct.doc

Garlick, S., and Pryor, G. (2004). Benchmarking the university: Learning about improvement. Canberra, ACT: Department of Education, Science, and Training.

Higher Education Council. (1997). Quality in resource based learning. Canberra, ACT: National Board of Employment, Education, and Training.

Inglis, A., Ling, P., and Joosten, V. (2002). Delivering Digitally: managing the transition to the knowledge media (2nd ed.). London: Kogan Page.

Inglis, A., Ling, P., and Joosten, V. (1999). Delivering Digitally: Managing the transition to the knowledge media. London: Kogan Page.

Jevons, F., and Northcott, P. (1994). Costs and quality in resource-based learning on and offcampus (Commissioned report no. 33). Canberra, ACT: National Board of Employment, Education, and Training.

McKinnon, K. R., Walker, S. H., and Davis, D. (2000). Benchmarking: A manual for Australian universities. Canberra, ACT: Higher Education Division, Department of Employment, Education, and Youth Affairs.

Nunan, T., and Calvert, J. (1992). Quality and standards in distance education. Unpublished report to the National Distance Education Conference.

O’Reagain, S., and Keegan, R. (2000). Benchmarking Explained. In European Commission (Ed.) Benchmarking in Europe - working together to build competitiveness. Brussels, Belgium: European Union.

Phipps, R., and Merisotis, J. (2000). Quality on the Line: Benchmarks for success in Internetbased distance education. Washington, DC: Institute for Higher Education Policy. Retrieved October 24, 2004 from: http://www.e- 
Inglis

guana.net/organizations.php3?action=printContentItem\&orgid= 104\&typeID=906\&itemID =9239\&templateID=1422

Public Sector Benchmarking Service. (n.d.). What is benchmarking? Retrieved June 28, 2004 from: http://www.benchmarking.gov.uk/about_bench/whatisit.asp

Twigg, C. (2001). Quality Assurance for Whom? Providers and consumers in today's distributed learning environment. Retrieved October 28, 2004 from:

http://www.center.rpi.edu/PewSym/mono3.html

Vidovich, L. (2002). Acceding to Audits: New quality assurance policy as a 'settlement' in fostering international markets for Australian higher education? Paper presented at the Australian Association for Research in Education conference: Brisbane. Retrieved July 20, 2004, from: http://www.aare.edu.au/02pap/vid02168.htm

Western Cooperative for Educational Telecommunications. (2003). Balancing Quality and Access: Principles of good practice for electronically offered academic degree and certificate programs. Retrieved October 20, 2004 from:

http://www.wcet.info/projects/balancing/principles.asp

Wigforss, E., and Badersten, L. (2000a). Indicators of best practice for delivery of online learning. In A. R. Trinidade (Ed.) Proceedings from the Lisbon 2000 European Conference: ODL networking for quality learning. Lisbon, Portugal: Universidade Aberta.

Wigforss, E., and Badersten, L. (2000b). Managing the transition to the delivery of online learning (unpublished paper). Retrieved June 28, 2004 from: http://www1.ldc.lu.se/logopedi/department/WIGFORSS/indicator.pdf

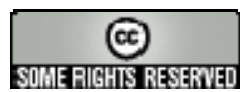


March - 2005

\title{
Using Integrated Enterprise Systems to Achieve Strategic Goals: A case study of a dual mode university
}

\author{
Alan Smith \\ Distance and e-Learning Centre \\ University of Southern Queensland \\ Toowoomba, Australia
}

\begin{abstract}
Since 1999, the University of Southern Queensland has embarked on a range of initiatives designed to improve the infrastructure and systems used to support its widely ranging activities in teaching and learning and research and its expansion into new international markets. This has involved the careful selection and implementation of various enterprise systems, together with the use of horizontal process teams. The results of this approach are now being realized, with demonstrable improvements to many university services, together with significant cost efficiencies. This paper discusses the reasons for the changes, the processes used to drive the changes through the various university committee structures, and the outcomes of the implementation of the enterprise systems.
\end{abstract}

Keywords: higher education; enterprise systems; change management; integrated systems

\section{Introduction}

Established in 1967 as a conventional tertiary education institution, the University of Southern Queensland (USQ) became a dual mode institution in 1977, when it began offering courses via distance education (see also Reid, this issue). Today, USQ teaches and researches as a dual mode university (that is, with on- and off-campus student populations), and also with triple option teaching styles (that is, students can study on-campus by 'traditional' distance education, or online via the Internet). It offers well in excess of 100 full degree awards, consisting of over 1,000 subjects/ courses across five faculties. The university provides access to educational opportunities to approximately 25,000 students annually, with about 19,000 studying via distance education and the remaining 6,000 on-campus at the Toowoomba and Wide Bay campuses. USQ's student enrollment is truly multicultural, with students from more than 100 different countries.

Since the late 1990s, USQ has embarked upon a range of initiatives designed to improve the infrastructure and systems used to support its widely ranging activities in teaching and learning, research, and its expansion into new international markets (see also Cummings, Phillips, Tilbrook and Lowe; Nunan; Reid; Inglis; McConachie, Danaher, Luck, and Jones, this issue). This has involved the careful selection and implementation of various enterprise systems (see also 
McConachie and Danaher; McConachie, Danaher, Luck, and Jones, this issue), together with the use of horizontal process teams. The results of this approach are now being realized, with demonstrable improvements to many university services, together with significant cost efficiencies. This paper discusses the reasons for the changes, the processes used to drive the changes through the various university committee structures, and the outcomes of the implementation of the enterprise systems. The paper also provides an account of the lessons learned during the implementation and the next steps which have emerged from this approach.

USQ has progressively developed its physical and technical infrastructure over its 38 year history. Its development as a strong community-based regional higher educational institution with a strong focus on student-centered education has positioned it to become a leading innovator in the use of educational technologies. This, in turn, enabled it to expand its influence as a national and global provider. USQ is a regional university with strong community links, a flexible education provider offering higher education opportunities for Australians nationally, and an international provider of quality higher education experiences to international students both on-campus in Australia and offshore. USQ's mission will continue to be as a higher education leader in transnational education which is regionally based and globally focused (University of Southern Queensland, 2004b).

USQ also continues to develop its 'University Cities' concept built on community partnerships, service, and engagement, while implementing strategies for internationalization that bring benefits and opportunities to its regions. USQ aims to prosper in a highly dynamic and challenging operating environment. Growth is planned for all USQ campuses, and nationally and internationally through flexible learning, to help achieve further recognition of USQ as a potent regional presence and to secure USQ's position as a successful local, national, and international business (University of Southern Queensland, 2004b).

What led the USQ senior management to decide on these directions? As well as considering the local Australian context and its immediate competitors, USQ also examined its future in the broader context of what it observed occurring internationally.

\section{International Influences}

The Internet has already had a major influence on the growth of international education, especially as the cost of access to information communication technologies (ICTs) continues to fall. This decline in costs has also been evident in the telecommunications industry. As Cairncross (1997) predicted, "The death of distance as a determinant of the cost of communications will probably be the single most important economic force shaping society in the first half of the next century” (p. 28).

It is in this context of the rapid increase in institutions offering courses via the Internet and associated user pays for quality service that higher education has become increasingly market driven. The transition from the Industrial to the Information Age has been traced by Dolence and Norris (1995), who argue that to survive organizations need to change from rigid, formula driven entities to organizations that are "fast, fluid, and flexible." Indeed, many universities are struggling to come to terms with the imminent organizational development challenges posed by competition for students through the emergence of the global lifelong learning economy.

The fact that the present traditional approaches based on conventional, classroom-based teaching and learning are not capable of meeting the escalating demand for higher education in the knowledge society has failed to register in the minds of many higher education institution leaders. 
Conventional, classroom-based approaches to higher education are increasingly becoming economically unsustainable. In many areas of the world, we cannot build educational institutions and develop teachers at a fast enough rate to meet the growing demand for all levels of education, including higher education (Bray, 1998). The major challenge confronting university leaders is how to boost academic productivity - how to change the fundamental structure of teaching and learning through the integration of ICTs. There is an immediate need for major investments in ICT and an associated proactive commitment to organizational development and institutional transformation in higher education.

\section{Local Influences}

In recent years, USQ has constantly examined the changing costs of its educational operations, particularly as the breadth of its activities internationally has significantly increased. Given its relatively modest budget and resources, USQ must target its activities carefully to ensure sustainable and quality education provision. Recent information demonstrated that conventional classroom approaches in certain disciplines requiring specialist equipment and facilities were difficult to sustain where class numbers are low (University of Southern Queensland, 2004a). In addition, while revenue from international activities had risen substantially in recent years, the overall costs associated with delivering and supporting teaching in many instances proved quite expensive when traditional models of face-to-face tuition were adopted (University of Southern Queensland, 2004a).

What has this meant for higher education institutions like USQ? Such changes have led to the ascendance of distance education methods through the evolution of all traditional universities into dual mode institutions, offering e-learning courses, and supporting both on-campus and offcampus students through Internet-based delivery systems. USQ's history in distance education enabled it to recognize its potential position to adapt its teaching and learning infrastructure and delivery methods, and to be better placed to become a more important player in a global education environment.

The USQ approach is unashamedly proactive and based on embracing new technologies, fundamentally rethinking and rewiring structure and infrastructure to become a more accessible university in a rapidly emerging e-world. While the USQ approach is clearly a function of the specific institutional characteristics and unique personalities that contribute to the ethos of a particular institution, as a case study it highlights the fact that, to effect the qualitative change necessary to accommodate the online teaching and learning process, it is also necessary to generate qualitatively different organizational infrastructures.

The USQ approach is also strongly based on Taylor's (2001a) fifth generation distance education theory (see also Nunan; Reid, this issue). Although a detailed account of this description is beyond the scope of the present paper, it is fair to say that USQ's distance education operations have progressively evolved through four generations: first, the correspondence model based on print technology; second, the multimedia model based on print, audio, and video technologies; third, the telelearning model, based on applications of telecommunications technologies to provide opportunities for synchronous communication; and fourth, the flexible learning model based on online delivery via the Internet. A fifth generation, derived from the fourth, capitalizes on the database and structured storage and presentation capacity of Web-enabled content and interaction (Taylor, 2001a).

Taylor has worked at USQ for over 25 years and believes that fifth generation distance education has the potential to decrease significantly the costs associated with providing access to 
institutional processes and online tuition. Through the development and implementation of automated courseware production systems, automated pedagogical advice systems, and automated business systems, the fifth generation of distance education has the potential to deliver a quantum leap in economies of scale and associated cost effectiveness. Further, the effective implementation of fifth generation distance education technology is likely to transform not only distance education, but also the experience of on-campus students (Taylor, 2001a). Taylor was able to convince senior management at USQ of the need to change its traditional philosophy and approaches to educational delivery. Consequently, USQ adopted the challenge and used enterprise systems as a key lever in the development of its fifth generation capabilities.

\section{USQ University-wide Enterprise Systems}

The use of university-wide enterprise systems as mechanisms to help attain USQ's specific objectives has been critical to the university's continued financial viability and growth. Specifically, enterprise systems have been pivotal to the concept of an 'e-university,' which offers a range of cooordinated services and access to resources through integrated enterprise systems, and have been fundamental to the university's administrative, teaching and learning, and student support functions. The e-University Project was conceptualized in terms of three fundamental foci: the e-Information repositories; a variety of e-Applications; and the e-Interface respectively. A graphic overview of USQ’s e-University Project is presented in Figure 1.

Figure 1. USQ e-University Project Overview

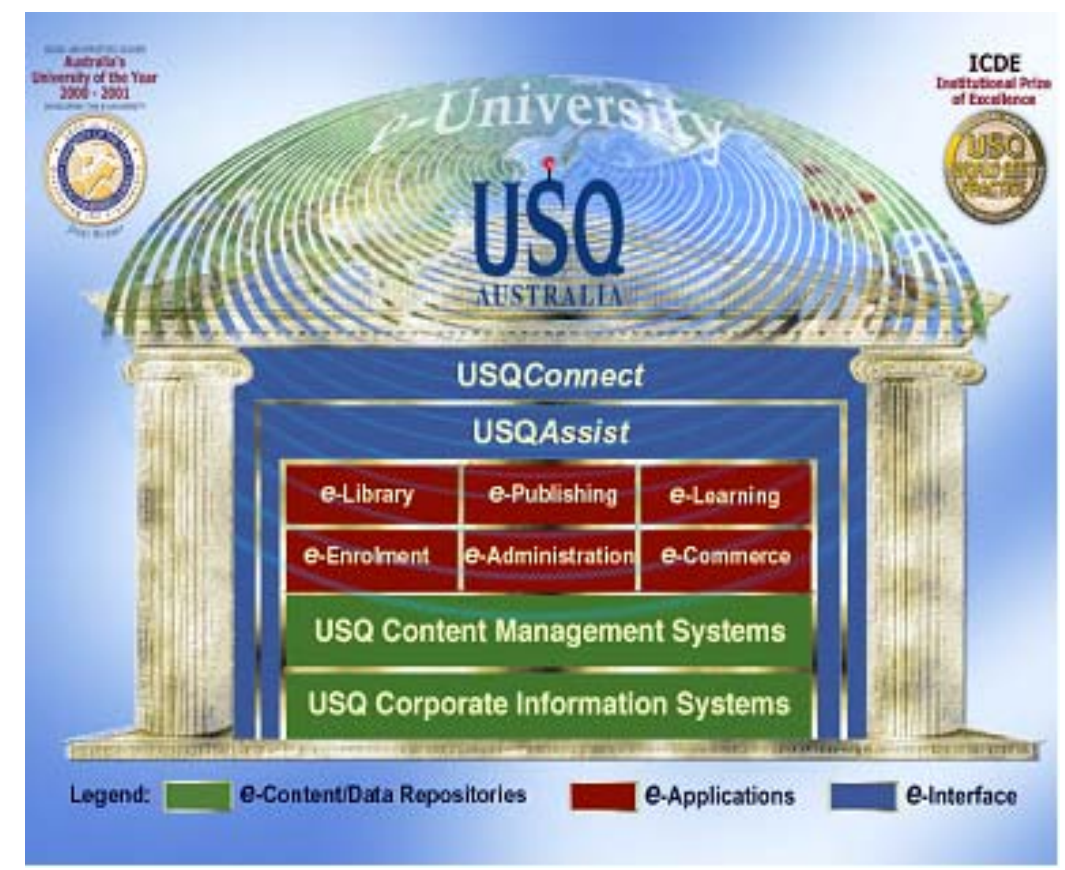

At the base of the 'e-temple' are the USQ corporate information systems which control the university's finance, student administration, and human resource functions. In mid 1999, USQ selected the PeopleSoft enterprise software to replace its existing systems, which required major updating both in scale and in functionality. The implementation of the PeopleSoft software modules (finance, student administration, and human resources) was completed early in 2002. Figure 2 shows the interface developed to access USQ's PeopleSoft Student Administration system. 
Figure 2. USQAdmin Interface

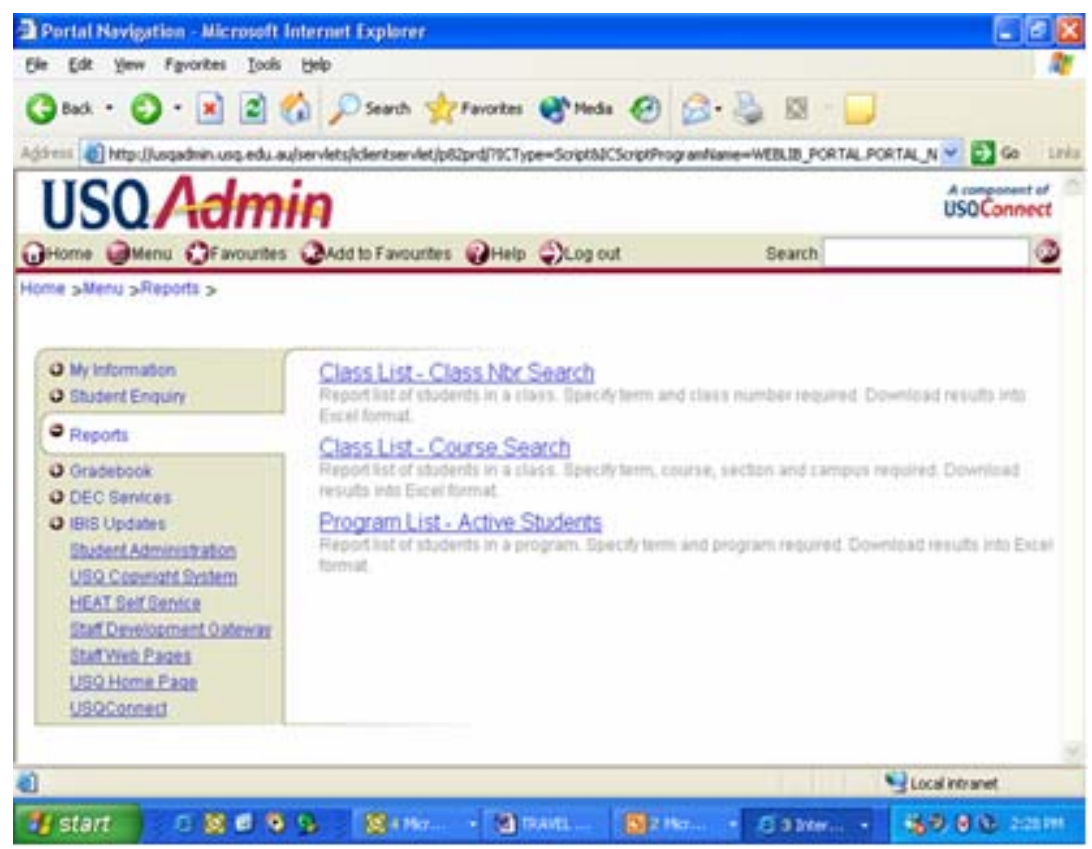

The continuing relationship with PeopleSoft will ultimately lead in 2005 to the implementation of PeopleSoft Version 8.0, which is fully Web-enabled and therefore consistent with USQ's strategic commitment to the e-University Project. Prior to the implementation of PeopleSoft 8.0, the existing integrated applications will provide an essential source of e-information in conjunction with the e-content management system at the heart of the Generic Online Offline Delivery (GOOD) Project, an application developed locally at USQ. Figure 3 demonstrates the basic functionality of the GOOD System.

Figure 3. GOOD System Functionality

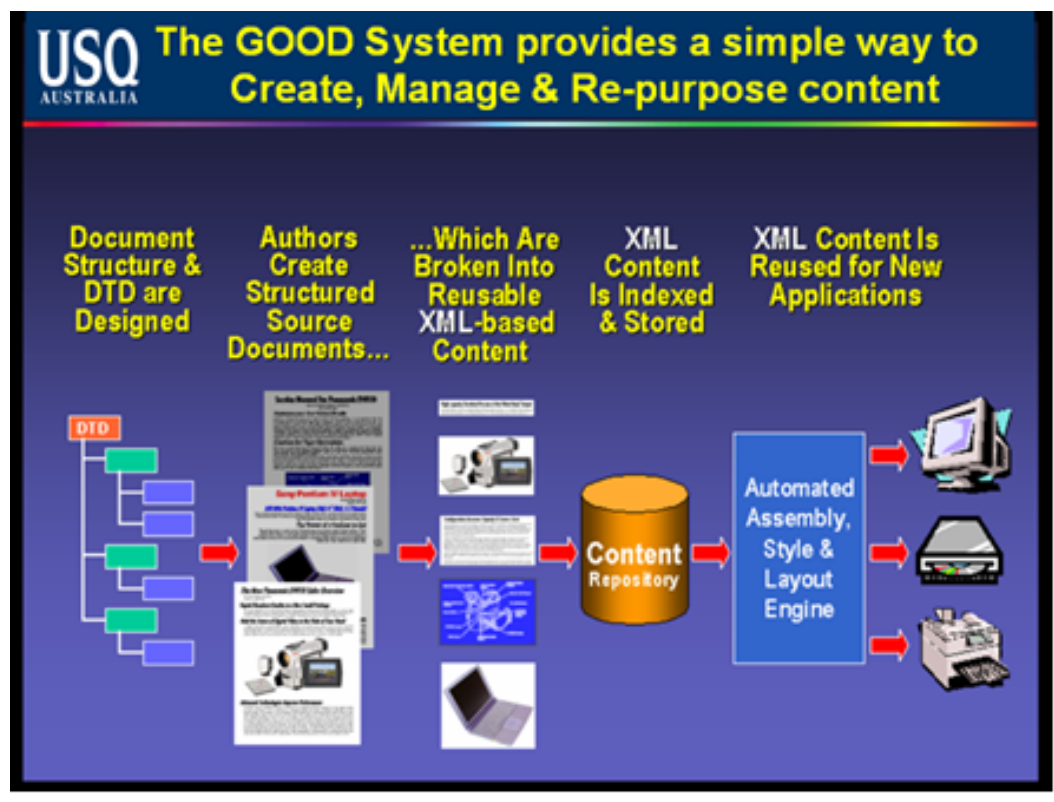


In essence, the e-content management system incorporated in the GOOD Project enables crossmedia publishing from a single document source. This means that USQ is able to make courseware available to students in a variety of delivery modes (print, online, CD, DVD, etc.) from a single document source. At the core of the GOOD cross-media production system is a content management system, which provides an integrated document management, workflow, and a content editing environment. Further, the cross-media publishing process has been automated through the use of standard markup languages. The GOOD project is gradually enabling USQ to replace its resource intensive proprietary production system for courseware with a single document source system based on the XML (Extensible Markup Language) standard. XML-tagged courseware documents are structured within consistent, comprehensive parameters, with the substantive content and structure able to be treated discretely from layout and presentation. The document layout is generated by applying XSL (Extensible Stylesheet Language) to the XML-tagged content. While initially focusing on the cross-media production of courseware and the university handbook, in time the GOOD system is being progressively rolled out to other areas across the university, including the cross-media publication of course information, admissions and enrollment documentation, and the like. Figure 4 shows the course materials production process using the GOOD System.

Figure 4. GOOD System Course Materials Production Process

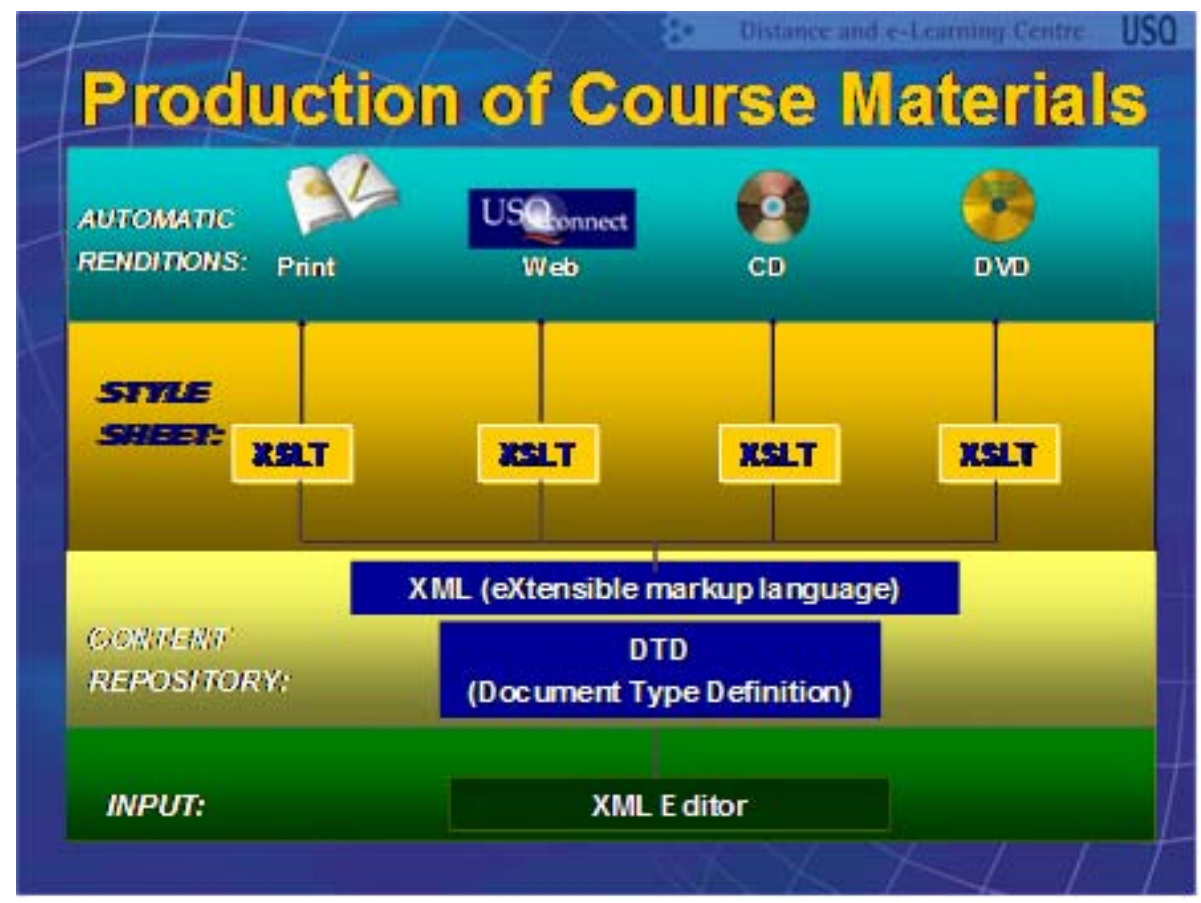

While the GOOD system provides a critical foundation for the efficient development and delivery of courseware, it also provides an integral 'engine' for the provision of a range of e-applications, including e-Enrolment, e-Administration, e-Commerce, e-Publishing, and not least e-Learning. This is supplemented by a Web content management system which maintains the corporate level information contained on the USQ website (see Figure 5 below), ensuring that all information pertaining to critical areas of university business remains up-to-date and accurate at all times, no matter what entry point or method of navigation is used to locate that information. 
Figure 5. USQ Website Interface

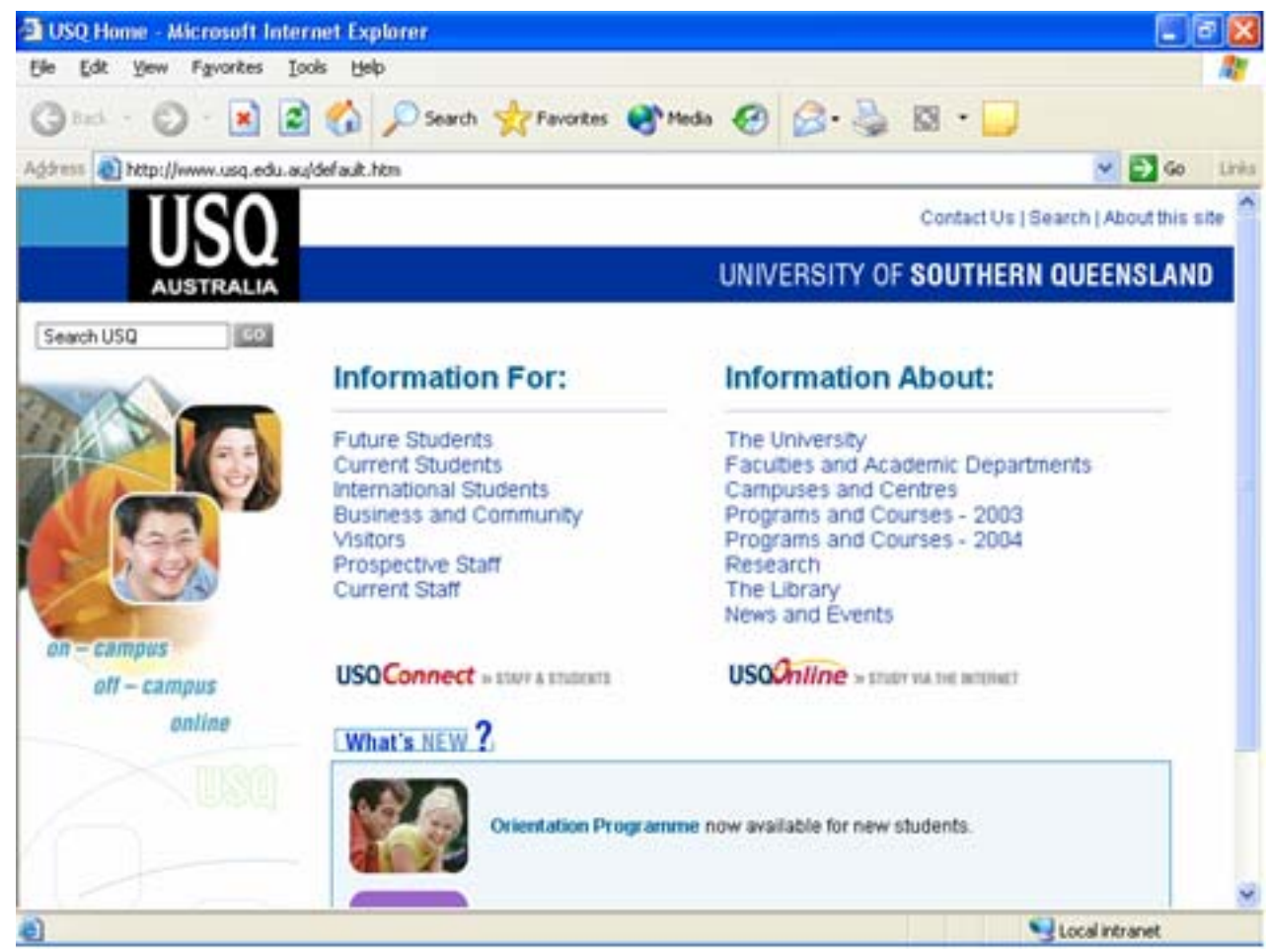

Course materials are delivered to USQ students in a variety of ways, depending on the mode selected, location of students, or contractual arrangements with selected USQ partners. There is now an expectation that all students will have the use of a minimum standard of hardware, communications software, and Internet access to undertake their studies. Some specific programs and courses have particular computing requirements above these general minimum requirements. With the use of learning managements systems such as Blackboard and more recently WebCT Vista (see also Cummings, Phillips, Tilbrook, and Lowe; McConachie, Danaher, Luck, and Jones, this issue), all USQ courses, regardless of delivery mode, have the option of providing both essential and/ or supplementary study materials, as well as the use of communication tools such as asynchronous discussion forums and virtual chat sessions as part of course delivery. This in turn has spawned the development of new 'hybrid' forms of delivery, where the elements of the study package are provided to all students and a range of different learning activities are facilitated in various modes, including online and face-to-face where appropriate. This has resulted in the emergence of new and innovative pedagogies across several disciplines and a significant change to teaching styles and classroom organization. Figure 6 below shows the types of activities which support the resource-based learning models being developed at USQ. Figure 7 shows the WebCT Vista learning management system interface being used by USQ. 
Figure 6. Hybrid Delivery Options

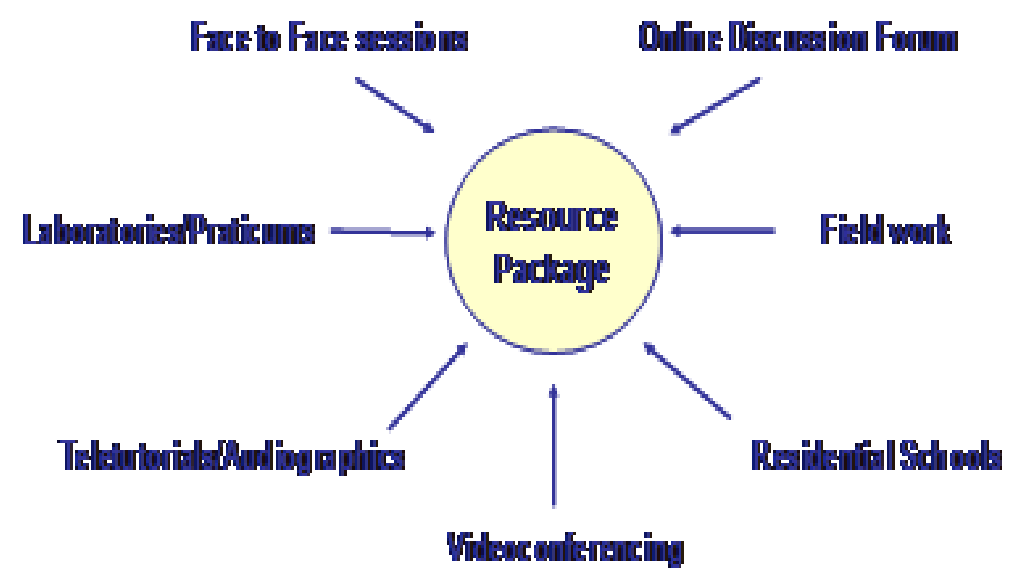

Figure 7. USQStudyDesk Interface

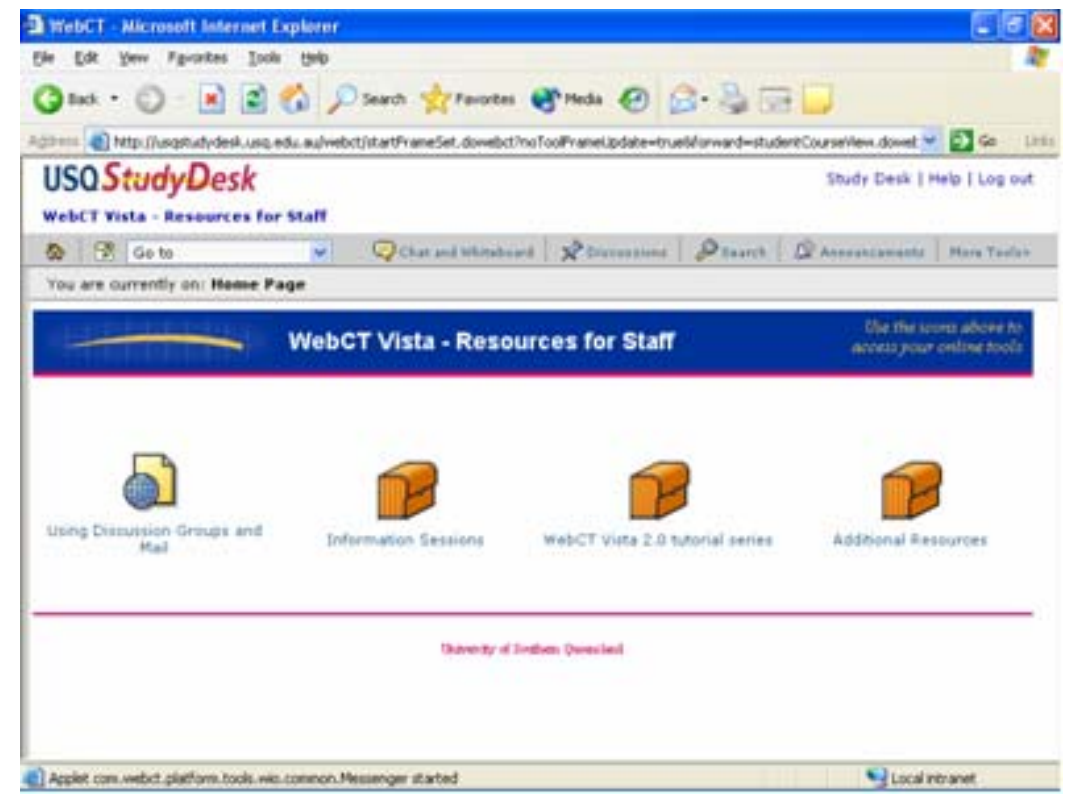

While the use of these enterprise systems at USQ has contributed significantly to the development of new pedagogies, it is in the area of student support that they have made perhaps the most significant difference. The USQ approach to learner relationship management has incorporated technologies to automate certain aspects of interaction with students, ultimately improving cost effectiveness, reducing both response times and costs to students and potentially increasing access to higher education on a global scale.

The USQAssist initiative deploys tracking and automation tools to manage the interaction between the university and both its existing and its prospective students. As USQ already has a need to provide global learning services to students enrolled in more than 100 countries, the university has to face the challenge of being responsive to client needs 24 hours per day, 7 days per week. The most efficient, cost effective way to manage the 24/ 7 challenge is to deploy 
effective automation tools, as opposed to running three shift student service desks or employing online tutors in different continents (although USQ already does the latter). The aim of such a system is to provide effective and efficient service to existing and prospective students at minimal variable cost.

When the project was initiated in late 1999, there were 13 toll free telephone numbers and numerous help desk facilities offered by various sections of the university. Each of these services provided a valuable service and collected some useful information, but there was no systematic recording and processing of enquiries that would enable USQ to be more responsive to satisfying student needs. The deployment of e-Customer Relationship Management (e-CRM) software will ultimately enable the use of a single toll free number integrated with an email-based enquiry tracking system that will exploit the fundamental strengths of the Internet in enhancing communication and managing information. Using structured, intelligent databases, the knowledge generated by solving student problems/ enquiries is being progressively stored and made available so, wherever possible, students with equivalent or similar problems can have their enquiries dealt with immediately through the self-help, automated response capacity of the USQAssist system, thereby facilitating effective first point of contact resolution (Taylor, 2001a) (see Figure 8).

Figure 8. Schematic Representation of USQAssist

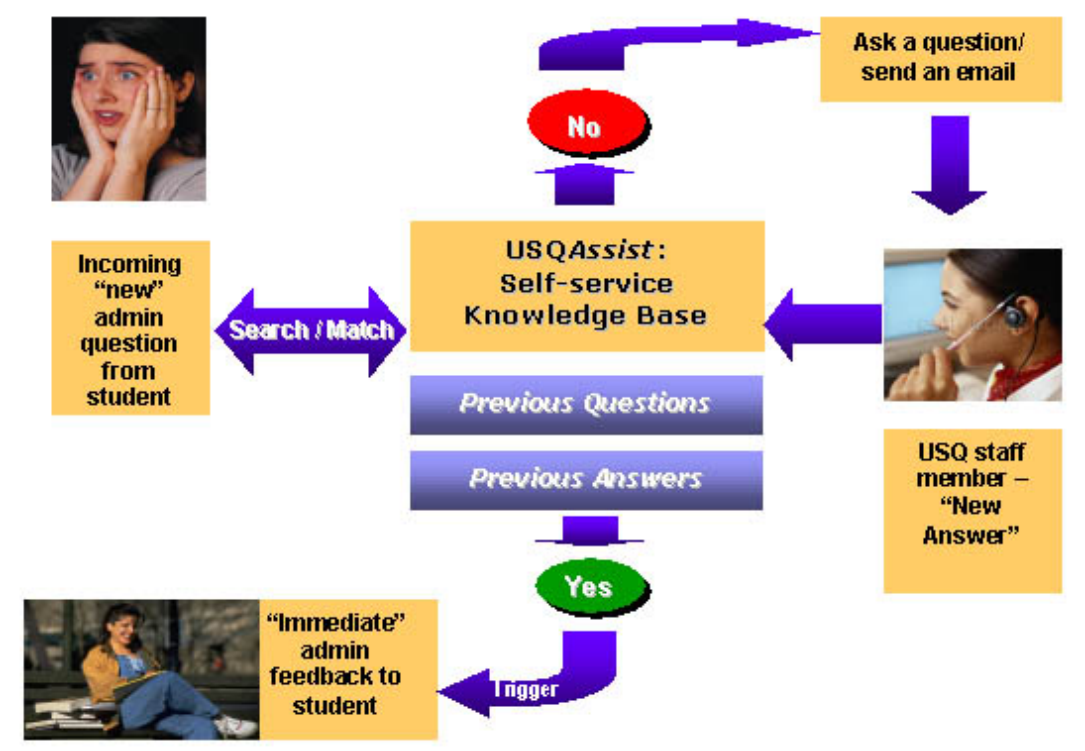

As the dynamic knowledge databases become more comprehensive, enabling personalized, immediate responsiveness to an increasing number of student queries, the institutional variable costs for the provision of effective student support further reduces. The judicious use of such technology not only improves the responsiveness of the institution, but also frees up student support personnel to provide personal assistance via email dialogue or telephone as necessary. Further, every interaction is tracked from initiation to resolution, including flexible routing of enquiries based on explicit rules-based escalation protocols to ensure timely and successful responsiveness, and subsequent statistical reporting of system performance. Tracking interactions with prospective students enables the collation of the effectiveness of institutional marketing strategies, an increasingly important strategic issue for universities in the emerging global learning economy, which demands a highly effective public e-Interface with the university (Taylor, 2001b) (see Figure 9). 
Figure 9. USQ Assist Interface

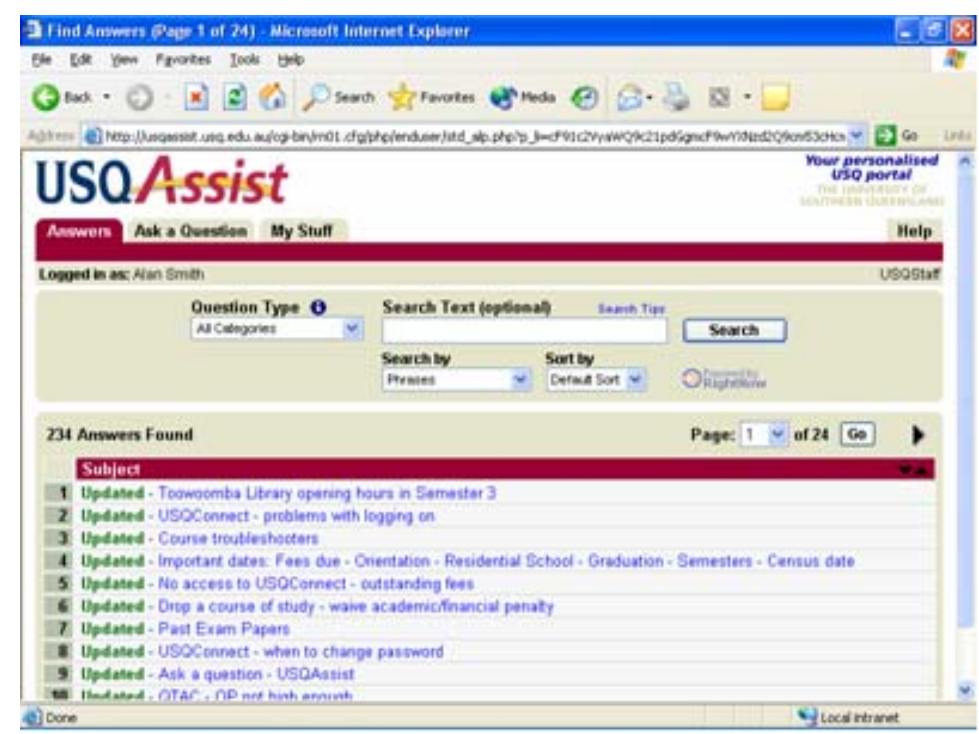

An additional learner relationship management feature of the USQ e-University Project is the development of a customizable e-Interface, a campus portal through which students, staff, and other stakeholders can engage with the university in a highly interactive and compelling manner. To be successful in the emerging global lifelong learning market, a university needs to create a campus portal that will achieve a degree of interactivity, user friendliness, and personalization that does not exist in the vast majority of higher education campus websites at present. The USQ e-Interface has developed through the application of a Web services approach, the implementation of which has entailed the creation of a new Internet Systems Design, Development, and Integration Team. The e-interface allows all students and staff appropriate levels of access to the full range of USQ enterprise systems and their associated services and benefits (see Figure 10 on the next page).

Figure 10. USQConnect Interface

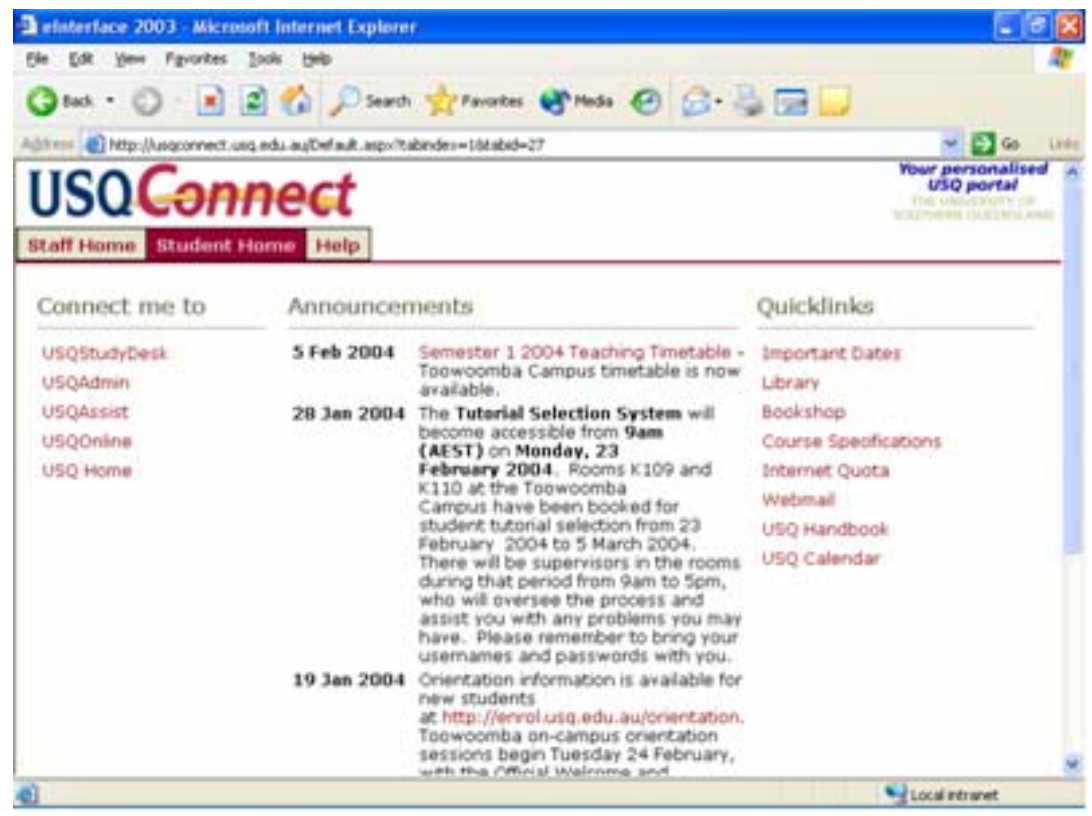


Learner relationship management is further supported by the implementation of USQ's wireless networking initiative. This part of the plan emerged from concerns expressed by on-campus students that they were becoming increasingly disadvantaged by a lack of sufficient access to online resources and services, since the campus-based computing laboratories were devoted primarily to the teaching of specialized software applications, often requiring access to 'high powered' hardware and software. USQ is now in the second phase of the project, with funding allocated to enable the installation of wireless hubs to ensure access to the Internet from about 90 percent of on-campus locations.

The implementation of USQ's wireless networking initiative and the use of integrated enterprise systems have raised important questions about the security of local networks and their susceptibility to attack from hackers and other unwanted intruders. An increasing number of resources has been necessarily devoted to analyzing the vulnerability of USQ IT systems to unauthorized entry from others, ensuring that appropriate backup systems are in place, and working toward single sign on access.

While the use of technology has been important in USQ's development of the e-University Project, the use of horizontal functional teams in a number of these development projects has proven critical to delivering the level of integration and to successful implementation (Gratton, 2000; Ostroff, 1999). Almost all the different aspects of the e-University Project have involved key players from the Distance and e-Learning Centre, Information Technology Services, the Library, and Faculties, together with other stakeholders from areas such as Student Administration, the International Office, Student Support Services and Financial Services. Whether as part of specific e-University project teams or through committees such as the Information Infrastructure and Services Committee, the active participation of a range of individuals and groups with either technical or operational expertise has been essential to the design and development of these new systems and to the relatively smooth implementation of new processes and procedures to key areas of university operations.

Much of this has been assisted by the clear communication from senior management of the need to maximize the functionality of all enterprise systems and to ensure that no single entity in the university makes an individual decision about technology or systems which in any way undermines the strategic directions outlined earlier in this paper. The size of the university, its financial procedures, and its current organizational structures certainly assist in this regard, but it still requires vigilance and regular monitoring by senior management and strategic committees to ensure that appropriate purchases and implementations of technologies takes place.

USQ has derived considerable benefits from its use of enterprise systems. The latest activitybased costing reports show increased student numbers without the 'normal' corresponding increases in student support staff. Importantly, student satisfaction with the quality of university services and systems remains high. Response times are constantly improving and both staff and students are utilizing the additional features and convenience provided by the integrated systems approach. Savings on additional staffing enable more resources to be directed to improvements in infrastructure and the development of new technical solutions/ enhancements to the e-University interface (University of Southern Queensland, 2004a).

\section{Conclusion}

In many universities, the development of Web-based initiatives and the use of enterprise systems are not systematic, but rather are more often the result of acts of innovation initiated by risktaking individual academics or of decisions made by individual faculties or service divisions. By 
contrast, the implementation of the e-University Project at USQ is strategically planned, systematically integrated, and institutionally comprehensive. This organizational culture has evolved over many years, and is essentially a reflection of one of USQ's guiding objectives: “To be a leader in flexible learning and the use of information and communication technologies in the tertiary education sector.”

The USQ case study also demonstrates that technology alone is not sufficient to engender much needed organizational development. If the power of the increasing array of new technologies is to be exploited in higher education, an appropriate organizational development strategy needs to be devised and implemented to bring about necessary institutional reconstruction.

USQ's use of enterprise systems to develop its fifth generation model of distance education (Taylor, 2001a) has enabled it to provide students with a valuable, personalized pedagogical experience at noticeably lower cost than traditional approaches to distance education and conventional face-to-face education. Fifth generation distance education not only has been less expensive, but also provides students with better quality tuition and more effective pedagogical and administrative support services than many other traditional universities.

USQ will continue with this approach and progressively upgrade and replace enterprise systems as licence and maintenance agreements come up for renewal. The objective will be not to be totally dependent on any single vendor, but to be able to select new applications and technologies as they are developed and to integrate them into the university's overall infrastructure and processes. The continuing development of open source technologies will be watched with considerable interest by many, in the belief that they may provide additional alternatives to the current proprietary enterprise systems.

\section{Postscript}

The quality and standing of USQ's teaching and learning activities have been widely recognized both nationally and internationally. In 1999, the Executive Committee of the International Council for Open and Distance Learning awarded USQ the Inaugural Institutional Prize of Excellence for a dual mode institution in recognition of both the university's significant contribution to providing education at a distance to the world and its leadership and innovation in the field of distance learning (see also Reid, this issue).

In August 2000, USQ was joint Winner of the Good Universities Guides 'University of the Year' for 2000-2001. The Award recognized USQ's leadership in developing the 'e-university' where students learn and are supported through the innovative and strategic use of educational Webbased technologies that encourage e-world expertise. The university has also won a Commonwealth of Learning Award of Excellence for Institutional Achievement at the third PanCommonwealth Forum on Open Learning held in Dunedin, New Zealand, in July 2004 specifically for its provision of flexible learning opportunities for people with diverse social and cultural backgrounds.

\section{References}

Bray, M. (1998). Financing Education in Developing Asia: Issues, trends and policy implications. Manila, Philippines: Asian Development Bank.

Cairncross, F. (1997). The death of distance. In O. Morton (Ed.) Exploiting the Information Age. London: Profile Books. 
Dolence, M. G., and Norris, D. M. (1995). Transforming Higher Education: A vision for learning in the 21st century. Ann Arbor, MI.: Society for College and University Planning.

Gratton, L. (2000). Living Strategy: Putting people at the heart of corporate purpose. London: Prentice-Hall.

Ostroff, F. (1999). The Horizontal Organization. New York: Oxford University Press.

Taylor, J. C. (2003). USQOnline, Australia. In S. D’Antoni (Ed.) The Virtual University: Models and messages. Lessons from case studies. Paris: Institute for Education Planning, UN Educational, Scientific and Cultural Organisation.

Taylor, J. C. (2001a). 5th Generation Distance Education (Higher education series, Report no. 40). Canberra, ACT: Higher Education Division, Department of Education, Training, and Youth Affairs.

Taylor, J. C. (2001b). The Future of Learning - Learning From the Future: Shaping the transition. Open Praxis, 2, 20 - 24.

University of Southern Queensland. (2004a). USQ activity based costing report 2004 (Internal working paper). Toowoomba, QLD.: Author.

University of Southern Queensland. (2004b). USQ directions 2004 (Internal working paper). Toowoomba, QLD.: Author.

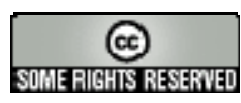


March - 2005

\title{
Central Queensland University's Course Management Systems: Accelerator or brake in engaging change?
}

\author{
Jeanne McConachie, Patrick Alan Danaher \\ Jo Luck, and David Jones \\ Central Queensland University \\ Rockhampton, Australia
}

\begin{abstract}
Central Queensland University (CQU) is a highly complex institution, combining campuses in Central Queensland and distance education programs for Australian domestic students with Australian metropolitan sites for international students and a number of overseas centres, also for international students. In common with many other universities, CQU has recently reviewed its course management systems (CMSs). In doing so, CQU has signalled its desired strategic position in managing its online learning provision for the foreseeable future.

This paper analyzes that strategic position from the perspective of the effectiveness of CQU's engagement with current drivers of change. Drawing on online survey results, the authors deploy Introna's (1996) distinction between teleological and ateleological systems to interrogate CQU's current position on CMSs - one of its most significant enterprises - for what it reveals about whether and how CQU's CMSs should be considered an accelerator of, or a brake on, its effective engagement with those drivers of change. The authors contend that a more thorough adoption of an ateological systems approach is likely to enhance the CMS's status as an accelerator in engaging with such drivers.
\end{abstract}

Keywords: Australia; course management systems; enterprise systems; open and distance learning; teleological and ateleological systems

\section{Introduction}

To realize its goal of becoming acknowledged universally as a leader in flexible teaching and learning, Central Queensland University (CQU) is using different technologies as drivers of organizational change (Central Queensland University, 2003; see also McConachie and Danaher; Cummings, Phillips, Tilbrook and Lowe; Nunan; Reid, this issue). In common with many other Australian universities, CQU has implemented an enterprise resource system, PeopleSoft, to improve its administrative procedures. More recently, to improve its teaching and learning, the university has reviewed its course management systems (CMSs) (the terminology choice is explained later in the paper) and implemented Blackboard as an enterprise CMS. In this paper, CMSs are defined as software packages that provide Web-based tools, services, and resources to support teaching and learning processes for both online and blended delivery. At the same time, 
CQU is seeking to reduce the use of Webfuse (Jones and Gregor, 2004), a home-grown CMS. In attempting to use Blackboard as an enterprise system (see also McConachie and Danaher; Smith, this issue), CQU has signaled its desired strategic position in centralizing and unifying the management of its open and distance learning provision for the foreseeable future.

Drawing on the results of an online survey and deploying Introna's (1996) useful distinction between teleological and ateleological systems, the paper analyzes the university's identified strategic position from the perspective of the effectiveness of CQU's engagement with an enterprise CMS as one of the identified drivers of change. The university's current CMS, Blackboard, is one of its most significant enterprise systems, a significance that is based not only on CQU's history as a nationally acclaimed distance education provider, but also on its ongoing search for institutional identity in an increasingly unstable national and international educational, political, and socio-economic environment. In the process, the university's strategic position is interrogated for what it reveals about "whether" and "how" CQU's approach to the use of CMSs should be considered an accelerator of, or a brake on, its effective engagement with the drivers of change.

\section{Central Queensland University}

CQU is a highly complex institution, combining campuses in Central Queensland and distance education programs for Australian domestic students and Australian metropolitan sites for international students with a number of centres based overseas. This complexity derives in part from the equally complex array of forces confronting all Australian universities, including an accelerated blending of delivery modes and pressure to boost non-government funding sources, as well as forces distinctive to regional universities, such as competition with their larger and more established counterparts in capital cities.

Figure 1. CQU Student Course Enrollment by Campus 1996-2004

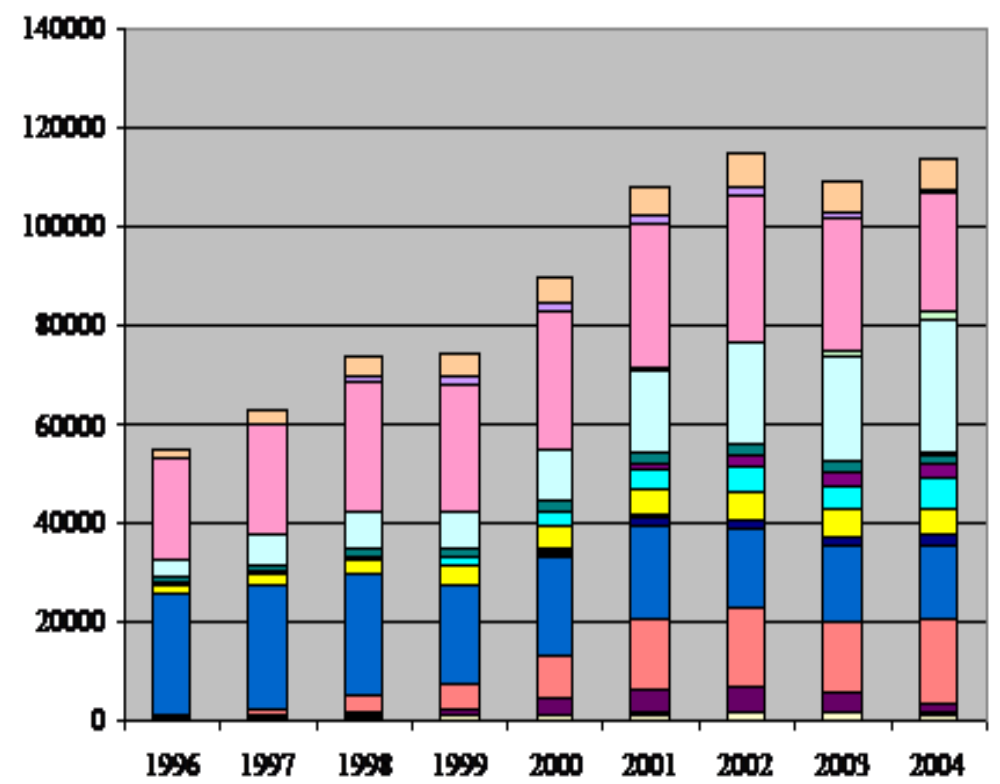

Figure 1 shows the increase in the size and complexity of student course enrollments at CQU from 1996 to 2004 inclusive. It shows student course enrollments more that doubling, from 
56,773 in 1996 to 115,601 in 2004 . In that same period, the number of delivery modes increased from 11 to 19, including the closure of some delivery modes and the opening of others.

In the context of this ongoing complexity and diversity, the university has recently promulgated its vision and revised its five-year strategic plan (Central Queensland University, 2003). The current Strategic Plan replaced the concept of a 'hybrid university' with a vision to become a "unified university" (p. 2). Indeed, the then vice-chancellor identified strategies that are perceived to create a sense of 'one university.' Furthermore, she requested the factions to reduce political lobbying for local and individual interests and instead to develop an organizational perspective. One of the identified drivers to achieve this particular change has been the implementation of Blackboard as the chosen enterprise CMS.

\section{Course Management Systems}

CMSs have gone from small tools used by supposedly quirky staff members to dominant elements of higher education's information technology capability in less than a decade (Katz, 2003). CMSs are software systems that are specifically designed and sold in the higher education market (see also Cummings, Phillips, Tilbrook and Lowe; Nunan; Reid; Inglis; Smith, this issue) to educational institutions to support teaching and learning and that typically provide tools for communication, student assessment, presentation of study material, and organization of student activities (see Luck, Jones, McConachie and Danaher, 2004, in which some of the material in this section also appears).

Within the e-learning literature, it is possible to observe authors using a number of alternative terms for CMSs. Amongst the most popular such labels are Learning Management System (LMS) (Clark, Cossarin, Doxsee and Schwartz, 2004; Fahrni, Rudolph and de Schutter, 2004; Paulsen, 2002; Sturgess and Nouwens, 2004) and Virtual Learning Environment (VLE) (Dyson and Campello, 2003). The choice of preferred label often depends on the country of origin (for example, VLE is particularly popular with authors from the United Kingdom) or discipline. We have chosen to use 'course management system' as we contend that Blackboard is a tool to manage course content, not student learning. The term 'CMS' has also been used widely in previous literature (for example, Dutton, Cheong and Park, 2004; Katz, 2003; Morgan, 2003).

CMSs are but one part of the spectrum of information systems being implemented in contemporary institutions of higher education to support their operations. Paulsen (2002) identifies a chain of four more or less integrated systems: content creation tools; course management systems; student management systems; and accounting systems. Other authors have identified additional system types or used alternative labels such as Learning Content Management Systems (LCMS), Enterprise Resource Planning (ERP) systems, and Managed Learning Environments (MLE). CQU's chosen ERP is PeopleSoft Higher Education and its chosen CMS is Blackboard.

CMSs form the academic system equivalent of ERP systems in terms of pedagogical impact and institutional resource consumption (Morgan, 2003). Enterprise systems are not universally regarded as being useful in achieving an organization's goals. By their very nature, such systems will impose their own logic on a company's strategy, structure, and culture and will push an organization toward generic processes, even when customized processes may be a source of competitive advantage (Davenport, 1998). CMSs automate and standardize elements of higher education that have been subject to refinement and protection for nearly a millennium, and possess a structure that threatens faculty hegemony (Katz, 2003). 
Another criticism of using enterprise systems to drive and enable change is that these systems impose a hierarchical perspective on organizations, in that they require centralized monitoring (Davenport, 2000). Enterprise systems presume that information will be centrally monitored and that organizations have a well defined hierarchical structure. According to Davenport (2000), "for better or worse, most organisations I have encountered in the world are still quite hierarchical. It's fairly clear 'who reports to whom'” (p. 19). He argues that concepts such as empowering employees through 'participation' are intriguing, but that few large organizations have adopted them successfully.

Moreover, implementing enterprise systems often reflects a conscious or unconscious move toward standardization (Morgan, 2003). Standardization and inherent values in CMS design can create a number of implications, which push teaching and learning in a particular direction. CMSs, as with any technology, are not value neutral transmitters of facts, but instead carry the values and priorities of their producers (Dutton and Loader, 2002). As teaching and learning are personalized sets of processes within institutions of higher education, any attempt at standardization is likely to be radical, painful, and problematic (Morgan, 2003).

\section{Using Planning to Achieve a Purpose Driven Approach}

Approaches to planning are varied, as are the results of the planning effort (Bourgeois and Brodwin, 1984; Chakravarthy and Doz, 1992). The logic and purpose of integrating technology planning into the organization's strategic planning are readily understood; the actual process and its appropriateness within the context of an organization are more complex (Porter and Millar, 1985). Wildavsky (1973) states that "if planning is everything, then maybe it is nothing" (p. 127). In contrast to this assertion, Self (1974) believed that even more planning may be preferable to a non-planning situation and may be more relevant when using a CMS as a driver of organizational change.

Gaddis (1997) questions, as do many others, not only the methods and processes of strategic planning, but also the very concept of future-oriented management. He contends that change need not be conceptualized in advance but merely allowed to emerge, perhaps with management facilitation. This theory, which argues that strategies are not necessarily positive, or emergent ideas necessarily negative, had been endorsed previously by Mintzberg (1994). Furthermore, Porter (1987) states that "Strategic planning in most companies has not contributed to strategic thinking” (p. 7). However, he asserts that, with the increasing dependence on technology, the answer is not to abandon planning and gaining ownership of a common vision for the organization; instead strategic planning needs to be rethought and recast.

Since Porter's work in 1987, proactive planning strategies have been significantly revised by researchers (Hamel and Prahalad, 1994). Writers such as Neuhauser, Bender, and Stromberg (2000) argue that a totally different planning and decision-making framework is imperative. Together with Stubbart (1995) and Davenport (2000), they suggest that long-term goals should be replaced by renewed emphasis on the creation of organizational identity. Moreover, to overcome negativity about a change in direction, Wheatley (2000) believes that it is necessary for leaders not only to develop a common vision but also to encourage a change from the traditional thinking that if organizations do not plan and control then change will not happen.

On the one hand, theorists tend to agree that hierarchical cultures force organizational members into competition and conflict with one another (Davenport, 2000; Kraus, 1980; Thayer, 1981). On the other hand, some studies (Creith, 2000) challenge these writers who identify hierarchy as the single or major culprit in inhibiting an organization from achieving a common vision. There are 
many elements to be considered (Dunphy and Stace, 1988). The management concept of strategic planning to create a common vision should be used if this concept enables the development of the right strategies at the appropriate time for a particular organization.

Enterprise systems such as Blackboard require stability achieved through staff having a high level of understanding about the direction of the organization (Davenport, 2000). Therefore the need to achieve acceptance of a common vision and a unitary approach to change is seen as a risk factor that must be managed when using an enterprise system as a driver of change.

\section{Information Technology and Systems}

Researchers have looked closely at the role of information technology (IT) in organizational change (Cnaan and Parsloe, 1989; Tapscott, 1996). They say that, because technology is in a state of perpetual innovation, IT has introduced a level of complexity within organizations that is different from anything that has been experienced before. On the one hand, the role of IT in facilitating organizational change (Markus and Robey, 1988), and thereby in providing value (Ives and Learmouth, 1984), is widely acknowledged. On the other hand, the lack of quantitative measures has prompted the 'productivity paradox' researchers to question whether IT investments, in fact, add value to organizations (Brynjolfsson and Hitt, 1996). As Robert Solow (1987) stated succinctly, "We see the computer age everywhere except in the productivity statistics” (cited in McGee, 2000, p. 1).

The relationship between IT and organizational change continues to be a double-edged sword. While IT often helps to redefine and change organizational processes, structures, and roles, these organizational elements may also have a corresponding effect on the success or failure of IT. The difference between the success and the failure of IT implementation is due to the unique characteristics of an organization (Brynjolfsson and Smith, 2000; Davenport, 2000). An organization's ability to encourage innovation in both technical and organizational arenas is crucial to remaining competitive in an increasingly changing world (Davenport, 2000; Schein, 1992). Therefore it is important for managers to understand how IT enters organizations and transforms some of their practices (Schein, 1992).

Traditional methods of implementing IT are no longer valid for enterprise systems (Davenport, 2000). As Wheatley (2000) notes, rarely are there instances when it is solely the software system that fails. Traditionally management concepts such as creating a corporate vision, setting goals, and strategic planning have been based on the notion of problem solving, where a problem is defined as the difference between the status quo and the desired state (as defined by the goals). The aim, therefore, is to search continually for problems and to generate actions as solutions. What these concepts neglect to address is that what is identified as the 'vision' is subject to normative judgments, which will always serve the interests of some over the interests of others. Thus the vision, goals, strategies, and outcomes are political and subject to debate and questioning.

As a result, the problem facing organizations today is that many information systems development projects are still developed through a planning process with purpose driven methodologies. The strengths of this type of approach are its emphasis on predictability, stability, and control of the development process and its account of rational problem solving behavior (Lyytinen, 1987). Purpose driven development has dominated the research and practice of information systems development since the inception of the field (Introna, 1996; Truex, Baskerville and Davis, 2000). Nevertheless a number of authors (Baskerville, Travis and Truex, 1992; Highsmith, 2000; Introna, 1996; Truex, Baskerville and Davis, 2000) have recognized that 
these methodologies may, at best, superficially address the social reality of the information systems and that this causes significant shortcomings.

Consequently many authors have sought to develop alternatives to the purpose driven or teleological development of information systems. Much of the earliest published work in this area was published within the information systems discipline (Baskerville, Travis and Truex, 1992; Introna, 1996). Many of the principles from that early work can be seen in recent interest and developments in agile software development practices (Highsmith and Cockburn, 2001) such as extreme programming (Beck, 1999).

In his paper, Introna (1996) suggests a distinction between teleological development (the dominant paradigm) and ateleological development, and proceeds to develop the principles of ateleological development. It is this distinction that we draw on within this paper (see also the distinction between 'top-down' and 'bottom-up' approaches to management deployed by Cummings, Phillips, Tilbrook and Lowe, this issue). “Ateleological systems development” (p. 25) is described by referring to four principles of ateleological development: local and contingent; historical; piecemeal; and random (p. 29-30). These principles can be summarized as follows:

An ateleological development process is a piecemeal process that aims to take maximum account of local emerging contingencies, as well as actively pursuing 'random' unexpected possibilities while maintaining some sense of overall coherence (p. 30).

The differences between teleological and ateleological systems development approaches are illustrated by the attributes of the design process, as listed in Table 1.

Table 1. Teleological and Ateleological Development Systems

(adapted from Introna, 1996, p. 26)

\begin{tabular}{lll}
\hline $\begin{array}{c}\text { Attributes of the design } \\
\text { process }\end{array}$ & \multicolumn{1}{c}{ Teleological development } & \multicolumn{1}{c}{ Ateleological development } \\
Ultimate purpose & Goal/ purpose & Wholeness/ harmony \\
Intermediate goals & Effectiveness/ efficiency & Equilibrium/ homeostasis \\
Design focus & Ends/ result & Means/ process \\
Designers & Explicit designer & Member/ part \\
Design scope & Part & Whole \\
Design process & Creative problem solving & $\begin{array}{l}\text { Local adaptation, reflection, } \\
\text { and learning }\end{array}$ \\
& & Time \\
Design problems & Complexity and conflict & Decentralized \\
Design management & Centralized & Indirect via rules and regulators \\
Design control & Direct intervention in line with a & \\
& master plan & \\
\hline
\end{tabular}

Implementing change driven mainly by technology continues to be a complex matter for the majority of organizations (see for example Williams, 2000). The human side is integral to the success of change, since organizational changes are planned, negotiated, implemented, interpreted, reacted to, and continuously altered by people (Dunphy and Stace, 1988). Because human behavior is unpredictable, uncontrollable, and discontinuous, the level of understanding by staff about the goals of the organizations and therefore the requirements of any system will vary (Beck, Giddens and Lash, 1994). Using a traditional teleological model for information systems 
development, as outlined in Table 1, may result in the hierarchy of goals and objectives becoming an issue, thereby leading to conflict.

\section{CMSs as Drivers of Change}

Having presented a conceptual account of CMSs, and having distinguished between teleological and ateleological approaches to systems development and planning (Introna, 1996), we turn now to analyze the survey data underpinning this paper (see also Luck, Jones, McConachie and Danaher, 2004, where different data from the same survey were used to address different research questions). The online survey was conducted between August and October 2003, and was completed by 91 respondents. Questions were divided into two sections: demographic and attitudinal. Attitudinal questions sought to map such phenomena as respondents' understandings of what a CMS is and of what makes it effective, and of why CQU selected Blackboard as its 'preferred' CMS. Table 2 summarizes the survey participants' roles at the time of completing the survey.

Table 2. Respondents’ Current Roles

\begin{tabular}{|c|c|c|}
\hline Response & Count & Percentage \\
\hline Academic & 52 & 57.8 \\
\hline Adminstrative support staff & 22 & 24.4 \\
\hline Designer & 2 & 2.2 \\
\hline Head of School & 2 & 2.2 \\
\hline Manager (i.e., in charge of budget and staff) & 2 & 2.2 \\
\hline Student & 2 & 2.2 \\
\hline Technical support staff & 7 & 7.8 \\
\hline Not Stated & 1 & 1.2 \\
\hline
\end{tabular}

In analyzing the survey data, we are aware of some limitations. The survey had been intended as a kind of 'pretest,' with a follow-up survey to be administered after Blackboard has become more firmly established at CQU. Consequently, the survey was administered at a time when most respondents had no direct experience of using Blackboard and, indeed, when many of them had little or no direct experience of using any CMS.

Survey responses, however, indicate that 54 percent of staff have taught online and over 43 percent of staff have learned using online learning. CQU had been using WebCT as its enterprise CMS since 1999, and by late 2002 there were 231 courses using WebCT (Sturgess and Nouwens, 2004; see also Cummings, Phillips, Tilbrook and Lowe; Smith, this issue). In 2002, Webfuse, a locally developed CMS, was used by 118 staff to modify 308 course websites, with staff usage increasing in subsequent years (Jones and Gregor, 2004). In addition, the university had already completed what was perceived by management to be a broad consultation process (Sturgess and Nouwens, 2004) to identify the appropriate CMS to be implemented at CQU. Consequently it might be expected that significant numbers of CQU staff and, in particular, academics, should have knowledge of and interest in CQU's directions with respect to CMSs.

Because of these limitations, we combined the statistical analysis of responses to the survey's closed questions with the qualitative analysis based on identifying patterns and disparities in responses to the more open ended, attitudinal questions on the survey. We accept that this is selective rather than representative of both questions and responses. Nevertheless, we argue that the resulting analysis provides strong evidence for our assertions that the traditional, purpose 
driven, teleological approach to systems development and planning (Introna, 1996) is not maximizing the possibilities of using a CMS as a driver of organizational change at CQU.

The limitations duly noted, our qualitative analysis focused on identifying both similarities in, and variations on, responses to four key questions:

1. "How likely is the implementation of Blackboard to help CQU to become a universal leader in flexible teaching and learning?”

2. "Which groups and organizational units should have the leading role in quality control and/ or quality assurance in the use of Blackboard at CQU?”

3. "Do you believe that implementing Blackboard is a way to place additional controls on teaching and learning activities at CQU?”

4. "Does it matter to you whether CQU implements Blackboard or any other Course Management System?”

These similarities and variations form the basis of our claims about the effectiveness of CQU's use of a CMS as a driver of change.

Since its establishment as a university in 1992, CQU has had four vice-chancellors. Appropriately, each of these vice-chancellors has attempted to increase the ownership of her/ his vision across the organization. The second and third vice-chancellors have used the implementation of large enterprise systems such as PeopleSoft Higher Education, PeopleSoft Financials, and Blackboard to develop a unified approach to administration and teaching across the organization (the arrival of the fourth and present vice-chancellor coincided with a comprehensive organizational review whose findings are currently being worked through, with at this stage unknown implications for CQU's CMSs). In that context, we were particularly interested for the purposes of the paper in identifying what advantages respondents saw in having an enterprise approach to the use of a CMS compared to a less structured and more devolved approach using a mix of Blackboard and the 'in-house' developed product, Webfuse (Jones and Gregor, 2004).

Table 3 summarizes the responses to Question 18: "How likely is the implementation of Blackboard to help CQU to become 'acknowledged universally as a leader in flexible teaching and learning and well focused research' (Item 2 in the 'Vision Statement' section of the CQU Strategic Plan 2003-2007)?”

Table 3. Blackboard's Ability to Assist CQU to Become a Flexible Learning Leader

\begin{tabular}{lcc}
\hline \multicolumn{1}{c}{ Response } & Count & Percentage \\
No response & 1 & 1.1 \\
I don't know & 51 & 56 \\
Very unlikely & 15 & 16.5 \\
Fairly unlikely & 8 & 8.8 \\
Fairly likely & 10 & 11 \\
Very likely & 6 & 6.6 \\
\hline
\end{tabular}


The survey shows that over 50 percent of staff “don't know” if Blackboard will assist the university to achieve one of its major goals, that of becoming an acknowledged leader in flexible teaching and learning. This might reflect respondents' lack of familiarity with the CMS. On the other hand, the fact that 25 percent of respondents felt that such an outcome was "fairly unlikely" or "very unlikely, " while only 17.5 percent felt that such an outcome was "fairly likely" or "very likely," suggested a polarization of opinion that might make a teleological systems approach (Introna, 1996) more difficult to implement.

Tables 4 and Table 5 summarize the responses to Question 23: "Which groups and organizational units should have the leading role in quality control and/ or quality assurance in the use of Blackboard at CQU?” (see also Reid; Inglis, this issue).

Table 4. Groups Responsible for the Quality of CMS

\begin{tabular}{lcc}
\hline \multicolumn{1}{c}{ Response } & Count & Percentage \\
Administrative support staff & 0 & 0 \\
Associate Dean (Teaching and Learning) & 32 & 49.2 \\
Designer & 9 & 13.9 \\
Head of School & 8 & 12.3 \\
Technical support staff & 8 & 12.3 \\
\hline
\end{tabular}

Table 5. Organizational Units Responsible for the Quality of CMS

\begin{tabular}{lcc}
\hline \multicolumn{1}{c}{ Response } & Count & Percentage \\
No response & 0 & 0 \\
The relevant faculty & 36 & 61 \\
Division of Teaching and Learning Services & 16 & 27.1 \\
Information Technology Division & 7 & 11.9 \\
\hline
\end{tabular}

Table 4 shows that nearly 50 percent of respondents believed that the associate deans (teaching and learning) and the faculty should be responsible for the quality assurance of Blackboard within the university. Associate deans (teaching and learning) are faculty- and workplace-based; they are not a central or enterprise resource. Table 5 shows a similar finding: that more than 60 percent of respondents believed that the relevant faculty is the most appropriate organizational unit. These results are perhaps unsurprising, given that most respondents were academics working in faculties.

The qualitative data, including the respondents' respective occupational roles, highlight the fact that many respondents were concerned about the prospect of control being removed from academics and faculties to a central body.

- None of the above! Academics are the only ones who should be responsible for quality control of their materials! If by 'designer' you mean the academic who designs the course material, then that person - but by no means a Division of Teaching and Learning Services or other 'expert.' (Academic)

By contrast, there was a perception by some respondents that there needed to be an increased control at the enterprise level. 
- Chancellery - as a decree will be needed to kill off other systems as CQU can only eventually get expected value from the Blackboard system if it is adopted as the standard approach. (Administrative support staff)

Table 6 summarizes the responses to Question 25: "Do you believe that implementing Blackboard is a way to place additional controls on teaching and learning activities at CQU?

Table 6. A CMS As Controlling Teaching and Learning Activities

\begin{tabular}{lcc}
\hline \multicolumn{1}{c}{ Response } & Count & Percentage \\
No response & 9 & 10 \\
Yes & 40 & 44.5 \\
No & 12 & 13.3 \\
No Difference & 29 & 32.2 \\
\hline
\end{tabular}

Nearly 45 percent of the respondents believed that the university has implemented Blackboard as an enterprise system as a way to place additional controls on teaching and learning. We plan at a future stage of the research to ask respondents whether they regard such an approach as positive and necessary in a context of increasing bureaucratization around teaching quality and other accountability measures. Potentially this result suggests a reasonably high level of concern about centralization of decision-making that does not augur well for Blackboard as a driver of change consistent with teleological systems (Introna, 1996).

Table 7 summarizes the responses to Question 26: "Does it matter to you whether CQU implements Blackboard or any other Course Management System?”

Table 7. Significance of Blackboard as the University’s Chosen CMS

\begin{tabular}{lcc}
\hline \multicolumn{1}{c}{ Response } & Count & Percentage \\
No response & 2 & 2.2 \\
Yes & 47 & 52.2 \\
No & 29 & 32.2 \\
I don't care & 12 & 13.4 \\
\hline
\end{tabular}

Over 50 percent of the respondents cared whether Blackboard were implemented within CQU, which demonstrates a level of ownership for whichever CMS the university chooses as its driver of change. Unlike the responses in Table 6, and given that most respondents had had no direct experience of Blackboard at the time of the survey, this suggests a high degree of professional commitment and concern that might be likely to endorse an ateleological approach (Introna, 1996) to the CMS as a driver of change at CQU.

This suggestion might have been part of the explanation for the fact that there appeared to be no consensus about whether teaching and learning should be monitored and controlled centrally, by the faculty, by the school, or down to the level of the individual lecturer designing the course.

- The relevant school. Nobody else has a clue about what the needs are for individual courses. (Academic)

- The school, as the faculty may have no understanding of the pedagogical methods used in the school. (Academic) 
- The Division of Teaching and Learning Services. (This response was submitted by respondents with a variety of roles: academic, administrative support staff, head of school, technical support staff)

- Should be a joint effort with the Division of Teaching and Learning Services [and the relevant faculty]. (Administrative support staff)

- $\quad$ Each Unit’s quality management system. (Administrative support staff)

Because of their lack of knowledge about the processes underlying, and the intended use of, Blackboard as the enterprise CMS, many respondents found it difficult to comment on why CQU was implementing Blackboard as its preferred CMS.

- I don’t know, not sure. (15 responses)

- Stop-gap. (Academic)

- $\quad$ No idea. (Academic)

Others understood the process and the direction but appeared cynical about the decision.

- $\quad$ Peer pressure - it’s being done everywhere else. (Academic)

- The technical staff were happy with how this system worked. (Designer)

- There is a perception that if you're not online then you're not at the 'cutting edge' - that perception need not be correct. (Academic)

- Personal agenda of decision makers. (Manager)

By contrast, others appeared to be supportive of Blackboard as a CMS, but perceived that management needed to make further decisions in order to maximize the effectiveness of the system.

- If purchased to become a standard[s] what about all the other approaches being used - are they now to be outlawed? (Administrative support staff)

- A genuine interest in trying to cater to students['] needs - just don't let it become like an ATM [automatic teller machine] or [as] online banking was to the banks, where they pushed people out of the branches - don't ever let it replace face to face teaching, to only cut staff costs. (Academic)

- We have to have some type of CMS. It makes sense to have one used CQU wide. (Academic)

- Training has not been as widely available (frequent) . . . (Academic)

- $\quad$ Let it be a long term decision. (Academic)

- I'm pleased CQU has taken the step to provide innovative resources for staff to enable them to continuously improve the flexibility of their course offerings. (Academic) 
- The survey has made me realise I should attempt to know more about the system. (Administrative support staff)

Although there are clearly differences among the responses received for the research project, we argue that there is also evidence that much would be gained from CQU increasing the knowledge of its staff about whether, and how, the university proposes to use Blackboard as the CMS to drive organizational change that will enhance CQU's reputation as a leader in flexible learning. We contend that, given the divergence in opinions, the level of understanding about the expected benefits from an enterprise CMS will be improved through replacing the traditional, purpose driven approach to systems development with a more flexible, ateleological system (Introna, 1996).

\section{Conclusion: CMS as an accelerator or a brake in engaging change}

If we agree that the teleological, purpose driven approach to systems development and strategic planning (Introna, 1996) seems not to have provided the answers that organizations desperately need to maximize value from IT, what are the alternatives? This question is a crucial one for all contemporary Australian universities to address, a fact that highlights the wider applicability of this paper's analysis of survey comments by staff members at a single university.

The preceding analysis discussed the survey participants' responses to each of the four key questions identified earlier:

1. "How likely is the implementation of Blackboard to help CQU to become a universal leader in flexible teaching and learning?”

2. "Which groups and organizational units should have the leading role in quality control and/or quality assurance in the use of Blackboard at CQU?”

3. "Do you believe that implementing Blackboard is a way to place additional controls on teaching and learning activities at CQU?”

4. "Does it matter to you whether CQU implements Blackboard or any other Course Management System?”.

What is clear from the foregoing analysis is that there are several challenges associated with CQU's identified wish to become a "unified university" (Central Queensland University, 2003, p. 2). On the one hand, one of the key challenges currently confronting CQU is to identify drivers of change that will increase the level of ownership of the vision. On the other hand, another challenge for CQU is to manage its organizational complexity without fragmentation and in ways that encourage innovation. These challenges have underlain this paper's focus on the contrast between a traditional, purpose driven, problem solving, teleological approach and a more decentralized, locally adopted, flexible, ateleological approach to systems development and planning (Introna, 1996).

At the organizational level, there is a distinct need to evaluate regularly the use of any chosen driver of organizational change (see Nouwens, Ross, Harreveld, Thomson and Danaher, 2004), which in this instance has been the CMS. Evaluations should be conducted in a systematic and methodologically rigorous manner and the outcomes of these evaluations should be used to make informed decisions to update, change, or implement new policies. Policies, documented practices, and implementation strategies should be integrated into the strategic and operational fabric of the 
institution. Such a transparent process will increase the level of understanding as to why change is necessary and, therefore, increase the level of ownership of the university's vision.

From the strategic planning documents (Central Queensland University, 2003), it is evident that CQU has identified its vision to become a "unified university" (p. 2), and it has as one of its goals to be recognized as a universal leader in flexible learning. This paper suggests that the organization's traditional strategic planning and systems development methodology have not achieved a high level of understanding within the university of how Blackboard as an enterprise CMS will assist the achievement of this vision and this goal. With this realization as a starting point, a key assumption of the paper has been the need to identify different strategies that will increase the understanding of staff about how and why an enterprise CMS is functioning as a driver of organizational change. In a context of budgetary constraints and political pressures, there is a crucial need to move from the traditional, goal-oriented, purpose driven approach to less teleological systems development and planning (Introna, 1996). If the enterprise CMS is to be used as an accelerator of, rather than a brake on, change, there is much to be gained from the organization embracing ways that encourage staff to engage with the challenges through the use of the ateleological development and planning approach identified in the paper.

Nevertheless, in view of the organizational complexity that is an indisputable feature of contemporary universities, whether in Australia or elsewhere, such an organizational embrace is unlikely and that unlikelihood points to something of a paradox about teleological and ateleological systems. Teleological systems development is better suited to a commercial organization in which a single vision is more likely to be accepted by employees. By contrast, ateleological systems development can be considered more appropriate to enactments of academic collegiality and decision-making in universities as they used to be (or perhaps as they are claimed to have been), because of the ateleological emphasis on local contingencies. Yet contemporary universities are poised - generally uncertainly and uncomfortably - on the cusp between commercial and academic organizations. A crucial dimension of the interplay between teleological and ateleological approaches to systems development, therefore, is its reflection of an even more fundamental and ongoing struggle for meaning and understanding around the questions, "What should universities in the early 21st century be and do and look like? And how can distance education, enterprise systems, and so on help them to be and do and look like in those particular ways?”

\section{Acknowledgments}

The authors are grateful to the respondents to the survey reported in this paper. Robynn Freeman deployed her research skills to great effect, Michael Secker's editing precision enhanced the paper's readability, and Debbie Murphy provided exemplary administrative support.

\section{References}

Baskerville, R., Travis, J., and Truex, D. P. (1992). Systems Without Method: The impact of new technologies on information systems development projects. In K. E. Kendall, K. Lyytinen and J. DeGross (Eds.) The impact of computer supported technologies on information systems development (p. 241-270). Amsterdam, The Netherlands: North-Holland.

Beck, K. (1999, October). Embracing change with extreme programming. Computer, 32(10), 70 77. 
Beck, U., Giddens, A., and Lash, S. (1994). Reflexive Modernization: Politics, tradition and aesthetics in the modern social order. Cambridge, UK: Polity Press in association with Blackwell Publishers.

Bourgeois, L. J., and Brodwin, D. R. (1984). Strategic Implementation: Five approaches to an elusive phenomenon. Strategic Management Journal, 5, 241 - 264.

Brynjolfsson, E., and Hitt, L. (1996). Paradox Lost? Firm-level evidence on the return to information systems spending. Management Science, 42(4), 541 - 558.

Brynjolfsson, E., and Smith, M. D. (2000). Frictionless Commerce? A comparison of Internet and conventional retailers. Management Science, 46(4), 563 - 585.

Central Queensland University. (2003). Strategic plan 2003-2007. Rockhampton, QLD.: Author. Retrieved July 12, 2004 from:

http://www.cqu.edu.au/webmaster/Production/officialdocuments/ STRATEGIC_PLAN_2003-2005_VERSION_4.pdf

Chakravarthy, B. S., and Doz, Y. (1992). Strategy Process Research: Focusing on corporate selfrenewal. Strategic Management Journal, 13(5), 5 - 14.

Clark, S., Cossarin, M., Doxsee, H., and Schwartz, L. (2004). Integrated learning management systems. International Review of Research in Open and Distance Learning, 5(1). http://www.irrodl.org/content/v5.1/technote_xxix.html

Cnaan, R. A., and Parsloe, P. (1989). The impact of information technology on social work practice. New York: Haworth Press.

Creith, S. (2000). Optimizing organization design for the future. Educause Quarterly, 23(1) 32 38.

Davenport, T. H. (2000). Mission Critical: Realizing the promise of enterprise systems. Boston, MA.: Harvard Business School Press.

Davenport, T. H. (1998). Putting the enterprise into the enterprise system. Harvard Business Review, 76(4), $121-131$.

Department of Education, Science, and Technology. (2004). Higher Education Statistics Collections. Retrieved July 15, 2004 from: http://www.dest.gov.au/highered/statpubs.htm\#studpubs

Dunphy, D. C., and Stace, D. A. (1988). Transformation and Coercive Strategies for Planned Organizational Change: Beyond the OD model. Organisation Studies, 9(3), 317 - 334.

Dutton, W. H., Cheong, P. H., and Park, N. (2004). The Social Shaping of a Virtual Learning Environment: The case of a university-wide course management system. Electronic Journal of e-Learning, 2(1). Retrieved February 19, 2005 from: http://www.ejel.org/volume-2/vol2-issue1/issue1-art3.htm 
Dutton, W. H., and Loader, B. (2002). Introduction. In B. Loader (Ed.) Digital Academe: The new media and institutions of higher education and learning (p. 1-32). London: Routledge.

Dyson, M. C., and Campello, S. B. (2003). Evaluating Virtual Learning Environments: What are we measuring? Electronic Journal of e-Learning, 1(1), 11 - 20.

Fahrni, P., Rudolph, J., and de Schutter, A. (2004). Vendor-assisted evaluation of a learning management system. International Review of Research in Open and Distance Learning, 5(1). Retrieved February 17, 2005 from: http://www.irrodl.org/content/v5.1/technote_xxx.html

Gaddis, P. O. (1997). Strategy under attack. Journal of the European Strategic Planning Federation, 30(1), $38-45$.

Hamel, G., and Prahalad, C. K. (1994). Competing for the Future. Boston, MA.: Harvard Business School Press.

Highsmith, J. (2000). Adaptive Software Development: A collaborative approach to managing complex systems. New York: Dorset House.

Highsmith, J., and Cockburn, A. (2001). Agile software development: Business of Innovation. Computer, 34(9), $120-122$.

Introna, L. D. (1996). Notes on ateleological information systems development. Information Technology \& People, 9(4), 20 - 39.

Ives, B., and Learmouth, G. (1984). The information system as a competitive weapon. Communications of the ACM, 27(2), $1193-1201$.

Jones, D., and Gregor, S. (2004). An information systems design theory for e-learning. In S. Elliot, M. Williams, S. Williams and C. Pollard (Eds.) Managing New Wave Information Systems: Enterprise, government and society (Proceedings of the 15th Australasian Conference on Information Systems). Hobart, Tasmania: Australasian Conference on Information Systems.

Katz, R. N. (2003). Balancing Technology and Tradition: The example of course management systems. Educause Review, July/ August, 48 - 59.

Kraus, W. A. (1980). Collaboration in Organization: Alternatives to hierarchy. New York: Human Science Press.

Luck, J. T., Jones, D., McConachie, J., and Danaher, P. A. (2004). Challenging Enterprises and Subcultures: Interrogating 'best practice’ in Central Queensland University's course management systems. Studies in Learning, Evaluation, Innovation and Development, 1(2), $19-31$.

Lyytinen, K. (1987). Different Perspectives on Information Systems: Problems and solutions. ACM Computing Surveys, 19(1), 5 - 46. 
Markus, M. L., and Robey, D. (1988). Information Technology and Organizational Change: Causal structure in theory and research. Management Science, 34(5), 583 - 598.

McGee, M. K. (2000). It’s Official: IT adds up. InformationWeek, 782. Retrieved February 19, 2005 from: http://www.informationweek.com/782/productivity.htm

Mintzberg, H. (1994). The Rise and Fall of Strategic Planning. New York: Free Press and Prentice-Hall International.

Morgan, G. (2003). Faculty Use of Course Management Systems. Educause Center for Applied Research.

Neuhauser, P., Bender, R., and Stromberg, K. (2000). Culture.com. New York: John Wiley.

Nouwens, F., Ross, E., Harreveld, R. E., Thomson, J., and Danaher, P. A. (2004). Evaluation perspectives: Interrogating open and distance education provision at an Australian regional university. Turkish Online Journal of Distance Education, 5(3), Retrieved February 19, 2005 from: http://tojde.anadolu.edu.tr/tojde15/index.htm

Paulsen, M. F. (2002). Online education systems in Scandinavian and Australian universities: A comparative study. International Review of Research in Open and Distance Learning, 3(2) Retrieved February 17, 2005 from: http://www.irrodl.org/content/v3.2/paulsen.html

Porter M. E. (1987). The state of strategic thinking The Economist 23 May, 21 - 28.

Porter, M. E., and Millar, V. E. (1985). How Information Gives You Competitive Advantage. Harvard Business Review, 63(4). 149 - 160.

Schein, E. H. (1992). Organizational Culture and Leadership (2nd ed.). San Francisco: JosseyBass.

Self, P. (1974). Is comprehensive planning possible and rational? Policy and Politics, 2(3).

Stubbart, C. (1995). Advocacy of Powerless: Long Range Planning (LRP). The International Journal of Strategic Management, 28(3).

Sturgess, P., and Nouwens, F. (2004). Evaluation of online learning management systems. Turkish Online Journal of Distance Education, 5(3). Retrieved February 7, 2005 from: http://tojde.anadolu.edu.tr/tojde15/index.htm

Tapscott, D. (1996). The Digital Economy: Promise and peril in the age of networked intelligence. New York: McGraw-Hill.

Thayer, F. C. (1981). An End to Hierarchy and Competition: Administration in the post-affluent world (2nd ed.) New York: New Viewpoints.

Truex, D. P., Baskerville, R., and Travis, J. (2000). Amethodical systems development: The deferred meaning of systems development methods. Accounting, Management and Information Technologies, 10(1), 53 - 79. 
Wheatley, M. (2000). ERP Training Stinks. Enterprise Systems: Chief Information Officers Magazine, 13.

Wildavsky, A. (1973). If planning is everything, maybe it’s nothing. Policy Science, 4.

Williams, R. (2000). Diffusion of Appropriate Educational Technology in Open and Distance Learning in Developing Commonwealth Countries: Final project report. August. Vancouver, BC.: Commonwealth of Learning.

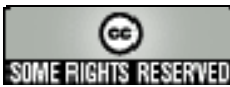




\title{
Globalizing Flexible Work in Universities: Socio- Technical Dilemmas in Internationalizing Education
}

\author{
Michael Singh and Jinghe Han \\ School of Education and Early Childhood Studies \\ University of Western Sydney \\ Sydney, Australia
}

\section{Introduction}

We engage with and respond to the debate raised by this theme issue of the International Review of Research in Open and Distance Learning with a particular question in mind: namely, as universities are using new labor displacing technologies to export degrees to meet the international demand for higher education, how is this influencing - negatively and positively the workers involved? Contemporary transitions in political and economic globalization are being used to press universities into becoming 'transnational businesses,' seemingly driven by a primary concern for marketing educational commodities. The neo-liberal politics driving these currents in universities are increasing the multiple online and offline networks. These local/ global meshworks engage the labors of a small but growing percentage of the world's population (Singh, 2002, pp. 217-230). Writing this paper at Jilin University in China, we find that many of our academic colleagues and students have limited access to a personal desktop computer, the Internet, and email. They must pay for timed access to their email accounts and for downloading attachments. They do not have access to high-speed data networks. A timer indicates how long it will take to open and send emails. Around us, construction workers are building massive facilities to house the burgeoning on-campus student population. Their offline education is being supplemented - but not replaced by ever-advancing online technologies.

Neo-liberal governments are ideologically committed to reducing investment in the tertiary education of a democratically inspired citizenry. This has stimulated people's desire to engage in learning and re-learning throughout their lives in their quest for socio-economic security. These state-sponsored changes lead Cummings, Phillips, Lowe, and Tilbrook (this issue) to cite the assertion by the Federal Minister for Education, Science, and Training that "Australian universities [have] nowhere to hide from the winds of change." Smith (this issue) suggests that funding-cuts by these governments have pressed universities to seek private sources of income. This explains the drive to recruit full-fee paying students from countries in the Majority World. 
Downsizing their labor force through technology replacement strategies is also part of these reforms. The rationing of education to inform and to give form to 'the public' has led to costcutting reductions in offline, class-based teaching/ learning. Universities are struggling with their economic and cultural sustainability, while at the same time they are trying to meet the demand for low-cost higher education by producing graduates for the world's multilingual knowledge economies. Updating higher education has been a significant topic of public policy debate for over two decades (Cummings, Phillips, Lowe, and Tilbrook, this issue). As public universities have come to be disparagingly characterized as costly, labor intensive and lacking in productivity gains,

. . . commercial teaching machines, computers and instruction programmes are [being] introduced on a growing scale, effectively creating a situation in which [the state subsidises and] individuals pay industry for the means (terminals, teletext, receivers, access to memory storage and specific programmes) (Smart, 1992, p. 86).

Key issues concern the millions in public taxpayer being used to fund the commercialization of the information technology industry. Such anxiety is compounded by the technological displacement of workers. In this paper, we foreground related dilemmas shaping the internationalization of education by teaching students at a distance.

\section{The International Market in Higher Education}

Higher education institutions are updating their work of teaching/ learning through the use of new technologies. So too is the administrative labor which supports it. Universities are being driven by neo-liberal policies which are promoting their economic destructuring and recurrent organizational restructuring. Their attention is now on securing a share of the competitive global education markets being created by the General Agreement on Trade in Services. In this environment, 'quality' university teaching is defined by the 'employment' of online technologies in the work of delivering international education (Smith, this issue). Universities face a dynamic and challenging operating environment created by the diminution of government investment in the public sector. Many have now positioned themselves largely within the English-only segment of the world's multilingual knowledge economies. Others have initiated a range of online teaching/ learning innovations. Some are conducting research into creating new markets using labor saving technologies. Internet delivery systems are claimed to provide flexible teaching/ learning opportunities for students from diverse ethnic, social, and cultural backgrounds - or at least online education is there for those who can afford to pay and who can study in English.

The pressure of government disinvestment in the education of a democratically informed and formed public has pushed - or invited - universities to integrate new technologies into educational work. In seeking to reform their relationship with students, universities are struggling to make financial - if not pedagogical - advantages of the Internet. The key is to have fee-paying, off-campus, online customers perform the many student administration tasks for which staff were once employed (Cummings, Phillips, Lowe, and Tilbrook, this issue). This positioning of universities as successful local, national, and international businesses in state driven and regulated local/ global markets provides another focus for public debates. Not everyone willingly accepts 
the subordination of university education to the political and economic demands of neo-liberal globalism:

Intellectual producers [are] more directly subordinated to the demand of economic and political powers to the emergence of a mass market for intellectual ideas increasingly controlled by the new media industries (Lane, 2000, p. 186).

The struggle for a competitive advantage may or may not contradict the effort to maintain the value and integrity of decent education. For over a decade, certain governments have been engineering transnational markets in higher education. This competition is being orchestrated as a principal determinant of the success or failure of their public universities (Nunan, this issue). Many are now experiencing crises. Some have been caused by the high financial and human costs of going online. One factor in the survival or redundancy of universities is the growing international education market. The marketing function of universities seems to be best met by representing themselves through future-oriented images and imaginings of online technologies. This is so even though the education of students from Quanzhou Normal University in Fujian Province, China, for example, may be better served by other modes of education.

Full-fee paying students from China studying abroad regard offline education as a significant advantage to their future work-life trajectory. Benefits include the enhancement of their English language proficiency, transnational networks, and cosmopolitan identity (Singh, 2005). Few prospective international students, such as academics from Dalian Maritime University in Liaoning Province, China, however, can afford such in-country studies. Even those who 'might' be able to pay fees plus living costs do not have the opportunity because of other constraints. Yet online delivery is mistakenly imagined to be a cheap, labor saving intervention, especially where there is no accountability for the costs of displaced labor. It is seen as an economic way of meeting government funding shortfalls. It promises to fulfill newly established policy commitments to provide for fee-paying students, having due regard for location and discipline. The potential of the Internet to contribute to online education globally is imagined by some to increase as the cost of access to information and communication technologies promises to fall (Smith, this issue). However, the rise in the traded value of some overseas currencies during the years 2003-2005 has resulted in students from China having to pay an additional 25 percent in Yuan to study abroad. Claims about the death of distance arise from imagined cost reductions in communications. This is an important source of rhetorical appeal for policy-makers concerned to effect cost cutting through labor reduction in the multi-modal university (Smith, this issue).

\section{Multi-modal Universities and Their Strategies}

Universities are struggling against the regulatory force of the state to be "fast, fluid, and flexible" (as Smith this issue cites Dolence and Norris, 1995) in their uses of labor and technology in the global lifelong learning market. Online delivery is imagined as offering ways of addressing this problem (Smith, this issue). New technologies may contain fees and generate surplus income through transferring administrative work onto the students-as-customers. This continues to occur in other service industries such as supermarkets and banks. It is occurring through the intensification of academics' work, despite enterprise bargains claiming reductions in their 
working hours. The displacement of librarians via electronic data search, retrieval, scanning, and transmission services may make some aspects of studying online attractive, especially as a supplement to offline education (Nunan, this issue). However, the hierarchically structured, status-oriented international education market creates challenging opportunities. Universities from some countries are unequally positioned in the competition with others for the online delivery of education.

By using technological tools, universities are imagining ways to provide access to online educational resources for onshore and offshore students (Cummings, Phillips, Lowe, and Tilbrook, this issue). Some universities wish to balance the 'poaching' and 'loyalty factors' inherent in marketing strategies. They try to keep their currently enrolled students and at the same time maximize the 'capture' of students from other institutions.

The new technologies of online education have created opportunities for the flexible delivery of courses for offshore students. Flexible delivery assumes possibilities for a rapid response to the changing market conditions and the recruitment of students beyond national geographical boundaries (Nunan, this issue). Those offering online education are working to produce and expand multi-modal delivery courses in an attempt to protect market interests.

However, clever universities are articulating online and offline delivery (Nunan, this issue). Online modes are used to supplement labor intensive, face-to-face processes. Students seem satisfied that their educational experiences are not being devalued by any limitations of distance. Similarly, clever university managers have encouraged and supported academics to research the combined potential of online/ offline teaching and learning (Cummings, Phillips, Lowe, and Tilbrook, this issue). Offering education via flexible delivery involves a dual mode of provision for on-campus and off-campus students. These teaching/ learning experiences involve oncampus/ offline, text-based distance education, and online studies via the Internet (Smith, this issue).

A number of universities teach offshore students through a range of partnerships with overseas organizations. They use local tutors and have their academics conduct site visits for intensive, offline, face-to-face teaching (Reid, this issue). A key purpose of universities being multi-modal providers is to bring together both national and international students with diverse ethnic, linguistic, social, and cultural knowledge and skills. Planning helps with consistency in communication between academics and both onshore and offshore students (Reid, this issue).

For some universities, however, the distance between the dream and the reality of online education has been a nightmare. This has been particularly so in places where academic management systems have been introduced to reduce the number of administration staff. There have been false appraisals by senior university managers arising from their superficial understandings of online education and the fiercely competitive transnational market forces. They have made faulty financial calculations of online academic management systems. Frankel (2004) observes that "technologically illiterate ... education managers continue to be sucked into multimillion dollar information technology outlays that bring little improvement in teaching and learning . . . at the expense of expenditure on under-resourced teaching staff, library books, and 
buildings” (p. 219). Some senior university managers seem to have serious limitations with respect to the complex dilemmas of reforming work around technology rather than human labor. Castells (2001) captures this concern for power without knowledge: “[The] Internet is indeed a technology of freedom - but it can free the powerful to oppress the uninformed, it may lead to the exclusion of the devalued by the conquerors of value” (p. 275).

\section{Technological Systems in Online Teaching/ Learning}

Online modes of educational delivery accommodate significant sociological changes. In particular, they provide important infrastructure for new ways of working higher education, especially in terms of intensifying the productivity and surveillance of academics. New technologies enable the creation of qualitatively different infrastructures for organizing academic work to accommodate online teaching/ learning practices. University infrastructure is now understood as the configuration of human labor and the balance of technological substitutes. Smith (this issue) reports that this infrastructure has been redesigned to support university 'business' expansion into new international markets, administering online teaching/ learning, and managing quality. As a supplement to offline education, online education has experienced a series of metamorphoses in work practices. It has moved from the correspondence, to multimedia and tele-visual teaching/ learning, through flexible teaching/ learning, to the current Internet and Web-based approaches (Smith, this issue).

Universities use different systems to support online learning as part of the public sector's contribution to underwriting the commercial viability of the information and communication technology industry. In the process, they contribute to the displacement of human labor. Some universities have introduced 'enterprise systems' (McConachie and Danaher, this issue) to direct online teaching/ learning. These provide access to cooordinated services and resources through integrated technological systems that are fundamental to a university's administrative, teaching/ learning, and student support functions. These enterprise systems may contribute to cost effectiveness by potentially increasing access to education on a global scale. It may be their labor saving costs that make them especially attractive, however. Others ways of achieving cost effectiveness are to produce 'thin pedagogies' and increase pressure on staff for 24/7/365 response times (Smith, this issue). And this is despite academics having bargained for an officially designated shorter working week. Lessard and Baldwin (2000) provide insights into the permanently temporary Web workers whose job-to-job existence is to hold the online economy together.

Individual universities may decide on a single system so that students can access all they need from one platform having consistent formats and user functions. In that context, the provision of the Generic Online Offline Delivery (GOOD) system at the University of Southern Queensland promises the efficient dissemination of courseware and the integration of e-applications (Smith, this issue). For instance, Blackboard and WebCT Vista can blend online and offline face-to-face course delivery, supplementing teaching and class organization strategies. At Jilin University, a whiteboard using computerized radio links is being used in electronic-based distance teaching. Besides being able to be used with a data projector, this system has a number of advantages. First, 
when it is used in teaching or conferencing, the notes on the whiteboard are recorded in the computer in their entirety and displayed on computer screens. Students can read, edit, print, or download the whiteboard notes through any personal computer. This can release both face-to-face and online students from being busy taking lecture notes in class. In turn this makes possible their increased participation in class discussions. Second, the use of this Internet-based system overcomes time and space limitations. Students can participate in a conference or lecture discussion simultaneously from all over the country, if not further abroad.

Likewise E-Uni Assist holds the promise of managing interactions between the university and its students. It claims to serve existing and prospective students at minimal variable cost effectively and efficiently. The Jilin University Distance Education System uses E-Uni Assist and E-Uni Teaching for enrollment, teaching, and assignment marking. Enrollment is done through the EUni Assist system so that both on-campus/ off-campus and distance students do not have to come to the university. By using the E-Uni Teaching system, the teachers engage in interactions with the students in their class during lectures. Also the teachers and their students use interactive telecommunications to solve problems in class.

Similarly, the course management system at Central Queensland University claims to support teaching/ learning by providing tools for communication, student assessment, the presentation of study material, and the organization of student activities for institutional identity (McConachie, Danaher, Luck, and Jones, this issue). It promises to do all of this in the uncertain environment of global/ local education, politics, and economics. Much technologically driven reform of academic work focuses on personal computers. At Changchun's Qin Bowl Restaurant we observed the possibilities for using an even cheaper technology to substitute for paid workers. This restaurant, which specializes in menus from the Qin era (2000 years ago), has waiters using mobile telephone and Mandarin characters to SMS customers' orders for meals to the kitchen. This suggests that the pedagogical possibilities of this relatively inexpensive computer technology have as yet to be realized.

A related problem facing universities is that some information systems are developed through a planning process with purpose driven methodologies. McConachie, Danaher, Luck, and Jones (this issue) observe that there is no consensus about, and much contestation over, whether teaching/ learning should be monitored and controlled by central administration. Business development units, faculties, schools, and the lecturers who do the work of developing, designing, delivering, and assessing marketable courses also struggle for control.

\section{Quality Assurance Regimes}

Is the nation state retreating from, or intervening in, local/ global education markets? Ostensibly, one function of a quality audit is to assure the quality of the national brand for university education. Concerns about the perceived value of undergraduate and postgraduate degrees in the emerging local/ global higher education economy have been generated by failed endeavors. These 'crises' may not be unrelated to government decisions to disinvest in the education of their own citizens. This is part of the neo-liberal state's retreat from underwriting their socio-economic 
security. Governments have used these 'crises' in the market to create quality assurance agencies (Strathern, 2000). This has increased governments' regulation of, and extended their intervention in, universities to the level of determining course offerings. Those public universities that have increased their dependence on funds - other than from government - by growing as commercial entities have also experienced greater, not less, state regulation. Reid (this issue) observes that the quality assurance regime has grown to provide state legitimation where its citizens or customers question whether governments are providing quality public universities.

Questions about the quality of offshore operations have provided a stimulus for efforts by governments to protect their collective higher education 'national brand.' Managing quality processes has become critically important work for higher education institutions as they become involved in flexible or online international education (Inglis, this issue). Quality assurance workers are important in the educational politics affecting the governance of flexible, online teaching/ learning (Reid, this issue). Ostensibly the desire is to keep offshore teaching at the same quality as that delivered by other means.

Offshore students do need to receive the same material, and hence receive quality teaching“... in order to protect their critical market ... in overseas education, universities have wanted to ensure that the standard of the educational products that they have been offering matches the standard of what they are offering onshore” (Inglis, this issue). Quality is assured in offshore delivery through various ways. These include effective crosscultural communication, having dedicated and committed staff, ensuring sameness with other forms of delivery, and developing explicit frameworks for conceptualizing and structuring educational, administrative, and commercialization processes (Reid, this issue). Ironically, the decline in government funds for offline, on-campus education may provide another means for lowering and thereby equalizing quality standards internationally. Some countries have established agencies to manage, conduct, and negotiate the quality audits of their universities (Inglis, this issue).

The concern with quality assurance regimes in higher education has led universities to invest heavily in managers of quality processes. Sometimes this work is put ahead of delivering quality teaching/ learning (Inglis, this issue). In Australia, the Quality Framework and Benchmarking Framework offer potentially complementary, and perhaps sometimes conflicting, ways of conceiving and managing the application of quality surveillance regimes. These Frameworks may be used by managers to regulate university processes relating to flexible, online learning (Inglis, this issue). Not surprisingly, these two regulatory tools were the products of government-funded projects. The Quality Improvement Framework was devised to enable corporate managerialists within universities to legitimize, rationalize, and institutionalize the regulatory ideology and politics governing the use of new teaching/ learning technologies. This Framework centers on regulating those aspects of university work that are concerned with teaching, program delivery, and student support (Inglis, this issue).

The Benchmarking Framework is intended to regulate university work by making comparisons with other universities across a selected range of corporate managerialist functions. As a regulatory device, its purpose is to enable universities to compare themselves with their 
competitors in the government-sponsored markets for students, funding, and staff (Inglis, this issue). Both Frameworks perform similar regulatory, ideological, and political functions for governments. Each of the Frameworks serves to guide, invite, or even coerce certain ways of doing flexible teaching/ learning, administration, and commercialization. The Benchmarking Framework supports a more general regulatory regime. The Quality Improvement Framework allows this regulatory force to be effected at the operational level of academics' daily work. When it comes to making operational decisions regulating the work of academics and their organizational units, the Quality Improvement Framework is likely to be especially powerful (Inglis, this issue).

The quest to establish an individual and national university brand in this 'dot-com era' seems to involve robbing academics of the power that they once imagined themselves having to control their own educational work. This may be due to the increasing power of government surveillance mechanisms represented via quality assurance regimes. On- and offline technologies of power are proving to be effective mechanisms in this regard (Reid, this issue). This leads to quality assurance and marketing regimes being more business driven than having any educational rationale (Nunan, this issue). Considering the emerging online environment, it is difficult to make claims concerning its educational quality because this means of teaching/ learning is rapidly changing. Quality is associated with experience developed over a long period of time.

Number 7 Middle School in Quanzhou, Fujian Province, China offers insights into new permutations in quality assurance. Here new technology is linked to the desire to control the work of educators. A closed circuit television system is being used to monitor students and teacher performance in classrooms. This system is mainly used in beginning teachers' class so as to assist them in solving pedagogical problems. Parents interested in observing their child's classroom behavior and performance have access to this system. This system, however, has not been installed in the classrooms of foreign teachers because the school is confident of their teaching ability. Moreover, these teachers have refused to be monitored in class.

\section{Updating e-University Administration}

It is wrong to claim that the major problem with updating e-university administration is merely a technical matter. Online academic management systems do have technical problems; they have also had disastrous managerial problems. In at least one instance, the disaster created by 'leaderled change' - or the top-down approach as described by Cummings, Phillips, Tilbrook, and Lowe (this issue) - in this area was equivalent to the mayhem, chaos, and injury of a train crash (Singh and $\mathrm{Li}, 2004)$. 'Leader-led change' refers to a single person asserting self-interest in power and laying claim to being able to determine a path supposedly preordained to guarantee happiness for all. The cause of these socio-technical problems arose from the misadventures of senior university managers. The culpability of curriculum developers, educational designers, information technology and online specialists, evaluators, academics, and administrators was much less. Commitment to develop innovative socio-technical pedagogies finds expression in concrete actions by academics on the ground. In addition to these technological and pedagogical problems, the work of ensuring the continuation of innovative pedagogical projects, more often than not, 
involves confronting the problems of corporatism, commodification, image management, and old style feudalism.

Another problem for online education is how evaluations are conducted. Systematic, methodologically rigorous evaluations compete with market-oriented image management to provide senior university managers with evidence informing their decisions about the trialing, roll-out, updating, or implementation of new on/ offline policies, procedures, and systems (McConachie, Danaher, Luck, and Jones, this issue). Informed and prudent university managers take responsibility for integrating good policies, documented practices, and implementation strategies in a coherent and complementary way into their strategic operational structures. This increases the transparency as to why change is necessary. It also demonstrates how senior university managers are responsibly engaging with the multimillion dollar dot-com changes that they are sponsoring. This may also increase the level of ownership by academics of a university reform through involving them in its productive reworking (McConachie, Danaher, Luck, and Jones, this issue). The nightmares experienced by administration and academic staff to date lend credence to such an approach.

Attention is required, however, by any mismatch between university management's policies and the centrally administered academic management system(s) (Reid, this issue). There is conflict between an educationally driven, problem posing approach and a more centralized, less-thanflexible, corporate managerialist approach to academic systems development and planning (McConachie, Danaher, Luck, and Jones, this issue). The use of flexible education technologies is a key plank in the corporate managerialist strategy, sometimes developing through failure and injury (Reid, this issue). Decentralized professional, administrative, and academic integrity cannot always compensate for the failure of the command and control system of centrally administered online delivery.

Leadership density is a critical element in updating management in universities. A broad leadership base and an engaged management are complementary elements. Cummings, Phillips, Lowe, and Tilbrook (this issue) note that both leadership density and managerial integrity are necessary to produce tactful, sustainable, and thoughtful change. But such a dialogic approach stands against conflicting claims for either top-down or bottom-up approaches. For instance, topdown approaches such as 'leader led change' seek to achieve reforms through the imposition of central policies. Power-coercive strategies prevail despite the milk and honey language used to make such policies palatable. This change is effected through force, intimidation, and victimization as much as through seductions using rhetorical, legal, financial, and industrial means.

By contrast, an interactive approach brings the main policy actors in the change process together. University management, administrators, and academics engage in a dialogic relationship, rather than one based on surveillance by the former of the latter. This problem-oriented, questionprovoking approach emphasizes collaboration, negotiation, and distribution of authority. This approach involves capitalizing on the best of the organic changes arising from the work of innovative academics, using this both to inform policy advocacy and as exemplars of policy-in- 
action. Here educational change is understood as collaborative cultural work. The personal motivations of early adopters are harnessed to deepen and extend leading edge pedagogies, policies, and politics already present within universities. Experiences of alienation, disaffection, and exhaustion in universities create environments in which leadership density and dialogic approaches to innovation may now seem legitimate options:

The creation and development of the Internet . . . highlights people's capacity to transcend institutional goals, overcome bureaucratic barriers, and subvert established values in the process of ushering in a new world ... [C]ooperation and freedom of information may be more conducive to innovation than competition and proprietary right (Castells, 2001, p. 9).

Universities prepared to nurture the professional integrity of academic and administrative staff might change small elements (units or courses) without disrupting the larger environment. Cummings, Phillips, Lowe, and Tilbrook's 'low risk, low cost' model of change (this issue) might be appropriate in an environment of government disinvestment in the educational formation and informing of a democratically inspired public.

The destructuring of many universities and of academic work under the contemporary agenda of neo-liberal globalism aims to increase productivity as much as it seeks to manage or otherwise to direct or even to control the cultural processes of educational work. In China, as elsewhere, new technology is being used in the administration of universities and schools. For example, Number 7 Middle School in Quanzhou has operated its daily administration through the Internet and a closed circuit television program. Each class has an online computer with its own webpage. The school's daily arrangements and notices are accessed through the Internet, and school news is received through an internally broadcasted television program.

\section{Conclusion}

This is a time of renewal for higher education internationally. Their destructuring and restructuring expresses and reflect changing patterns of global/ national/ local integration, stratification, and exclusion. The supplementation of static industrial labor with work involving the handling of information means that knowledge workers can be recruited - and disposed of on a global scale. Academics experience the frustration of exploring educationally sound pedagogies using new technologies in the face of state sponsored marketing and regulatory forces that 'de-skill' them. Corporate managerialist pressures constrain possibilities for enabling the dialogic production of knowledge. Nevertheless, there are constant challenges to the boundaries imposed by their exclusionary and homogenizing pedagogical projects.

It is important to position students on the knowledge production side of using new technologies. This is underwritten by high levels of education within one's immediate funds of community knowledge and the income to enjoy the benefits of access. New technologies are being used to open up spaces for unbounded, multi-directional flows of communication, networking, and bonding. This may rework the limits of managerial and academic imaginations. The Internet expands the spaces used by educational communities to communicate and engage in knowledge 
production. This challenges restrictions imposed by the centralized command and control systems of corporate managerialists who favor, if not impose, knowledge reproducing pedagogies. There are educational movements which network globally to investigate innovations in computer use to mediate collaborative knowledge production.

There is a need to be vigilant in detecting technological determinism. Serious questions have to be asked of claims that new technologies are the cause of changes in higher education. The logics and limitations of these technologies are still poorly understood. We do know that they provide no guarantees for sustaining educational communities, nor do they necessarily lead to the alienation and disaffection of educators and students.

Typically, educational communities have relied on networks to expand their immediate locale to the transnational, if not the global, scene. Through debates, they negotiate the construction of shared discourses about research processes and their theoretical framing, as well as the substantive issues under investigation. Online educational work offers opportunities to investigate a shared agenda around educational change and globalization, students' sense of identity as knowledge producers, and their imaginings of a transnational learning community with all of its richness and complexity. These online pedagogies, however, are often initiated and sustained through real world, offline conditions. Opportunities for face-to-face meetings reinforce the desire and capacity of educators and students for online connectivity. Both the off- and online elements seem to be integral to sustaining this educational community through time and space. Pedagogically the productive educational gains come from the integration of the work of off and online education. Online connections function to extend and, in turn, benefit from face-to-face, offline teaching/ learning engagements. This makes the work of online education even more effective. 


\section{References}

Castells, M. (2001). The Internet Galaxy. Oxford, UK.: Oxford University Press.

Frankel, B. (2004). Zombies, Lilliputians and Sadists: The power of the living dead and the future of Australia. Fremantle, WA.: Curtin University Books.

Lane, J. (2000). Pierre Bourdieu: A critical introduction. London: Pluto Press.

Lessard, B., and Baldwin, S. (2000). Netslaves: True tales of working the web. New York: McGraw-Hill.

Singh, M. G. (2005). Enabling transnational learning communities: Policies, pedagogies and politics of educational power. In P. Ninnes and M. Hellsten (Eds.) Internationalizing Higher Education: Critical explorations of pedagogy and policy. Hong Kong: Comparative Education Research Centre, University of Hong Kong.

Singh M. G. (2002). Rewriting ways of globalising education. Race Ethnicity and Education, 5(2), $217-230$.

Singh, M. G., and Li, L. (2004). Educating Adult Researchers: Mitigating neo-conservative globalism and mediating eco-cultural sustainability. In P. Kell, S. Shore and M. G. Singh (Eds.) Adult Education @ 21st Century. New York: Peter Lang.

Smart, B. (1992). Modern conditions, postmodern controversies. London: Routledge.

Strathern, M. (2000). Audit Cultures: Anthropological studies in accountability, ethics and the academy. London: Routledge.

\section{Acknowledgments}

Thanks to our anonymous reviewers and to Yuping Wang from Yuncheng University for critical feedback on this paper.

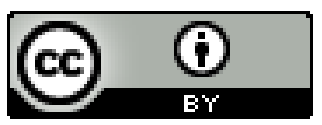




\title{
Elements of Effective e-Learning Design
}

\author{
Andrew R. Brown \\ Queensland University of Technology \\ Brisbane, Australia
}

Bradley D. Voltz

St Joseph's Nudgee College

Brisbane, Australia

\begin{abstract}
Preparing and developing e-learning materials is a costly and time consuming enterprise. This paper highlights the elements of effective design that we consider assist in the development of high quality materials in a cost efficient way. We introduce six elements of design and discuss each in some detail. These elements focus on paying attention to the provision of a rich learning activity, situating this activity within an interesting story line, providing meaningful opportunities for student reflection and third party criticism, considering appropriate technologies for delivery, ensuring that the design is suitable for the context in which it will be used, and bearing in mind the personal, social, and environmental impact of the designed activities. Along the way, we describe how these design elements can be effectively utilized by contextualizing them with examples from an e-learning initiative.
\end{abstract}

Keywords: e-learning; educational design; learning resource development

\section{Introduction}

Educational materials that have been effectively designed will facilitate the achievement of desired learning outcomes for students. Effective design of electronic learning materials relies on instructional design processes that reflect the absence of or reduction in face-to-face instruction. This change in learning context is an important factor distinguishing online or e-learning from traditional instruction, and therefore requires different educational design considerations such as those outlined in this paper. The effects on student learning of changing from traditional to elearning contexts have been widely researched, and a qualitative summary of these findings has been presented by Shakar and Neumann (2003), who conclude that e-learning programs can, but do not always, deliver improved learning outcomes. Young (2003) describes this emerging elearning environment as one that is "adapted and developed for intellectual partnerships" (n.p.), 
suggesting that rich learning activities allow students to learn with computers rather than from computers. The change in learning context affects the student-teacher relationship, which becomes a multifaceted interaction among student, online materials, the broader community of Internet users, and, in many cases, teachers as facilitators and mentors. The unpredictability of the student context and the mediated relationship with the student require careful attention by the educational designer to details which might otherwise be managed by the teacher at the time of instruction. We hope that the elements presented here will assist in clarifying the significant aspects of e-learning design and enable a design process that takes account of considerations traditionally deferred where face-to-face delivery is assumed.

For the purpose of this discussion, we define 'e-learning' as teaching and learning that are delivered, supported, and enhanced through the use of digital technologies and media. We consider that e-learning may encompass face-to-face, distance, and mixed mode or blended delivery models. The six design elements introduced in this paper provide a framework within which designers of e-learning materials can create online resources, appropriate for $\mathrm{K}-12$ and tertiary settings.

In this paper, we are concerned with the design phase of the e-learning resources. By 'design' we mean the planning or working out of the e-learning resource. This combines tasks including lesson planning, instructional design, creative writing, and software specification. Our design considerations take into account the constraints of building and delivery, but do not assume any particular software methodology or development platform. We acknowledge other variables that may affect design: for example, the use of courseware for delivery. While the use of this kind of software may limit flexibility in designing learning activities, it is nevertheless still important to consider activity at the design stage. Our particular concern is the creation of engaging and appropriate learning experiences that are likely to be utilized and to achieve the intended learning outcomes.

\section{Background}

There is much deliberation in the literature concerning instructional methodology and design. Discussion ranges from considerations of media options and technological hurdles (Bersin, 2003) to attempts to distinguish between online and traditional class materials (Nash, 2004). Existing pedagogical research is limited, according to Frydenberg (2002), who suggests that this is because few fully developed programs have arrived at a stage where summative evaluation is possible. Studies concern mainly the application of traditional teaching concepts to e-learning environments. For example, Roslin Brennan (2003) cites communication, interactivity, and social cohesion as key pedagogical goals, while George Siemens (2003) contends that variety is a central requirement for learning, and that media choices should be made according to desired learning outcomes. Many of these concepts can be traced back to the work of John Dewey (1970), who, in writing about experiential learning, argued that education must engage with and enlarge experience, and that interaction and environments for learning provide a continuing framework for teaching practice. "This process of making meaningful connections is at the core of all learning” (Horton, 2000, p. x; emphasis in original). E-learning materials often reflect these 
concepts through the use of simulations and a focus on interactive learning activities. Jasinski (2001) explores improvization as a strategy to make online materials more meaningful to learners by providing a better balance between content and process. Jasinski contends that this strategy enables a fast transition from the conceptual to the operational, and that students "learn by playing with rules, not by rules, or to create new rules” (n.p.).

A feature of online instruction over paper-based distance learning processes is the ability to employ multiple media types to present ideas and concepts. "Online courses are much more than the posting of traditional in class materials on the Web” (Nash, 2004, n.p.). Text, images, and sound can be combined to create materials that cater for several learning styles, and allow a degree of interactivity on the part of the student. "In the modern world, language is not the only important communicational system. Today images, symbols, graphs, diagrams, artefacts, and many other visual symbols are particularly significant” (Gee, 2003, p. 13). In many cases, the constructivist ideal of online learning matches poorly against the reality of delivery (Brennan, 2003). We believe that paying attention to the core elements of e-learning design outlined here can reduce the gap between educational intention and the reality of student experience.

In this paper, we use as examples the work of The Le@rning Federation (TLF). The TLF is an initiative of state and federal governments of Australia and New Zealand. Over the period 20012006, the initiative aims to develop online interactive curriculum content specifically for Australian and New Zealand schools. References to the work of the TLF have been drawn from our observations of their design and review activities. Our comments are based on data drawn from specification documents, design workshops, conversations with writers and developers, teacher feedback, and the review of draft and final online resources. We elaborate on each of the six elements of effective design, and illustrate these with selected examples.

\section{Design Elements}

In this section, we present six elements at the heart of effective e-learning design, in an attempt to draw attention to the important considerations within a complex system. The design of e-learning resources requires understandings in education, multimedia content, resource publication, and electronic technologies. The sophistication of the task is highlighted by the fact that teams, rather than individuals, are often employed to undertake it. The six areas - activity, scenario, feedback, delivery, context, and impact - cover issues across all disciplines involved in e-learning design, but particularly focus on learning as the driving motivation. In many business situations, the elearning goal is to improve business outcomes. We make the assumption that this is achieved indirectly by the effectiveness of the e-learning training or education, and thus focus on improving that effectiveness.

\section{Activity}

As with other educational design, creating effective e-learning relies on having tasks for students to undertake that provide an experience likely to lead them to the desired new understanding. Despite the apparent obviousness of this requirement, it seems all too easy for providers of e- 
learning to become carried away with, or distracted by, other design elements and to overlook the necessity of providing a rich learning activity. A rich activity is one that opens up opportunities for action rather than directs students down a prescribed pathway. Such an activity "implies the active involvement of the learner in making choices about what experiences to undertake" (Muirhead and Haughey, 2003, p. 15), and is complex enough both to engage and to challenge students for the duration of the study, if not longer. This highlights the view that "the more ways in which the learner is involved in task related activity, the stronger the learning” (Biggs, 1991, p. 219). Learning takes place in the student's mind and body; therefore the activity needs to be considered from the perspective of the actions and challenges it affords the student, rather than the complexity of the materials or tools provided for the activity to take place. As Gee (2003) suggests, an active learning experience is one where students "experience the world in new ways, form new affiliations, and prepare for future learning” (p. 23).

Sonic Space City is a TLF online learning resource that allows students to manipulate and combine sounds typically found in a busy city to produce a soundscape. Trial feedback on this learning object indicates that learner discussion was successfully focused on the timbral choice and temporal structure of the soundscapes, as anticipated by the design. This successful outcome was a result of a design that removed unnecessary distractions from the activity, thus making the task clear, while providing an open ended activity that allowed extensive exploration of the desired creative task. In a review of another TLF resource, Where Do Frogs Lay Their Eggs? it was found that, although the explorative intention of the activity was clear, "it is unclear how the learner locates and identifies the eight different egg laying locations" (Muirhead and Haughey, 2003, p. 31). These examples highlight the fact that the use of an appropriate and clearly evident activity is fundamental to an effective learning outcome, and ensuring that the integrity of the activity is maintained as focus shifts to the media-focused development stages is an ongoing challenge for the e-learning designer.

\section{Scenario}

There needs to be a reason or motivation to undertake an educational activity if the learning is to be memorable and considered valuable. An interesting context or scenario can assist the activity to have meaning. In some situations, the context will either be evident or require little explanation, for example, in relevant workplace training situations or in situations where student motivation is known to be high. In other contexts, possibly the majority, where the learning agenda is largely institutional, students are encouraged and assisted by an interesting scenario into which the activities are placed. Scenarios are usually provided by a story, role play, or simulation, within which the activity plays a pivotal role in helping students to contextualize content (Brodsky, 2003). The scenario will most likely be fictional; however, there is an assumption that the learning or skill gained through the activity will be transferred to future real world situations. This transfer is assisted if the learning scenario raises issues and problems similar to those in the real world; scenarios with this real world correspondence are often referred to as being 'authentic.' An interesting scenario will make extensive use of humor, imagination, reward, anticipation, or drama to enhance the activity. It will have topics and themes likely to be relevant and interesting to the target audience. It will make the learning activity seem like an obvious or 
necessary thing to undertake, given the situation presented by the scenario. Designers of entertainment products have long understood this requirement, and the study of their techniques is of increasing interest to educators such as Gee. In his book What Video Games Have to Teach Us About Learning and Literacy, Gee (2003) suggests that "learners participate in extended engagement (lots of effort and practice) . . . in relation to a virtual world that they find compelling” (p. 67). For the effective design of e-learning materials, the target audience must be clearly identified in order to develop scenarios that are likely to engage and stimulate the learning.

At one TLF workshop that we observed, teachers commented on a number of potential online resources. One of these, entitled Goldfish Bowl, which simulated the maintenance of an aquarium, was well received by teachers. This resource features an authentic scenario, and engages students in the task of setting up and maintaining the tank with the fish of their choice. Another learning object discussed was Bunyip Transit. Its scenario involves a portal that allows a range of otherworldly Australian-based creatures the chance to enter the outside world and subsequently return. Students' problem solving task is to work out the best way to save the creatures by transporting them to the portal. Comments about this activity were that it was fun and that students would like it, but teachers felt that they would have trouble springboarding from it into other activities. They suggested that if a resource is too much like a game with rules unrelated to real world contexts, then teachers would avoid using it. From this feedback, it is clear that authenticity and interest are highly valued aspects of e-learning design scenarios.

\section{Feedback}

Experience becomes knowledge through reflection, which is enhanced by timely and appropriate criticism. Effective e-learning design will include provision for feedback that amplifies the learning from the experience, and enables students to increase their level of skill and knowledge. The range of available feedback strategies is vast, including reflective responses to prescribed questions, semi-automated responses by the system to student actions and work, shared comments in online forums and blogs, and personal responses via email, telephone, and post. The technologically mediated nature of e-learning is perhaps most apparent in the element of feedback, and the challenges are significant for e-learning in domains that have traditionally relied heavily on interpersonal communication, in particular, psychological counseling and the performing arts where "one-to-one is the traditional norm" (Green, 2002, p. 128). Timeliness of feedback is also a consideration. Timeliness may be enhanced through automation in some cases, or it might be delayed, such as where email responses replace tutorial question and answer sessions. Effective use of feedback will enable an e-learning design to set up a dialogue within which the student participates, without which designs may simply become plans for broadcasting content.

In the TLF learning object Sonic Space City, where students create a soundscape to visual stimulus, feedback mechanisms include the ability to monitor work in progress in real time, and the facility to analyze and enhance projects by recording and replaying audio. In addition, students can describe their finished soundscape according to whether they consider it peaceful or 
noisy, calm or busy, scary or safe. These descriptions may be printed and the views of other class members sought. In this design, deliberate attention has been paid to incorporating multiple avenues for feedback to the learner, both during and after the activity. Students who use this learning object have displayed high levels of motivation and engagement because of the immediate and rich feedback provided by the activity. Activities such as this might be enhanced by enabling feedback from a broader range of people via the presentation of their soundscapes in an online forum, where reviews and downloads could provide qualitative and quantitative feedback about the appeal of their musical creation to others.

\section{Delivery}

Good educational design relies on appropriate delivery to reach its full potential. Conditions for defining appropriate or effective delivery are not easily specified because of contextual variations on learning environments, and in this article we do not attempt to define any particular means of effective delivery. We do, however, provide some guidelines for the delivery of e-learning that relate to the elements of activity, scenario, and feedback. There is often a design tension between the practicalities of electronic production or delivery on the one hand (such as data transfer rates, file size, security, and cost) and the requirements of the learning activities on the other (for example, timely interaction, rich media content, and a desire for social communication and communal distribution). The appropriate delivery of e-learning should aim to maximize the engagement of the student with the activity, enable the communication of stimulating contexts, and maximize opportunities for feedback and reflection. At times, this may stretch the technical boundaries of e-learning systems, which presents an opportunity for new solutions and technologies, but, at other times, it may mean that simpler delivery strategies are most appropriate, perhaps even ones that are not electronic. As part of the design of the TLF learning resource Campaign Manager, where a student takes on the role of coordinating the activities of a candidate in an election for school captain, the issue of calculating election results was considered. A significant advantage of using electronic media in the delivery of this learning activity was that an interesting model of voting preferences (based on real student surveys) could be used to provide a dynamic situation where outcomes varied each time that the activity was undertaken, based both on user choices and on the 'random' choices made by computercontrolled opposition candidates. The use of dynamic simulation enabled by computer delivery offered a significant advantage over more static delivery options, such as paper and video.

\section{Context}

The situation within which the e-learning resources are to be used has a significant influence on the design, but may only be partially predictable. Some aspects of the usage context are implied by the elements previously described; however, the broader context is also relevant to addressing learning needs (Siemens, 2003). Elements of activity, scenario, and feedback need to take into account the users' profiles and the delivery element needs to consider the technical infrastructure. However, additional contextual considerations include the institutional objectives of the elearning program, the role and skills of any instructor, longevity of the resources, and cultural sensitivities. The connection between context and delivery methods is highlighted by Silverman 
and Casazza (2000), who note that "different systems of communication seem to be at the heart of many of the cultural and ethnic differences that affect the learning environment” (p. 42). Bearing this in mind, it is clear that the broader context within which the learning activity is delivered can influence many elements of e-learning design. One example of the broader context is the supervisory situation that might be assumed. One of the key criteria that inform the design of TLF materials, for example, is that the materials should be suitable for use as a stand alone resource, and not assume a detailed level of teacher input. This situation puts particular pressure on the explanatory clarity of instructional design, as reflected in comments on the TLF learning resource Dynamic Fractions. Muirhead and Haughey (2003) note that for this learning resource "the instructions associated with the control panel are complicated and must be simplified" (p. 63). Another aspect of context is how the activity fits into a sequence of learning, exemplified by Muirhead and Haughey's recommendation that the TLF resource Plant Scan would be used best as an assessment activity, since significant prior learning is required. Taking context into account requires that the designer consider the demands and scaffolding inherent in the learners' environment.

\section{Influence}

The difference that the e-learning materials will make is an important design consideration. The influence of the e-learning design can be assessed from a number of perspectives, including the way that it will affect the learner, the ramifications that it will have for the learning (and broader) community into which it will be implemented, and the environmental influence of its development and use. Considerations about the personal influence of the e-learning design might consider the extent of learning that is likely to take place compared to the effort required to produce the resource. They might also consider the potential effect of the content and its presentation on a person's self-esteem and other psychological states (Raskin, 2000) - in short, the extent to which the content benefits the user. Considerations about the social influence of the e-learning design might include the cultural appropriateness of the material, the extent to which the design makes demands on others working with or supervising the learner, the way that it may influence cultural capital in the educational setting, and the ethical values implicit in the design or content (Brennan, 2003; Ehn, 1992) - in short, the extent to which people other than the learner will benefit. Considerations about the environmental influence of the design include the use of resources required to develop and deliver the e-learning materials, and the influence on the environment of activities required by people using or administering the learning materials - in short, the extent to which the environment will benefit from the design. As Arnold Pacey (1999) concludes, "sensibilities regarding people and nature seem central to what technology ought to be about" (p. 222). Considering the influence of the design requires designers to appreciate their relationship with, and influence upon, the learner and the learner's social and physical context. Designers need to act in a responsible and ethical manner to ensure that the impact of their elearning design is of benefit to the learner, society, and the environment. The TLF employs participatory or cooperative design processes that include conducting workshops that involve expert focus groups. These groups, in addition to educational specialists and designers, are comprised of teachers from a range of Australian states and territories who participate in the quality assurance, evaluation, and review phases of a project by providing in-context user 
feedback about the development process. User participation in design can be particularly important where there are cultural sensitivity issues. The degree of attention to aspects of impact in TLF projects, however, was heavily dependent on the people involved in their development. A TLF project that paid particular attention to influence was Studies of Australia. This project developed digital resources that support the study of Australian history, geography, Indigenous studies, environmental studies, values, and cultural studies, with a focus on the experience of regional and rural Australians.

\section{Conclusion}

The elements of effective design highlighted in this paper stem from a focus on student experience, while taking into account the broader networks that contribute to and are influenced by that experience. We encourage a participatory design and implementation approach, where the e-learning system is a two-way street, allowing early and ongoing communications between designer and users, rather than a conduit directed at the learner or educator. We assert that the practicalities of design methodologies should elaborate on the elements presented in this paper. In compiling these elements of effective design, we were aware that technology affords opportunities to educational designers to amplify the strengths and weaknesses in both the activities and the delivery systems. It is because of this amplification of technological tendencies that the design phase is so critical. These six elements - activity, scenario, feedback, delivery, context, and influence - provide foci for the educational designer, assisting in the navigation of the complexities and the often contradictory pressures that influence the development of an effective e-learning design. 


\section{References}

Bersin, J. (2003). What works in blended learning. Learning Circuits, July. Retrieved October 19, 2003 from: http://www.learningcircuits.org/2003/jul2003/bersin.htm

Biggs, J. B. (1991). Teaching for Learning: The view from cognitive psychology. Hawthorn, Vic: Australian Council for Educational Research.

Brennan, R. (2003). One Size Doesn't Fit All - Pedagogy in the online environment: Vol. 1. Adelaide:

National Centre for Vocational Education Research. Retrieved October 17, 2003 from: http://www.ncver.edu.au/publications/965.html

Brodsky, M. (2003). E-learning Trends, Today and Beyond. Learning and Training Innovations, May. Retrieved October 17, 2003 from: http://www.elearningmag.com/ltimagazine/article/articleDetail.jsp?id=56219

Dewey, J. (1970). Experience and education. New York: Collier Books.

Ehn, P. (1992). Scandinavian Design: On participation and skill. In P. S. Adler and T. A. Winograd (Eds.) Usability: Turning technologies into tools (p. 96-132). New York: Oxford University Press.

Frydenberg, J. (2002). Quality standards in e-learning: A matrix of analysis. International Review of Research in Open and Distance Learning, 3(2). Retrieved October 17, 2003 from: http://www.irrodl.org/content/v3.2/frydenberg.html

Gee, J. P. (2003). What video games have to teach us about learning and literacy. New York: Palgrave Macmillan.

Green, L. (2002). How Popular Musicians Learn: A way ahead for music education. Aldershot, UK and Burlington, VT.: Ashgate.

Horton, S. (2000). Web Teaching Guide: A practical approach to creating course web sites. New Haven, CT.: Yale University Press.

Jasinski, M. (2001). E-Games: Improvisation through open platform design. Paper presented at the Moving Online conference. September 2-4. Gold Coast, Qld.

Muirhead, B., and Haughey, M. (2003). An assessment of the learning objects, models and frameworks developed by the Learning Federation Schools Online Curriculum Content Initiative. Retrieved February 11, 2004 from: 
http://www.thelearningfederation.edu.au/tlf/newcms/view_page.asp?page_id= 8620\&Men_Id=4

Nash, S. S. (2004). How the mind makes meaning in e-learning (Part 1). Xplanazine, June. Retrieved October 17, 2004 from: http://www.xplanazine.com/archives/2004/06/how the mind ma 1.php

Pacey, A. (1999). Meaning in Technology. Cambridge, MA.: The MIT Press.

Raskin, J. (2000). The Humane Interface: New directions in designing interactive systems. Reading, MA.: Addison Wesley.

Shakar, M., and Neumann, Y. (2003). Differences Between Traditional and Distance Education Academic Performances: A meta-analytic approach. International Review of Research in Open and Distance Learning, 4(2). Retrieved October 17, 2004 from: http://www.irrodl.org/content/v4.2/shachar-neumann.html

Siemens, G. (2003). Learning Ecology, Communities and Networks: Extending the classroom. elearnspace,

October Retrieved October17, 2004, from: http://www.elearnspace.org/Articles/learning_communities.htm

Silverman, S. L., and Casazza, M. E. (2000). Learning and Development: Making connections to enhance teaching. San Francisco: Jossey-Bass.

Young, L. (2003). Bridging Theory and Practice: Developing guidelines to facilitate the design of computer-based learning environments. Canadian Journal of Learning and Technology, 23(3). Retrieved October 17, 2004 from: http://www.cjlt.ca/content/vol29.3/cjlt293_art4.html

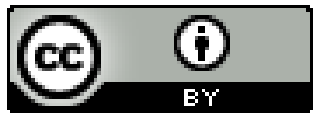




\section{Book Review - Vocational Education and Training through Open and Distance Learning}

Editors: Louise Moran and Greville Rumble (2004). Vocational Education and Training through Open and Distance Learning. 238 pages, softcover. Commonwealth of Learning and RoutledgeFalmer Press: London and New York. ISBN: 0415345243

Reviewed by: Zane L. Berge, University of Maryland, Baltimore County, USA

The increasing pace of change, combined with the exponential increase in knowledge-work and the growing numbers of persons worldwide in the workplace, all challenge the capabilities of training and education resources to effectively and efficiently develop the human capital needed by organizations to sustain and compete. Traditional, face-to-face training has often proved inadequate in meeting the challenges that staffing the workplace has presented. During the past two decades, open and distance learning is one of the ways trainers and educators have increasingly been using to help train and educate workers.

As more workers become part of knowledge-driven and knowledge-based world economies, the premise of the book edited by Moran and Rumble is that our traditional systems of delivering training will continue to fall short of meeting the current and anticipated demands for rapid and efficient workforce preparation. While successful initiatives in open and distance education have been useful and valuable, Gajaraj Dhanarajan, president and CEO of The Commonwealth of Learning, pointed out in the Forward to the book that "these ventures have been carried out by the enthusiasm of individuals, departments of larger institutions and in some rare occasions by clearly enunciated policy directives from governments” (p. xi). It is the contention of Dhanarajan that when there are unambiguous policy directives for open and distance learning, initiatives have met with considerable success. Without such clear policy directives, however, training and education efforts have often been characterized by high failure rates. It is with this in mind that editors Moran and Rumble have produced a book with contributions from some of the pioneers in online vocational education and training (VET). Taken together, the book has a great deal to say to policy makers and government planners who are developing policy to develop human capital in the workplace. A broad definition of policy used here is that it provides a framework for operations using an agreed upon set of guidelines that explain the roles and responsibilities of the participants (Gellman-Danley and Fetzner, 1998).

In Chapter 1, the editors set the stage by defining VET as "the acquisition of knowledge, skills and competences for job performance" (p. 3). They point out that VET is not a term that is 
universally used, and that depending upon the country or region of the world, other terms can be substituted, for example, "further education and training," "technical and vocational education and training," "technical education,” etc. The editors also explore answers to the general questions of why VET is important and to whom, how VET is organized, and where does distance education fit into the equation. At the root of these questions is the educational philosophy and beliefs of the person answering them about what the purposes of education. As the age-old debate about the difference between a "liberal" and a "utilitarian" education continues, the authors point out that over the last 30 years, policy makers and politicians have argued that the real purpose of education is to prepare people for the world of work, and to promote economic growth. Within that context, certainly VET can be an important stepping stone in furthering this mission.

The seeming interchangeability of the terms distance learning and distance education as used in the book is disconcerting. Education indicates a formal, institutionally sponsored activity, whereas learning is what students do. I would have preferred the book to be titled, Vocational Education and Training through Open and Distance Education, since it discusses policy and planning of formal educational programs with little direct attention to student learning.

The authors finish the first chapter noting that distance education is complex to design and deliver (Berge 2004), and not necessarily less expensive than traditional forms of education. Still, there are a dozen benefits of distance education and training to organizations other than the purely economic, such as reduction in the amount of worker time spent away from the job, content that can be updated more easily resulting in better quality, and it allows organizations to obtain, manage, and disperse knowledge quickly throughout their enterprise (e.g., Kruse 2003; Massy and Zemsky 2003; ThinQ Research Department n.d.; W.R. Hambrecht \& Co. 2001). Those who implement and set policy for distance education must balance the challenges against the benefits.

\section{International VET}

Chapters 2, 3, and 4 explore distance education models enabling vocational education to be provided internationally. In Chapter 2, Magdaleen Juma of the African Virtual University explores the model through which VET is being provided to workers in the countries of the subSaharan Africa. In Chapter 3, David Murphy draws on his experience in Hong Kong, Australia, and other countries to summarize the major planning and implementation issues faced by designers and developers. Vivien Martin shows in Chapter 4, how VET materials developed for workplace training in one country can be repurposed and adapted for use in another country.

Why is international VET needed? Why endure the added complexity and cultural tumult that often accompanies such efforts? According to Juma, tertiary institutions are overwhelmed with problems related to access, finance, quality, and internal and external efficiency. Essentially, "existing universities cannot meet existing levels of demand: there are too few trained faculty; research is limited; educational materials and facilities are of poor quality and academic programmes do not meet modern requirements” (p. 18). By tapping the best African and global academic resources, by improving connectivity in African Virtual University (AVU) learning centers and host universities, and by serving as a catalyst for new economic development, the 
AVU hopes to increase access to tertiary and continuing education in Africa. I think that the list of lessons learned is most useful, such as the problem of obtaining international accreditation for the AVU's curriculum, teaching methods, and delivery modes. There is also a good list of challenges that hinder the implementation of AVU programs, such as high communication costs and the necessity for a communication policy that can serve as a warning to those involved in similar efforts.

David Murphy and colleagues review "Continuing Professional Education Across Borders" in Chapter 3. After outlining three case studies, the authors draw some conclusions regarding lessons learned from these cases. One commonality stated was that, regardless of whether starting from scratch or repurposing exiting materials, the design and development of the courses needed to be of high quality. Secondly, student support was indicated to be a key to success. Thirdly, a systematic approach to continuous improvement was mentioned as a pathway to success. Feedback from students helps keep courses relevant and timely.

Vivien Martin, in Chapter 4, described an international project concerning the transfer of competencies in the healthcare field. Martin interviewed students, line managers, and tutors to gather multiple perspectives on what was effective and what could be improved in the training being implemented. Not surprisingly, one of the key difficulties for participants was the struggle with the shortage of time. Research conducted recently (Muilenburg and Berge in press) concerning students' perceived barriers to online learning found "lack of time and support for studies" as one of the factors both statistically and practically significant. Tutors helped students overcome these barriers through such efforts as psychological support, motivation, and summarizing key points to focus on. The author cautions that "learning materials have embedded values and assumptions that arise from the culture in which they were developed." These may be appropriate to other learning environments and cultures, but if they are not, it is difficult to disassociate them from the fabric of the already developed materials.

\section{VET Using Distance Learning at the National Level}

Chapters 5-8 turns the spotlight on national public policy programs. Models from Canada, Australia, the Commonwealth of the Pacific nations, and South Africa are examined. These countries have been proactive in setting an agenda for their vision for distance education in VET. Irene Lewis uses Chapter 5 to outline the Canadian need for alternative delivery of education and training. Given the geographic size of Canada, a coordinated educational transformation has been necessary over the past several decades. Part of the vision espoused is that learning is controlled by the learner. Technology is an important part of facilitating change to a culture of lifelong learners. McClenney (1998) reminded us:

Cultural change is extremely difficult and usually politically hazardous. It takes a long time and a sustained commitment. It means addressing values, expectations, priorities, sacred cows, the very identities of people and institutions. It is far more likely to occur in response to crisis than in response to a golden opportunity. This cultural change is a profound shift from a focus on the needs of faculty and administrators to a focus on the needs of students and other customers. It is a 
shift from a culture of entitlement to a culture of performance, from a culture of anecdote to a culture of evidence. It is a shift from a model focused on student and community deficiencies to a model presuming potential and capacity. Most importantly, it is a shift from teaching to learning (emphasis in original, n.p.).

Governments are setting policy to provide access to learning throughout Canada that will strengthen economic productivity and increase global competitiveness (p. 83).

In Chapter 6, Phoebe Palmieri discusses the “Australian Flexible Learning Framework.” The two overarching goals of the framework are to encourage accelerated use of flexible learning modes, and to position Australian VET as a world leader in applying information and communications technology (ICT) to vocational education. To do this, the framework articulates five goals that address the professional development, infrastructure, the development of online materials and services, creation of a supportive policy environment, and construction of a supportive regulatory environment. Additionally, these goals are guided by seven principles:

- Shared benefit to all states and territories

- Strategic use of new learning technologies

- Accelerated take-up of flexible-learning methodologies

- Strategic partnerships between VET agencies and other public-sector agencies and the private sector

- Leveraged investment of national funds

- Maximizing employee involvement in Framework projects

- $\quad$ Projects driven by client demand (p. 86.)

While this framework is well planned, there are challenges that continue to prove troublesome. For instance, the lack of involvement of industry in the planning efforts so far and the inability to modify policy in all areas called for by the framework. Sustainability is one of the watchwords Bartram, Lene and Williams (Chapter 7) discuss in their description of distance learning for VET in the island states in the Pacific. Their estimation of what is required to sustain distance learning include leadership and coordination within the governments involved, skilled personnel who can develop and deliver distance learning courses in VET, and policies directed on online learning initiatives.

With regard to South Africa, Ginger Bester argues (Chapter 8) that the lingering effects of discriminatory policies based on race still suppresses political, economic and social development (p. 113). The economic development of the whole country is hampered by a largely unskilled labor force. The shortage of skilled labor stifles the country's ability to successfully compete globally despite their enormous potential. The author believes that a successful VET program can play an important role in the overall human capital development objectives of government.

The increased attention that open learning is receiving in South Africa is based on a perspective that includes learner-centeredness, lifelong learning, flexibility, cost effectiveness, expectations of success, and learner support. It also is approached by seeing what barriers to learning can be 
removed from the learner's pathway. These include such things as geographical isolation, discrimination based on race, gender, age, or physical disability, the inability to take time off work for training, lack of 'appropriate' qualifications, and lack of the funds that restrict [student] access to educational opportunities” (p. 119). It becomes clear that organizations, approaches to learning, and existing management systems and policies will need to change pushed by the widespread changes in South African society.

There is a key issue as to whether a more comprehensive and systemic approach is required that links policy for the formal education system and for the adult community in synergistic ways so that outcomes are value added. Such an integrated and holistic approach would require further progress towards whole-of-government collaboration across the levels of the Australian federal system, and innovation in developing arrangements to bring about these outcomes. Achieving the full potential of ICT in education and in society, so as to transform the way people learn in the digital era, is likely to require policies that stimulate cultural change in education institutions, and in the communities they serve, in building a culture that supports enterprise, learning, innovation, and creativity (Kearns and 2002).

A similar vision seems to permeate the South African policies as described by Bester.

\section{VET and Distance Learning at the Organizational Level}

The third section of the book focuses on policy implications at the institutional level, with the contributors explaining educational models and policy issues that organizations must address when using distance education for VET. The issues range from "educational policy directions and choices about structure, organization and systems, to questions of program design and choice of delivery technologies appropriate ... the needs of the learners” (p. 125).

VET in the United Kingdom, using open and distance learning, is addressed by Sargant in Chapter 9. Sargant briefly describes several of the institutions that have been key to educational reform in VET: the Open University, the Open Tech, the Open College, and the University for Industry. The author points out that most of these initiatives have been government sponsored, and so several challenges are inherent regarding funding cycles, and the control or interference that the government may place on the organization. Additionally, there is a conflict between the economic goals of most organizations for each project, and the social goals the government may have for these same projects (p. 144).

Yoni Ryan describes the private sector model in the United States (Chapter 10). The author argues, and in many cases reiterates previous contributors, that there is a confluence of factors affecting VET such as:

- The shift from manufacturing to service industries and the consequent demand by employers for education and training beyond the K-12 level

- Gobalized industries made possible by new ICTs 
- An ideological shift to a more "market-driven” educational system from state provision of basic services in education and training

- An increased acknowledgement of the merit of student-centered education that shifts the focus of the educational experience to the learner and away from the teacher-expert and the subject of study (p. 147-148).

In other words, a manifestation of higher tuition, more flexible learning, more distance learning, and more focus on performance-based learning.

Peter le Cornu and colleagues (Chapter 11) examines VET institutions using three case studies, one each in Scotland, South Africa, and Kenya. The three are certainly different contextually, but have common traits that lead to their success. From the institutional perspective, there must be a clear vision for open and distance learning and the benefits it will bring to the table. Stakeholders must be convinced that high-quality programs in open and distance learning, meet the needs of the students. Noted to be of critical importance here and in many other chapters is the need for learning support. Finally, organizations that want to implement open and distance learning for VET must make sure that their administrative systems support the implementation of flexible forms of learning.

Mini-cases in Chapter 12 are from Mongolia, Bangladesh, and Australia. Haughty and her colleagues use these cases to discuss cooperation and partnerships, media choice, and skills-based training, and training designs. The authors also highlight blended learning that is - of a mixture of online and in-person delivery - as an effective means to increase retention and student satisfaction with the learning experience. While there may be validity to this approach at the present time, I am not sure I would endorse a hybrid type of learning on a wholesale basis. More on this below, but for now let me just say that blended learning may blend some of the least desirable characteristics in a learning environment, especially from the sponsoring organization's perspective.

\section{Conclusions}

In the last section of the book, Chapter 13, Greville Rumble and Louise Moran draw conclusions regarding "Policy Frameworks for VET in an Electronic Age." The editors note that one of the obstacles to open and distance education is the variability in the quality of and access to the communication infrastructure across the world. To this, add the lack of computers in many homes worldwide and lack of access is an important consideration to policy makers.

The editors speculate that while technology-based learning will increase, some form of blended (i.e., hybrid, mixed-delivery) will be settled on at the end of the day. I suspect they are correct. The editors also point out, however, elsewhere in this chapter that the more student support is given, the more direct student costs rise (i.e., reducing economics of scale hoped for by administrators). Since high levels of student support is found by authors in this book to be an important factor leading to student satisfaction and retention, it would seem that adding an online component to an in-person program will probably dramatically increase costs if the program is 
successful. Add to this the notion that while many students want the convenience that open and distance learning provides, they do not want to give up their in-person learning environment. Would not these factors indicate the possibility of a blending of the worse of both delivery modes?

Overall the book is well worth a careful read by anyone involved in the policy aspects of open and distance education, especially those who are involved in VET. Rumble and Moran state that what they "hope for from this book is that policy-makers, at whatever level they work, will gain a better appreciation of the factors that make for success" (p. 224) in VET through open and distance education. They surely have accomplished that.

\section{References}

Berge, Z. L. (2004). Complexity and confusion in distance education. Distance Learning. 1(2): 16.

Gellman-Danley, B., and Fetzner, M. J. (1998). Asking the Really Tough Questions: Policy issues for distance learning, Journal of Distance Learning Administration, 1(1). Retrieved January 17, 2005 from: http://www.westga.edu/ distance/danley11.html

Kearns, P., and Grant, J. (2002). Learning, Technology, Community, Partnership: A report on Australian policies for information and communication technologies in education and training. Australian Government: Department of Education, Science and Training. Retrieved January 14, 2005 from: http://www.dest.gov.au/highered/otherpub/aust_ict_report.pdf

Kruse, K. (2003). The benefits and drawbacks of e-learning. e-LearningGuru.com. Retrieved January 13, 2005 from: http://www.e-learningguru.com/articles/art1 3.htm

Massy, W., and Zemsky, R. (2003). The pros and the cons. Retrieved January 13, 2005 from: http://www.nwlink.com/ donclark/hrd/elearning/proscons.html

McClenney, K. M. (1998). Community Colleges Perched at the Millennium: Perspectives on innovation, transformation, and tomorrow. Leadership Abstracts, 11(8). Retrieved February 23, 2005 from: http://www.league.org/publication/abstracts/leadership/labs0898.htm

Muilenburg, L. Y., and Berge, Z. L. (in press). Student Barriers to Online Learning: A factor analytic study. Distance Education: An International Journal.

ThinQ Research Department. (n.d.). How e-learning can increase ROI for training. ThinQ White paper. Retrieved January 13, 2005 from: http://whitepapers.zdnet.co.uk/0,39025945,60024909p-39000612q,00.htm 


\section{Book Review - Online Education Using Learning Objects}

Editor: McGreal, R. (2004). Online Education Using Learning Objects. RoutledgeFalmer: London and New York. Hardback. ISBN: 0415335124

Reviewed by: Sanjaya Mishra, Reader in Distance Education, Staff Training and Research Institute of Distance Education, Indira Gandhi National Open University, India

In the context of online education, the use of "learning objects" (LOs) has received much attention in the recent past because of the range of "abilities" that LOs offer the field of teachinglearning. This book is all about creation of LOs, their standardization and contextualization, how LOs are currently used, and the emerging scenario of the semantic Web. McGreal's work complements the book Reusing Online Resources: A sustainable approach to e-learning, edited by Allison Littlejohn (Reviewed by Sanjaya Mishra: http://www.irrodl.org/content/v5.1/mishra_review.html).

Divided into five parts, Online Education Using Learning Objects covers 26 chapters excluding the introduction by the editor, Rory McGreal, who provides an excellent overview of learning objects and the concept of metadata "to help readers to get the most out of the chapters that follow" (p.14). In his overview of the terminologies and metaphors used in describing LOs, McGreal defines LOs "as any reusable digital resource that is encapsulated in a lesson or assemblage of lessons grouped in units, modules, courses and even programmes” (p.13).

Part I, "Learning Objects and Metadata," comprises five chapters presenting the basic concepts and pedagogy behind LOs. In Chapter 1, Stephen Downes - a guru of LOs - details the need for LOs and the importance of sharing them to create advantages through economies of scale. In Chapter 2, Mike Sosteric and Susan Hesemeier, question the heavy dependence on objectoriented programming (OOP), an approach they use to explain LOs in terms of their re-usability. It is from this context that Sosteric and Hesemeier ask several questions to put LO research back on the track of theory development. In Chapter 3, Rob Koper and Rene van Es of the Open University of Netherlands present the framework of the educational modeling language, which has now become part of the IMS Learning Design specifications. In Chapter 4, Norm Friesen, who is engaged in the CanCore initiative, describes three pitfalls: first, the terminology "learning objects" itself, on the one hand, is pedagogical (learning), while the other, it is technological (objects); second, the pedagogical neutrality of the LO standards causes barriers in 
contextualization; and third, the origin of the concept vis-à-vis the American-military industrial context is "antithetical" to education. In Chapter 5, Erik Duval and Wayne Hodgins critically analyze advanced and innovative interpretations of the use of LOs by looking into their taxonomy, components and aggregation related issues.

Part II, “Constructing and Creating Learning Objects” is comprised of six chapters. In Chapter 6, Mohamed Ally recommends adoption of a learner-centred design from the perspective of cognitive psychology, constructivism, and behaviourism in the design of LOs. Ally further identifies three components of LOs and their micro-strategies. In Chapter 7, Downes suggests the use of Rapid Application Design (RAD) methodology and OOP used in software engineering for the construction of LOs. In Chapter 8, Pithamber Polsani, using Peirce's theory of signs, proposes a semiotic model for creating LOs. In Chapter 9, a group of researchers from the Open University of Netherlands (Monique Doorten, Bas Giesbers, Jose Janssen, Jan Daniels, and Rob Koper) describe the process of transforming existing content into re-usable learning objects. In Chapter 10, Peter Sloep describes the need for an educational modeling language because chunking of content and metadata tagging are not satisfactory. In Chapter 11, John Nesbit and Karen Belfer focus on evaluation of learning objects, and review evaluation models applied to educational software and media. Subsequently they propose a convergent participation model of collaborative evaluation of LO.

Part III, "Contextualization and Standardization of Learning Objects," as the title itself suggests, introduces the concept of contextualization and explains standardization issues in LOs for their reuse, in the five chapters that comprise this section. In Chapter 12, Robby Robson emphasizes that the high contextual nature of LOs adds significant cost to reuse and thus little reuse can be seen in the real educational world, even though "reuse" is one of the most important features of LOs. In Chapter 13, Jon Mason outlines the importance of context in learning, and describes the context-driven metadata tags and specifications that would be useful in reuse of LOs. In Chapter 14, researchers from the Lower Saxony Learning laboratory in Germany (Heidrun Allert, Chistoph Richter, Hadhami Dhraif and Wolfgang Nejdl) describe their contextual metadata model for the Open Learning Repository 3 (LOR3). The OLR3 portal is based on a scenario design approach comprised of a domain model, an instructional model, and a structural model that helps learners and teachers to search LOs on the Web and communicate with each other. In Chapter 15, Luis Anido describes reference architecture for offering common e-learning services by Educational Content Providers (ECPs) and Educational Service Providers (ESPs). In Chapter 16, Demetrios Sampson and Pythagoras Karampiperis discuss management of learning object repositories, and describe the functional elements and components of a Learning Object Metadata Management System (LOMMS). The importance of such a system becomes significant while interoperating LOs from one system to other, and while mapping between two different metadata schemas.

Part IV, "Learning Object Profiles, Application and Models," is comprised of five chapters and introduces some well known application profiles and models used in implementation of LOs. In Chapter 17, Norm Friesen, Susan Hesemeier and Anthony Roberts describe CanCore application profile, while Chapter 18 by Griff Richards, Marek Hatala, and the book’s editor, Rory McGreal, 
discuss the Portal for Online Objects in Learning (POOL) project and associated developments. In Chapter 19, Mikael Nilson, Ambjorn Naeve, and Matthias Palmer, describe the Edutella peerto-peer network for exchanging information about LOs and not simply exchanging content. In Chapter 20, Gilbert Paquette, Karin Lundgren-Cayrol, Alexis Miara, and Louis Guerette, present the Explor@2 learning objects manager, which is based on the CanCore metadata schemata. Explore@2 has been designed as a suite useful to learners, content experts, teachers, and managers, and works as a specialized Learning Content Management System (LCMS). In Chapter 21, Neil Kestner describes the use of learning object repository (MERLOT) for developing a professional evaluation model to promote scholarship of teaching in the universities. MERLOT is a unique system that recognizes the work of teachers in developing quality LOs (it is satisfying to know that anonymous reviews by experts are highly rated in promotions and tenure packages).

Part V, "From the Semantic Web to EMP and Instructional Engineering," comprised of five chapters, introduces some complex aspects of LOs and their usage in education. In Chapter 22, for instance, Sean Palmer explores concept of semantic Web and related terminologies such as Resource Description Framework (RDF), XML, and Web Ontology Language (OWL). In Chapter 23, Terry Anderson and Anita Petrinjak describe the educational modeling language developed at the Open University of Netherlands that holds the potential to promote the emergence of educational semantic Web. In Chapter 24, Griff Richards and Marek Hatala describe the problems of interoperability in learning object repositories (LOR), and propose development of easy-to-use tools for "cobbling” together a network of LORs. In Chapter 25, Oscar Lin, describes a knowledge modeling approach to design LOs. In the last Chapter, Gilbert Paquette revisits the educational modeling language from an instructional engineering viewpoint, and concludes by suggesting that instructional design has evolved into instructional engineering integrating automatic instructional design, software engineering, and cognitive sciences.

This is a book to be read in depth and detail. McGreal's book has a lot to offer to both new and expert professionals working in the field of LOs. From conceptual clarifications to recent developments on the topic, this book presents an array of highly authoritative explanations and illustrations on this emerging area of educational technology. Rory McGreal is successful in bringing together the "who's who" in LO development, and knitting together a scholarly publication that can be relied upon as a fully informed source and a "what's happening in LOs" from around the world. Although much research is ongoing in the field of LOs, and clearly there are "miles to go" before we can see easy flow of LOs across institutions and national boundaries. The issue of semantic Web has the potential to make this possible, as this is akin to what I called a "classificatory-based organization of learning objects" in my review of the book by Allison Littlejohn. With the last chapter of this book, I also see the emergence of a new phrase that might herald a new fad in educational technology - Instructional Engineering - leading to emergence of new courses, programmes, and perhaps a whole new discipline.

Anyone who is interested in online learning or working in this area cannot afford to miss reading Rory McGreal's book. And even though you may prefer to be selective in your reading of chapters and sequence, this book is a "must read." 


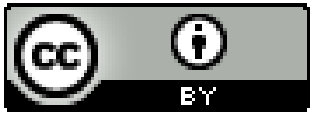


W.R. Hambrecht \& Co. (2001). eLearning: A key strategy for maximizing human capital in the knowledge economy. Primelearning.com White Paper. Retrieved January 17, 2005 from: http://www.primelearning.com/approach/pdf/maximizinghumancapital.pdf

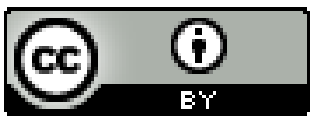




\title{
42. Contrasting LMS Marketing Approaches
}

\author{
Brian Carriere, Carl Challborn, James Moore and Theodorus Nibourg \\ Masters of Distance Education Programme \\ Athabasca University - Canada's Open University
}

\begin{abstract}
The first section of this report examines the CourseCompass learning management system (LMS), made available to educators by the Pearson publishing group as a vehicle for the company's extensive content library. The product's features are discussed, and the implications of Pearson's software/ textbook "bundling” policy for the integrity of course design. The second section of the report reviews Wordcircle, an open source (OS) LMS provided as a free hosted service or as source code downloadable for installation on the user's own server. The contrasting marketing approaches of these two products are discussed in the light of the increasing move by distance educators from proprietary to open source LMS products. As in previous reports in the series, the reviews are based on the six evaluation criteria of the American Society for Training and Development (ASTD): cost, complexity, control, clarity, common technical framework, and features.
\end{abstract}

\section{Product Trials}

\section{CourseCompass}

CourseCompass (http://www.coursecompass.com/ccindex.html) is a customized version of the Blackboard platform, and is made available free of charge to instructors and institutions who purchase content from the Pearson Education publishing group. The product allows instructors to build a course from scratch, or to supplement Pearson texts with their own materials. A large selection of published examinations is available for us "as is" or modified by the instructor. Pearson hosts the server software and no local installation is required. Instructor access to the CourseCompass system is limited to legitimate instructors who agree to make use of publications produced by Prentice-Hall or subsidiaries of Pearson Education. Full access to a Blackboardbased program is provided with all downloads, instructor tools, and telephone support. For this evaluation, we were given full instructor and student access. At no time did any representative of the vendor company attempt to influence the evaluation. 
A 30-minute introductory course and downloadable "quick start guides” orient students and teachers to all CourseCompass features that they need for their classes. The platform's screen displays are intuitive and easy to navigate. Even though its primary purpose is to act as a platform for the texts and courses already prepared by the Pearson group, the product is flexible and can be customized by instructors and students within a standard "look and feel" - an advantage for students who take more than one course. Special character palettes are available for French, German, Spanish and Italian. Students can set their own passwords and can modify their personal profiles, helping to streamline records administration. They can attend virtual classes, read and post to discussion boards, and participate in text-based synchronous chats. A digital "drop box" is provided for delivering and retrieving assignments, which can also be submitted as email attachments. Test banks are available to the instructor, mostly in a "true-false" or "multiplechoice” format, and a test-generating plug-in allows the instructor to create new tests and modify those provided with the textbook. Automatic and manual marking procedures are available, with the assigned marks stored immediately in an integrated grade book that tracks assignment completion. When giving students assessment feedback, instructors can include links to the section of the online textbook that discusses the topic in question. A calendar enables instructors and students to see the course and assignment schedule at a glance, and allows instructors to set the date on which each individual item of course content becomes available to the students. The lack of audio/video-conferencing will be noted by instructors who encourage online student discussion and interaction in these modes.

While the online version of the textbook is likely to provide the backbone of content for a course, CourseCompass allows various types of supplementary content to be added. Instructors can post documents, URLs, slide presentations, and other content formats in the students' documents or assignments folders, and can lead students on "Web safaris" via the whiteboard in the virtual classroom. Students can be divided into "breakout rooms" for small-group text conversations. Access to a comprehensive library of academic journals and other subscription-based content services is included with all courses offered on the CourseCompass platform. These include EBSCO's ContentSelect, the New York Times searchable archives, and a collection of professionally selected research sites accessed through the Link Library. An additional large section offers guidance on researching, writing essays, and citing references. Blackboard was selected as the vehicle for CourseCompass owing to its compliance with the Sharable Content Object Reference Model (SCORM) standards of scalability, interoperability, file-sharing and integration characteristics. Blackboard maintains relationships with major hardware and software vendors in order to ensure the functionality of its product. CourseCompass' success as a course delivery platform is indicated by the fact that, in just three years, it has grown to serve over 15,000 instructors with more than a quarter million students.

The merits of CourseCompass can be summarized, according to the evaluation criteria of the American Society for Training \& Development:

\section{Cost}

- Free if proprietary content is purchased

- No infrastructure costs 
- Student access can be purchased as part of textbook bundle, or as a separate card for approximately $\$ 20.00$

\section{Complexity}

- Technical support supplied by vendor

- Online technical support available (slow response after business hours)

- Instructor and student documentation available

\section{Control}

- Password-protected

- Wide range of administrative features

- Different access levels for teachers, teaching assistants and students

\section{Clarity}

- Intuitive and easy to navigate

- Standard "look and feel"

\section{Common Technical Framework}

- SCORM-compliant

- Scalable

- Integrated platform

- Wide-ranging third party support

- $\quad$ Mac OS 9.2 or later, Windows 2000 or XP, 28.8k modem or higher

\section{Features}

- Wide-ranging content library

- Whiteboard and text-based communication features

- Easy to add content

- Integrated record keeping and administrative functions

\section{The Coursecompass Marketing Approach}

A concern that educators may have with CourseCompass is the requirement to purchase textbooks from the product's provider in order to use it. It can be argued that this obligation might steer an instructor away from more appropriate texts - although this concern is somewhat mitigated by the fact that instructors can link their course sites to additional resources covering any subject or point of view. Another concern is the fact that CourseCompass' content-driven approach subscribes more to a pedagogical model more suited to the traditional classroom than to online educational delivery.

\section{Wordcircle}

Wordcircle (http://www.wordcircle.org/) is an open-source (OS) LMS written in PHP, and currently at a relatively early stage of development. The current version (2.17, release 11) is available free of charge either on a hosted system or as downloadable source code for mounting on the user's own server. The evaluation team took advantage of the hosted service and developed a test course in its entirety, in order to evaluate the system from both the instructor's and learner's perspective. Registration with the Wordcircle system is via an email address and password. Access to "My Courses" on the host server, and the option to remove courses, are 
obtained through a login script on the Wordcircle homepage. Course design is based on six categories (functions): course overview, content, news, discussion, calendar, and projects. The instructor mounts course materials in the Course Overview and Content areas, and can post announcements in the News area. The Discussion provides an asynchronous text-based forum; the Calendar and Projects areas allow students to make journal entries and upload files for sharing with other students and instructors. The interface, as a whole, is uncluttered and customizable, and "modify" functions are available to the instructor in all six categories. Email communication is external via the users' own email systems. A comprehensive online help system is available on the Wordcircle hosted site, with a public tutorial for Wordcircle course developers and users, and a support forum to handle unique questions and problems. The product is has been assessed as useful for small-course offerings, tutoring, and group collaboration. It does not aspire to be a comprehensive LMS, and is not designed for intensive educational programs that require assessment, student tracking, and synchronous communication.

In comparison with other LMS systems, for example, Wordcircle's instructor, learner, and administrator tools are currently quite rudimentary. Any content development (other than basic text messaging) must be done externally, and knowledge of HTML coding is needed in order to make extensive format changes or to direct students to other online sources. In response to an enquiry by the evaluation team, the software developer has indicated that he does not plan to include internal content development options in WordCircle. Instead, he has provided style sheets to enable course developers to develop an individual "look and feel” for their materials.

Not currently available are search engine, spell-checking, self-assessment, grade development, or student records management features, or report-generating features. Case sensitivity and file naming procedures may cause problems for users unfamiliar with old DOS conventions. In its present version, Wordcircle does not support software plug-ins or peripheral communication hardware. No bandwidth or firewall problems were apparent during the product trial. The evaluation team accessed Wordcircle successfully via a 26k dial-up connection and a 300k ADSL wireless network, and transferred files from behind two different firewalls. As the product is still in its infancy, critical mass is not yet available to determine whether functionality will be impaired by a large number of users.

The merits of Wordcircle can be summarized, according to the evaluation criteria of the American Society for Training \& Development, as follows:

\section{Cost}

- $\quad$ OS freeware incurring only the server and support costs.

\section{Complexity}

- Comprehensive online support available

- Hosted server has a high degree of intuitiveness

\section{Control}

- Overall interface customization available via the "My Courses" page

- Style sheet formats available for course content

\section{Clarity}

- Interface clean and intuitive 


\section{Common Technical Framework (CTF)}

- Operating system-independent

- No major interoperability issues were found during the evaluation

- No ADL (Advanced Distributed Learning) protocols currently in place

- File-sharing available

\section{Features}

- Content development and learner tools need further development

- Course development currently only possible outside the Wordcircle interface

\section{The OSS Evaluation Philosophy}

The current evaluation of Wordcircle was conducted because its creator, Matt Reider, had approached the evaluation team with an open interest in receiving product feedback. Previous reports in this series have avoided direct collaboration with the developer/vendor; and Report \#10 has specifically warned against the lack of evaluation objectivity that can result from such collaboration. The development of OSS freeware, however, is based on the principle that it is subject to constant, open, and freely provided user feedback; the Worldcircle website fulfils these principles completely. In this spirit, the evaluation team felt that a formative evaluation of Wordcircle was justified, and made a deliberate decision to work directly with the software developer on a formative basis via email dialogue. This approach's value is seen in the way that the current study has lead directly to a product modification. When the evaluators' first course trial was added to their "My Courses" page, a list of individuals who publicly accessed the trial was generated, accompanied by their email addresses. This flaw could lead to data mining of email addresses, spamming of users, or even identity theft. The concern was expressed to the product developer who immediately made the appropriate changes.

\section{Conclusions}

CourseCompass is useful for traditional classroom instructors who are already using the content published by the product's vendor. These instructors can easily create an online version of their courses to complement their regular classes at little or no cost. The product's value is more questionable when courses are not based on a specific textbook, and CourseCompass is inappropriate for those distance education situations where group interaction and conferencing are important. The reviewing team concluded that a major reason for the product's success to date may be that it has a high degree of "administrative efficiency" as opposed to wide-ranging pedagogical potential. If academic concerns become secondary to administrative criteria in the selection of such products, then content becomes a marginal commodity and the educational process is jeopardized.

Wordcircle is a simple, intuitive, user-friendly and cost-free interface for learning management. Users seeking a simple, functional LMS format can use it right away on the host server, or can download the code for use their own server. The evaluators recommend the product for small course development, tutoring or group collaboration, possibly used in conjunction with other freeware (e.g., Yahoo Messenger) for synchronous audio and text chat. Juxtaposed, these two 
product evaluations demonstrate a contrast between commercial software marketing strategy, with its costs and conditions, and the product development and testing spirit that prevails among open source software developers and users. As long as Wordcircle remains open source and costfree, the evaluation team feels that its formative evaluation input to the product developer has been of benefit to the product and its future users.

The next report in the series will compare open-source learning management systems.

N.B. Owing to the speed with which Web addresses are changed, the online references cited in this report may be outdated. They are available, together with updates to the current report, at the Athabasca University software evaluation site: http://cde.athabascau.ca/softeval/. Italicized product names in this report can be assumed to be registered industrial or trademarks.

JPB. Series Editor, Technical Evaluation Reports.

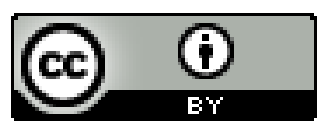




\title{
43. Open Source Software: Fully featured vs. "the devil you know"
}

\author{
Michael Hotrum and Brian Ludwig \\ Masters of Distance Education Programme \\ Athabasca University - Canada’s Open University \\ Jon Baggaley, PhD \\ Athabasca University - Canada’s Open University
}

\begin{abstract}
The ILIAS learning management system (LMS) was evaluated, following its favourable rating in an independent evaluation study of open source software (OSS) products. The current review found ILIAS to have numerous features of value to distance education (DE) students and teachers, as well as problems for consideration in the system's ongoing development. The current findings were compared with DE students' reactions to a similar LMS product, ATutor, also rated highly in the independent OSS evaluation. In comparing an ATutor course website with a simple HTMLbased version of the same site, the ten students voted unanimously to retain the simpler site. This result is consistent with previous evaluation findings in the current series of reports, and indicates that increasing integration of product features does not necessarily improve a product's ease of use or educational effectiveness.
\end{abstract}

\section{Introduction}

As the current series of reports has indicated, the number of online learning management systems (LMS) has proliferated, and at least a hundred are currently available. Leslie (2004) has identified over 50 such systems based on open source software (OSS) alone. In evaluating 35 OSS systems, Farrell (2003) has rated ATutor and ILIAS as the best, with Moodle close behind. The current evaluation studies have so far evaluated Moodle (Report \#25) and ATutor (Report \#37), rating both products favourably with respect to their potential value in distance education (DE). The current report completes this trilogy of reviews by examining the DE merits of Ilias. In deciding the criteria for its review, the evaluation team reviewed the LMS selection standards used by (1) the American Society for Training \& Development (ASTD: see previous reports in this series); 
(2) the Commonwealth of Learning evaluation study by Farrell (2003); and (3) the software comparison service, Edutools.info (2003). The criteria considered the most appropriate were combined and some new ones added. The final set of criteria is considered to represent the judgments that administrators, facilitators, designers and end users need to make in determining the value and usefulness of an LMS in DE. In addition, previous online opinions of ILIAS were considered in the light of the version currently reviewed (v. 3.2.0.). Following the ILIAS review, the report also examines the trends that have evolved in the review series so far, with respect to DE students' reactions to complex, fully-featured LMS platforms, in comparison with those described in Report \#8 as "lean and mean”. In keeping with the convention adopted earlier in this series (Report \#25), the LMS acronym is adopted in order to avoid the confusion of terms currently arising in the educational software literature.

\section{Evaluation of Ilias}

ILIAS is a free, open source (OS) Web-based learning management system (LMS) developed at the University of Cologne (2004). Originally released in July 2001, with early versions dating from mid-2000, ILIAS stands for Integrated Learning, Information and Co-Operative Work System. It has been designed as a collaborative, hypermedia working/ learning environment, flexible for use by teachers with different pedagogical approaches, and allowing the reuse and exchange of materials based on course-sharing standards (e.g., IMS, The Aviation Industry CBT [Computer-Based Training] Committee (AICC) and ARIADNE Foundation for the European Knowledge Pool). As the previous report in the series (Report \# 42) has indicated, all OSS is by definition a work in progress, constantly enhanced and modified as a result of user input and collaboration. ILIAS is no exception. Its website currently reports its use on over 100 servers, mainly at Universities in Europe and Asia. In the OSS sharing spirit, therefore, the current evaluation team contacted the four listed North American users with inquiries about their ILIAS experience (though none responded).

Particular aspects of ILIAS that support the moderate constructivism philosophy are:

- Team based authoring: ILIAS allows for the collaborative development of course materials.

- Personal annotations: ILIAS offers a personal context-related annotation function that permits a learner to add summaries, comments and annotations to text elements, graphics or images. These annotations can be retrieved at any time within the original context, printed out in a structured form, and exchanged with members of a learning group.

- Personal bookmark folder: learners can build and administer content-related resources available from the Web.

- Learning as a self-directed process: users can choose the learning materials to review, when to review them, and the sequence of materials. The materials are accessed from a central database which only displays the content relevant for the learner's current concerns and focus. A search engine allows the user to seek specific content within the materials. 
- Learning is a social process: facilitators and learners can create groups of users and define access privileges.

- Text elements are assumed to achieve the best educational effect for differently targeted learning groups: the text elements form the 'backbone' of an ILIAS course. Other elements (e.g., animations, interactive elements, co-operative elements, graphic, audio, and video) support this basic structure. Once the elements have developed and integrated into an ILIAS-based course, the author is free to associate and link them based on a specific pedagogical approach.

ILIAS is a cross-browser system, requiring Internet Explorer 6.0, Mozilla 1.4, Safari 1.0, and/ or Lynx 2.8.4 (or higher), and runs with JavaScript disabled. The system is frames-based, cannot support text-only navigation, and is not usable with large fonts. It requires MySQL 4.0.16 or higher. A digest of the product's features is as follows:

- Text discussions (viewable in threads and associated with course content)

- Integrated real-time text chat (java-based Babylon)

- File transfer available between users

- Small-group discussion environments (created by teachers and students)

- Each group can have its own discussion forum, chat room, and file exchange

- Web-based mailing system with usermail, groupmail, and integrated send mail functions

- Personal student homepage (desktop) linking to courses, groups, bookmarks, and email

- Students can attach notes to displays, and can search and compile them for the course as a whole

- Course content is downloadable for offline work and local printing/ storage

- A printable study guide can be generated

- Polls can be administered with online and print-based statistical reports

- Teachers can create self-assessment tests (multiple-choice and cloze) with automatic scoring

- Teachers can control a student's progress through course modules based on test results

- Students can use specified criteria to compile a collection of exercises from an item test bank

- Student exercises can yield a feedback report of correct and incorrect responses

- Administrators can set courses to be publicly accessible or can restrict access by ID and password (author, learner, administrator, and guest levels)

- Specific tasks can be assigned at each access level

- Users can maintain their own passwords

- Detailed reports tracking access to course materials, though not for individual users

- Integration with institutional IT architectures via LDAP/ RADIUS authentication

- Third party hosted services are available (in German only)

- $\quad$ No whiteboard (scheduled for next version)

ILIAS currently suffers from limitations common to many OSS products. These include: lack of interoperability and integration; lack of support for audio/ video-conferencing, time-zone or date localization; poor accessibility standards; and an unclear estimate of the true cost of ownership. 
Currently, many OS LMS platforms lack integration with the applications typically used for registration and employee management in universities, colleges, and industry (Bailetti, 2004). The same writer also notes that OSS systems tend to lack good user, developer and administration documentation; and this is true of ILIAS. Although the software contains a 13-language translation facility, up-to-date documentation for it is available only in German; non-German users have little chance of influencing the product's development via participation in the various help forums. (On the other hand, Farrell (2003) notes a growing following for the product in China.) While ILIAS is classified as freeware, its use is not actually cost-free. The time spent in installing and maintaining the system must be added to the costs of the hardware, technical support and training; and the current evaluators (both experienced server administrators) found the logistical problems of ILIAS installation to be considerable. They spent several days trying to install and configure it on Linux, in conjunction with its dozen or more required third party applications. Poor English documentation contained conflicting instructions. As a last resort, the messages in the German-language ILIAS user forums were scoured, until an English description of a Windows-based installation alternative was found. With this, ILIAS was working on a Windows/2000 server within 30 minutes. Despite its many current shortcomings, it has an admirable range of features, pedagogical integrity, and good potential for DE users. OSS applications such as this have come a long way within the three years of the current evaluation series, and they are continuing to advance quickly.

Previous reports in this series have indicated, however, that fully-featured online tools do not necessarily find favour with DE users. Students can find them difficult to master, and DE teachers do not necessarily share a need for the many features they offer. In addition, their integration with existing institutional systems can be expensive, and the overall costs of proprietary systems especially, may be excessive in the relation to the actual uses to which they are subjected. In Report \#8 in this series, a direct comparison was made between DE students reactions to a fullyfeatured conferencing product and a simple 'bare-bones' alternative. Unexpectedly, a majority of students preferred the simple application, and regarded a transfer to the more complex option as not worth the effort. In the two years since that study, online collaborative tools have converged within ambitious integrated products such as WebCT Vista, and in OSS applications (e.g., ATutor, ILIAS, and Moodle). Having now established that each of these products has a wide range of features of use to DE teachers and students, the next section of this report replicates the earlier study, by asking DE students to compare the comprehensive open-source ATutor product with the more limited HTML-based site of their current online course.

\section{Comparison of Course Website Formats}

Ten students in a graduate Masters in Distance Education (MDE) course at Athabasca University - Canada's Open University, were asked to compare the simple, home-grown, frames-based format of their current course website (see Figure 1) with that of the OSS LMS ATutor. The content of the course site was replicated in ATutor (see Figure 2), using the free trial and hosting facilities of the product's website. ATutor was selected for this purpose in view of its top rating by Farrell (2003), and its favourable evaluation in Report \#37 of this series. The current study 
fulfilled a promise stated in that report, that ATutor would be adopted for the MDE course depending on feedback from its current students as a whole.

Figure 1. The frames-based format of an online Master's in Distance Education course website

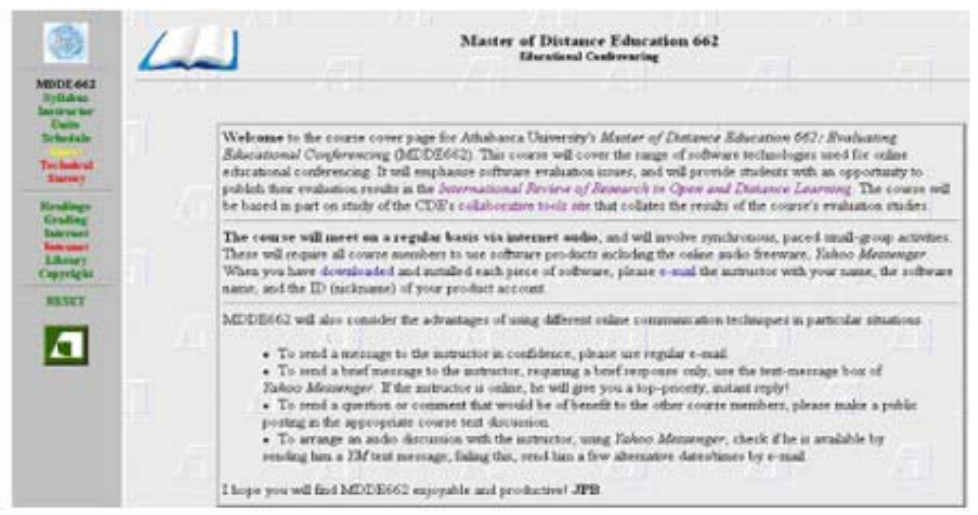

Figure 2. A sample configuration of Arutor (same course as Figure 1)

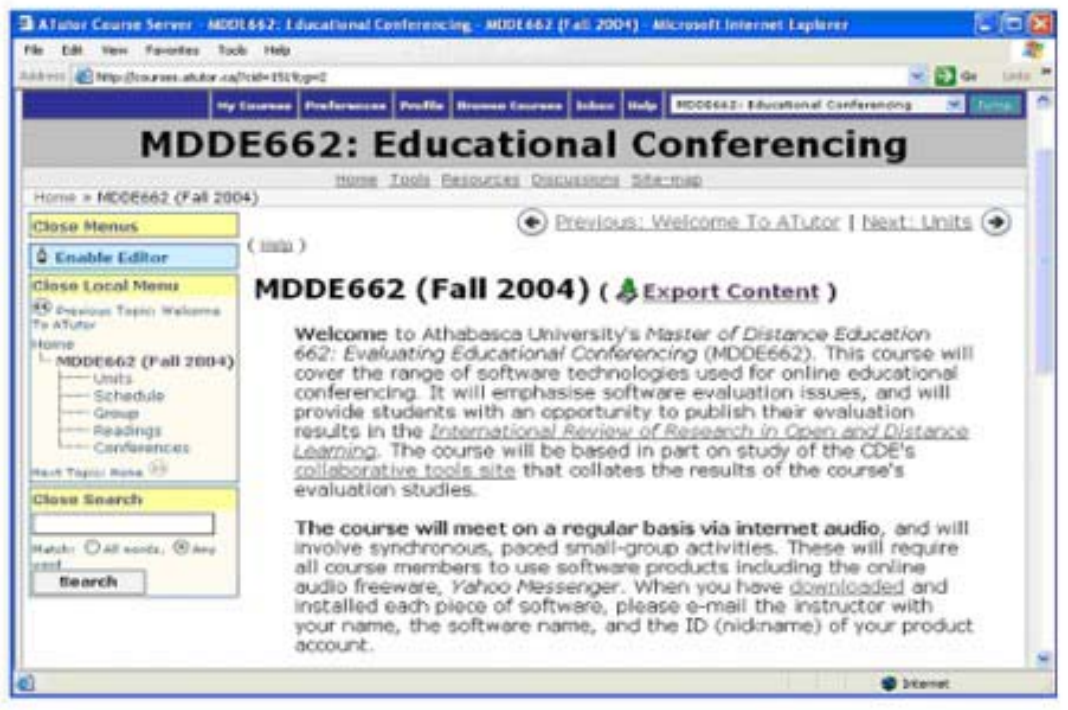

A representative selection of the students' responses to the two course platforms is as follows.

\section{Student A:}

- I am very impressed with ATutor. Based on the available tools and the initial appearance, it appears to have all of the features of WebCT ... plus much more customization.

- For the most part, navigation seems very intuitive, particularly at the higher levels. Once I get into the lower menu levels such as at this step of posting a message, the green and red circles confused me...

- I did not like the built-in email feature in WebCT, nor in this program either. I prefer using my regular email program. Having this feature just means I have another email box to check. 
- The chat is a nice tool, but I would rather use something like Yahoo Messenger. This chat only works if you are logged into the course. Yahoo works whether you are in the course, another course, or doing something completely unrelated to the course. It is much easier to stay in contact with individuals with Yahoo rather than using a built-in tool such as this that has only one specific use.

\section{Student B:}

- There are only so many things that can be done with a text based conferencing format.

- I do not like to use an additional email ... just adds to my daily chores.

- I don't personally like the "I'm online” feature . . . we can just be so over-solicited and sometimes it's good to just go about one's business in peace.

- I love variety, but I want simple, consistent, predictable access to my studies. Getting to them, I already have enough obstacles.

\section{Student C:}

- Too many tools makes for a cluttered toolbox with more time spent sorting than working.

- With so many tools and so many changes, one (cannot) get comfortable with an application before having to move on to the next version. This is an example of productivity paradox.

- My initial impression of ATutor was that it was busy. Icons are nice, but they take up screen real estate.

- I've never been a big fan of help files. I prefer to jump in and get my hands dirty. A truly intuitive application makes limited use of help files.

\section{Student D:}

- ATutor interface is extremely cluttered, although I like the icon/ text option - meets accessibility needs. At least as a user you can use preferences - maybe too much opportunity to change.

- (The many features are) like the result of a progressive build - someone wants something added, so it's added.

- I find the navigation is not intuitive, and the help files too lengthy and require scrolling no search feature. I think screen clutter impacts upon my comfort with the navigation.

- I like the embedded links to our MDE course, but they do clutter the screen.

\section{Student E:}

- I have been reflecting on how my rural, barely computer literate students will react to this software. I believe I would need to send detailed written instructions on how to logon and navigate. Online help is distracting and hard to use if you are uncomfortable in this environment.

\section{Student F:}


- In terms of interaction usability, at first I didn't find it that intuitive ... wasn't sure what some of the circle icon meant. However, the user interface was for the most part fairly predictable.

- Not impressed with some of the "bells and whistles" like the internal email . . . just one more thing to worry about.

- I do like some of the site tools. Changing the preferences made the overall appearance more palatable for me. Also, the search and site-map features made navigating more purposeful.

Despite ATutor's clear technical superiority in comparison with the existing HTML-based course site, the majority of students voted to retain the existing frames-based site shown in Figure 1. None voted to move to the ATutor platform. This result was disappointing to the course instructor, who had hoped for student feedback justifying a move to the superior support that would be available for ATutor in the University. A common theme in the students' responses is their reaction to the ATutor display as too "cluttered/ busy" with too many "obstacles/ bells and whistles.” These responses are essentially the same as those reported in the similar study reported earlier in the series (Report \#8). The clearest explanation for this preference for a simple course delivery format was provided in the present study by a student who stated: "I see advantages to both, but nothing compelling enough to make a change.”

\section{Conclusions}

The recurring finding of these studies brings into question the wisdom of providing DE students with ever more complex online learning systems; and it suggests the need to balance comprehensiveness of product features against clarity of usage. In the absence of unequivocal justification for moving to a new learning platform, both teachers and students are apt to select "the devil they know". If new systems have definite advantages, these should be carefully pointed out to them. It is inevitable that the developers of online software (OSS as well as proprietary) will continually offer "bigger and better mousetraps" on the assumption that the more features their products contain, the more competitive they will be. OSS as well as proprietary software developers are moving in this direction; and the increasing comprehensiveness of LMS software such as ILIAS and ATutor is evident from the current product reviews and those provided by Farrell (2003) and edutools.info (2003). Reviews based solely on the volume of a product's features, however, do not necessarily predict users' reactions to the product or its educational effectiveness; and it is clear that simple preferences for proprietary or OSS approaches do not predict the educational merits of a product either. DE students' reactions to the highly rated ILIAS and ATutor products, as expressed in the present report, suggest that too much product integration can be counter-productive in the online learning process, and that teachers and students may both benefit from a simple, modular-based approach that allows them to expand their online tools and skills as and when they need to do so. 


\section{Acknowledgement}

The authors thank the members of Athabasca University's MDDE662 course (Fall 2004), for their comments quoted in this study.

The next report in the series will continue the current discussion of attitudes to LMS methods. N.B. Owing to the speed with which Web addresses are changed, the online references cited in this report may be outdated. They are available, together with updates to the current report, at the Athabasca University software evaluation site: http://cde.athabascau.ca/softeval/. Italicized product names in this report can be assumed to be registered industrial or trademarks.

JPB. Series Editor, Technical Evaluation Reports

\section{References}

Bailetti, T. (2004). Improving Open Source Learning Content Management Systems. Article found at Eduforge.org website. Retrieved November 2, 2004 from: http://eduforge.org/wiki/wiki/eduforge/wiki?pagename=Improving\%20Open\%20Source

Edutools.info (2003). ILIAS Review. Retrieved November 2, 2004 from: http://www.edutools.info/course/productinfo/detail.jsp?id=203

Farrell, G. (2003). COL LMS Open Source. Paper found at the Commonwealth of Learning website. Retrieved November 2, 2004 from: http://www.col.org/Consultancies/03LMSOpenSource.pdf

Leslie, S. (2004). Open Source Course Management Systems. EdTechPost Blog. Retrieved November 2, 2004 from:

http://www.edtechpost.ca/pmwiki/pmwiki.php/EdTechPost/Open SourceCourse ManagementSystems

University of Cologne (2004). Didactical concept of ILIAS. Retrieved November 2, 2004 from: http://www.homer.ilias.uni-koeln.de/iliasdoc/doc/html/6_1.html 


\title{
Technical Evaluation Report
}

\section{Breaking Down the LMS Walls}

\author{
Michael Hotrum \\ Masters of Distance Education Programme \\ Athabasca University - Canada's Open University
}

\begin{abstract}
The traditional packaging of electronic learning — the learning management system (LMS) — is progressively being regarded as a hindrance to effective online learning. Its design, functionality, complexity, price, and value are being questioned. A new generation of Web-based tools and approaches is evolving that are better suited to meet the need for dynamic online learning content, interaction, collaboration, and networking. Whereas traditional LMS approaches traditionally tend to relegate students to the role of passive recipients of information, these new tools and collaborative approaches allow learners to take proactive control of their own learning. This paper will discuss how the LMS has affected the design and delivery of e-learning, and the emerging technologies that are better suited to current learning and performance needs.
\end{abstract}

"All in all it was just a brick in the wall. All in all it was all just bricks in the wall."

(Pink Floyd, November 30, 1979)

The Internet is independent of device (hardware or platform), distance, and time, and is wellsuited for open, flexible, and distributed learning. Yet traditional online, distributed learning methods are anything but flexible, open, or dynamic. What went wrong? Parkin (2004a, b) believes that we failed to appreciate that the Internet is a vehicle for connecting people with each other. We implemented LMS methods that imposed bureaucratic control, diminished learner empowerment, and delivered static information. "In a world hurtling toward distributed internetworking, e-learning was still based on a library-like central-repository concept.” Parkin suggests it is time to explore the true promise of e-learning, and to rework our ideas about how learning should be designed, delivered, and received. It is time to stop letting the LMS vendors tell us how to design learning. It is time to stop the tail from wagging the dog. 


\section{How the Tail Came to Wag the Dog}

The notion that the LMS tail has started to "wag the dog" has recently been advanced by Parkin (2004a, b). The LMS has proved attractive in the management sector or educational and training institutions because it allowed for the packaging of courses that could be sold and resold, and for the efficient transfer of information and the tracking and assessment of that transfer. Relay of information does not necessarily lead to the formation of knowledge, however. The LMS gave us a predefined learning environment based upon the classroom paradigm. Instead of exploring how to expand the effective usage of Web-based technology, we accepted the pre-packaged, boxed environment. It was comfortable and easy to adopt. As teachers, we used the LMS to collect and re-broadcast information, when we should have been reveling in the freedom offered by the Internet, and facilitating the sharing of experience and the creation of learning. We liked the way in which the LMS allowed us to retain control over the learning process. We touted the opportunity of the Web to personalize instruction, yet we neglected to tailor the learning experience to the needs, abilities, and goals of individual learners (e.g., too expensive, too time consuming, unprofitable). We allowed commercial software developers to tell us how learning should occur. We allowed content and technology to dictate the process of learning. We failed to leverage technology in order to fulfill the needs of our students. We went with the flow.

Similar effects were observed in the automation of the industrial workplace, as recommended by Taylor (1911). His workplace efficiency principles were strongly criticised by those who felt that they destroyed flexibility in the workplace, increased management control over the workers, and prevented individual workers from developing their own efficient approaches. In the design of proprietary e-learning systems, development and delivery has been shaped by the one-size-fits-all solutions of standardized LMS packages. But LMS approaches do not merely shape learning; they can actually impede it: if instructors design learning to accommodate the functionality of the LMS rather than the needs of the student, they may be replicating features of face-to-face instruction that function less effectively in the online environment.

In many situations, the proprietary nature of the LMS combined with a lack of interoperability, has worked directly against advances in learning design. New tools and functionality could not easily be integrated into the learning experience. Faced with the open vista of the Internet, LMS users have chosen to remain within the vendor's predefined, limited environment. LMS providers are now modifying their systems, adding functionality, and simplifying integration with third party software; but this is simply making the box larger, more complex, and less user-friendly. As the previous report (Report \#43) in this series has indicated, online students repeatedly state their preference for simpler, 'stand-alone' online tools, and regard the more complex, integrated software packages as "bloatware" that provides more features than they actually need (Baggaley, 2005; Hotrum, Ludwig and Baggaley, 2005).

Added functionality and integration also means added cost to the customer. WebCT, one of the leading LMS products, is currently being redefined as an "enterprise-wide” learning management solution: the WebCT VistaAcademic Enterprise edition. At one US university, this new identity involves annual licensing and running charges calculated as rising, in the first year of Vista 
operation, from $\$ 40,000$ to over half a million USD, depending on the volume of the system's usage (NMSU, 2003). As Report \#41 in the series has shown, other costs include conversion of existing courses, additional proprietary third party software, licensing agreements, and increased hardware requirements (Morningstar, Schubert and Thibeault, 2004). Not surprisingly, many educational institutions are currently looking at open-source (OS) LMS systems - cost-free, functional, and supported by a worldwide community of users. Even the best OS LMS packages still present navigational challenges and limited functionality, however (Hotrum et al., 2005).

It is feasible that high drop-out rates currently being observed in online training situations are due, in part at least, to the nature of the LMS methods typically used. James Madison University, on behalf of the Masie Center, surveyed 375 users of online learning, and discovered the attrition rate for online courses was approximately 26 percent (O’Connor, Sceiford, Wang, FoucardSzocki, and Griffin, 2003). This was much greater than the attrition rate for classroom learning (3 percent) reported by the same group of respondents. The figures can be disputed, as can be the actual reason(s) for dropping out. Of interest in the current context, however, are the top three factors reported as influencing drop-out rates:

- $\quad$ Lack of motivation (36 percent)

- Instructional design-related factors and learning style mismatch (36 percent)

- Ability to learn what one needs to know, and to complete the job by the end of the course (25 percent)

It can be argued that that all of these factors could be ameliorated if the institutions involved moved away from usage of the LMS as the central component of e-learning. Advances in new Internet technologies are too great for us to ignore, blinkered by the LMS domination, and the educational stakes are too high. Technology should be used to engage the learner actively in problem-solving and the construction of meaning, and should act as an intellectual partner with the learner (Salomon, Perkins, and Globerson, 1991). Allowing increased learner control, accessing social software, and building informal learning networks could retain people as active e-learning participants. Keeping people occupied on a continuous journey of learning, using multiple Web-based resources and tools, should be the goal.

\section{The Holistic Learning Environment}

Ultimately the LMS is the wrong place to start e-learning. By using it as the critical component of an online educational experience, instructors and learners alike give control over the learning process to the LMS. The typical LMS is designed as a learning management tool, rather than as a learning environment creation tool. If students are to be engaged and motivated, both students and their teachers need to be free to explore new tools and learning opportunities to interact and network with multiple learning resources. The LMS can be used as one tool in a greater holistic learning environment that give the end-users the flexibility and the control required to move along various paths according to learning needs and styles (Siemens, 2004). A variety of tools is required. Individually selected for their functionality, these should be forever changing as precise 
needs evolve. To remain fixed on a specific tool would be to allow the technology and the vendor to take control of the process. The types of tools that should be used in greater measure include:

- $\quad$ Social tools to allow for self-expression (e.g., blogs, wikis, syndication protocols, etc.)

- Digital repositories of personal artifacts (e-portfolios)

- Tools for content interaction and collaboration (shared workspaces, collaborative tools)

- Tools for connecting with instructors/ mentors/other learners (discussion forums, peer-topeer social tools, virtual communities)

- Tools for searching and ranking educational resources (search engines, semantic content filters)

- Tools that engage and facilitate higher-order learning (databases, spreadsheets, simulations, expert systems, and virtual worlds)

The instructor would truly be a "guide on the side," creating a context for learning, identifying suggested content, assisting in the development of personal learning intentions, and guiding students through a constructive engagement with the tools available. Learners would be free to explore, exchange and express themselves within this holistic learning environment or network, relying in part at least on peers to help them accomplish tasks and to learn. To many the idea of giving such liberty and responsibility to students would lead to chaos; but order can emerge from a network of disorganized and disparate sources (Downes, 2004). Networks are dynamic and growing. Common interest finds common interest, and a galaxy of knowledge bases is being created. As Siemens states (2004), "It is far easier to stay a life-long learner when plugged into a community or learning network, rather than having previous learning confined to a contentlocked LMS.”

\section{Conclusion}

The use of all-purpose learning management systems in distance education has had adverse effects similar to those unintentionally created by Taylor's workplace efficiency theory (1911). The industrial methods that Taylor recommended resulted in a diminution of worker autonomy and an increase in management control. The development and implementation of learning management systems in distance education has proved to be similar in intent and effect. Students have lost control of their learning process and activities, while the LMS vendors/ administrators (and by implication instructors) have increased their control over a fixed style of learning that fails to evolve. Distance educators now have an opportunity to usher in a second revolution in elearning. This time, they need to rescue e-learning from the confines of the LMS. It is time to take control of the technology, and use it to its full educational potential.

The next report in the series will discuss LMS approaches in terms of the "productivity paradox."

N.B. Owing to the speed with which Web addresses are changed, the online references cited in this report may be outdated. They are available, together with updates to the current report, at the Athabasca University software evaluation site: http://cde.athabascau.ca/softeval/. Italicized product names in this report can be assumed to be registered industrial or trademarks. 
JPB. Series Editor, Technical Evaluation Reports

\section{References}

Baggaley, J. (in press). Evaluating the quality of online educational methods. Chinese Journal of Distance Education.

Downes, S. (2004). The Buntine Oration: Learning networks. Australian College of Educators. Retrieved March1, 2005 from:_http://www.downes.ca/cgibin/website/view.cgi?dbs=Article\&key $=1097292310$

Hotrum, M., Ludwig, B., and Baggaley, J. (2005). Open Source Software: Fully-featured vs. "the devil you know." Retrieved March 1, 2005 from: International Review of Research in Open and Distance Learning 6 (1). Retrieved March 1, 2005 from: http://www.irrodl.org/content/v6.1/technote43.html

Morningstar, B., Schubert, J, and Thibeault, K. (2004). WebCT: a major shift of emphasis. International Review of Research in Open and Distance Learning, 5(3). Retrieved from January 5, 2004 from: http://www.irrodl.org/content/v5.3/technote6.html

New Mexico State University (2003). State of New Mexico WebCT Vista Academic Enterprise System Retrieved January 5, 2005 from: http://www.nmsu.edu/ training/CHECS\%20CMS/CHECS\%20WebCT.pdf

Parkin, G. (2004a). The tail is wagging the dog. Parkin Space Weblog. Retrieved January 5, 2005 from: http://www.trainingzone.co.uk/news/parkin/

Parkin, G. (2004b). E-Learning Adventures Beyond the LMS. Parkin Space Weblog. Retrieved January 5, 2005 from: http://www.trainingzone.co.uk/news/parkin/

Salomon, G., Perkins, D. N., and Globerson, T. (1991). Partners in cognition: Extending human intelligence with intelligent technologies. Educational Researcher, 20(3), 2 - 9.

Siemens, G. (2004). Learning management systems: the wrong place to start learning. Elearnspace Weblog Retrieved November 22, 2004 from: http://www.elearnspace.org/Articles/lms.htm

Taylor, F.W. (1911). The Principles of Scientific Management. New York: Harper.

O’Connor, C., Sceiford, E., Wang, G., Foucard-Szocki, D. and Griffin, O. (2003). Departure, abandonment, and dropout of e-learning: dilemma and solutions. Masie.com website: Masie Report. Retrieved January 5, 2005 from: http://www.masie.com/researchgrants/2003/JMU_Final_Report.pdf 


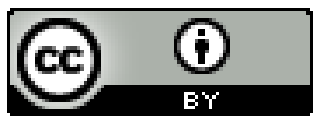

Athabasca 


\title{
45. Conferencing Tools and the Productivity Paradox
}

\author{
Theodorus Nibourg \\ Masters of Distance Education Programme \\ Athabasca University - Canada's Open University
}

\begin{abstract}
The previous report in this series (Report \#44) discusses current attitudes to distance education technology, with specific reference to the counter-productive effects of learning management systems. The current paper pursues this theme in relation to the evolution of online audioconferencing systems in DE, and revisits the notion of the "productivity paradox" proposed by Solow (1987). It also considers the slow evolution of DE technologies in comparison with the rapid rates of development predicted by Moore's Law (1965). The paper concludes by outlining the human factors that distance educators must consider in order to harness online audioconferencing technologies to full advantage.
\end{abstract}

\section{Introduction}

Robert Solow, Nobel Laureate in Economics, made this famous observation: "You can see the computer age everywhere but in the productivity statistics” (Solow, 1987, p. 36). Known as the Solow Paradox, or Productivity Paradox, the statement pointed out that computer technology had not lived up to its promise of raising the living standard in countries that had embraced the computer. Yet the technology itself cannot be faulted for failure to increase productivity. This paper aims to identify some of the causal factors that contribute to the paradox in distance education (DE), with particular emphasis on the promise of online audio-conferencing systems. The term "system" is used in this context, because a system is the best way to describe the complex integration of software, computers, peripherals, telecommunications, and humans that affects the issue. The paper demonstrates that no single factor contributes to the paradox.

Classic definitions of productivity involve a financial efficiency model (Carlson, 1975) focus on the coefficients of the production function. Increases in productivity are achieved either through a reduction of marginal costs (costs per unit of output), or through an increase in marginal revenue 
(revenue per unit of output). From a distance education perspective, this definition of productivity is problematic. Fahy (1998) has suggested that we should be cautious in accepting corporate models as a basis for measuring productivity in distance education, and that performance enhancement may be a better metric for assessing the impact of technology in DE. The current interest in online audio methods in DE provides a useful context for further discussion of these principles.

\section{Technological Factors}

It is inappropriate to blame the technology for productivity failures. Technologies are merely tools which, in the hands of skilled artisans, can produce good results. Conversely, if the tool is used by someone unfamiliar with it, its results can be disappointing or counter-productive. When technologies are blatantly defective, their applications tend to disappear. Many of the problems with technology in general, and DE audio-conferencing specifically, relate to the systems' integration rather than to failings of the individual components. With an audio-conferencing system, one has to consider the capacities of the computers used by the teachers and students, the quality of its sound card, headphones, and microphones, issues of Internet connectivity and bandwidth; and these factors must be assessed on both the client and server sides. In addition, many audio-conferencing systems require the service of a third-party server to handle the communication traffic; and the reliability of this server has a central bearing on the system's overall performance. Although each individual component of the system may be functional and state-of-the-art, difficulties can arise in their integration. Some components may be incompatible, causing conflicts that render the whole system inoperable.

Emerging technology is usually compared to its predecessor. As McLuhan observed (1964), each new medium is interpreted relative to an older, similar medium. The implications of this statement for computer conferencing have been discussed by Anderson, Rourke, Archer, and Garrison, (2001). The quality and ease of use of audio-conferencing, for example, can be compared with the more mature technology of the telephone. This sets up the expectation that, if unfilled, results in disappointment on the user's part, and in rejection of the new technology. Emerging technology has to mature before it can be accepted. While Voice Over Internet Protocol (VoIP) promises greater connectivity at reduced costs, notably for individuals separated by great distances, this connectivity can be cumbersome and costly. Indeed, some VoIP providers are charging higher long-distance fees than the telephone companies. Ironically, the greatest productivity contribution of the emerging technology may that it is forcing competition upon the more mature technologies. There has been relatively little development in the VoIP technologies themselves during the past five years. In some ways, the technology's efficiency actually appears to have declined. Faculty members of Athabasca University's Centre for Distance Education were teaching via VoIP methods in 1999 (Baggaley, 2004), using the FireTalk software. Although communication via this software was still adversely affected by occasional delays, students forgave this deficiency in view of the application's user-friendliness. Unfortunately, the FireTalk freeware did not survive in the marketplace. The applications that have replaced it still suffer from communication delays and server outages at times of heavy Internet traffic, and their overall 
user-friendliness has not markedly improved. Microsoft, for example, has not released a new version of its NetMeeting conferencing software since 1999.

Another well-known set of observations with regard to technological development was provided by Moore (1965). "Moore's Law” would suggest that we have experienced an eight-fold increase in computing power since 1998 (Silicon, 2003), yet exploitation of that capacity is not evident in today's online audio-conferencing software. The range of audio-conferencing products has expanded dramatically during the past five years (see other reports in this series), yet their lack of robustness and user-friendliness is surprising given the advances in computing hardware during the same period. Ultimately, this lack of development may prove beneficial, allowing users to "catch up" with the applications, and enabling a critical mass of users to develop. The general lack of advancement, however, indicates deficiency in the economic model of the Internet on which online audio-conferencing has been based.

There is a wide range of Internet business models (Rappa, 2005). At one extreme, free and open source software (OSS) is advocated, and the other there are those who wish to extract as much financial gain from their products as possible. Each end of the spectrum demonstrates the productivity paradox at work. The lack of sustainability of the OSS/ freeware philosophy is emerging as unproductive, in that users are frustrated with the need to invest time and effort in learning to use a system, only to have it disappear. Moreover, many freeware applications rely on the use of advertising to support their development, a strategy that has had an adverse effect in turning people away from the products. OSS applications have also suffered from lack of consistency in their development. Alternatively, the financial profit model has led to the development of software so costly that the user's return on investment (ROI) diminishes, and economies of scale or productivity increases can be powerless to make the application costeffective. Morningstar, Schubert and Thibeault (2004), in a recent software evaluation report (Report \# 41) about the new WebCT Vista learning management system cite a potential cost increase for some institutions sixteen times greater than their current annual cost. These writers question whether such a costly proprietary product can survive.

\section{Human Factors}

Beyond the technological issues affecting the productivity paradox in the conferencing, a complex range of human factors is evident. The major investment in technology from the DE student's perspective are often not financial at all; instead the investment is the time and effort spent in becoming familiar with the system's software. This is certainly the case in relation to audio-conferencing, in which field productivity failure appears to stem from software's underuse. It has been suggested that for a technology to start having a significant effect on productivity it must reach a penetration of at least 50 percent (Economist, 2000), whereas synchronous audio techniques in North American DE appear to be used at far lower levels than this. Synchronous chat, both text and audio based, has gained a following among younger users. Bates (2000) has suggested "that technology-based learning is more acceptable and more affordable to working adults"; yet the use of synchronous communication methods in DE may not suit all students' schedules or learning styles. The working day restricts the amount of time available for 
synchronous learning, and the problem is compounded by the wide range of time-zones that separate the members of a typical DE class. In this context, class members often revert to asynchronous methods in order to arrange meetings, and may fall back upon that mode exclusively for their general interactions. Students' learning styles may also affect their software preferences. Whereas asynchronous conferencing methods encourage rapid reflective thinking, the think-on-your-feet style of discussion generated by synchronous audio-conferencing can be disconcerting for students unaccustomed to that style of online interaction.

Moreover, older adults who are the typical consumers of DE may be technologically challenged perhaps more so than generally assumed. This, in turn, may impede their ready adoption of audioconferencing techniques. Older adults may also perceive the typical uses of freeware chat applications as juvenile, and may avoid them. Software vendors, in catering to the young user, have done little to reduce this impression. The user interface of Yahoo Messenger, for example, is rampant with happy face icons that appeal to the younger generation, but which must be modified if the product is to attract a mature user base. In general, each of the above human factors is likely to influence students' willingness to spend time in practising the use of synchronous conferencing applications.

Solutions to the productivity paradox of audio-conferencing software should be focused on the human element. Technology is static, and unless it is efficiently manipulated by it human users, it remains so. The technologies of DE need to have an increased life cycle in order for teachers and students to become familiar with them, before jumping ahead to the next application or version. The skills developed in using a previous version should be transferable to updated versions. The financial model of online audio-conferencing in DE needs to encourage the development of usable, sustainable systems. Modularizing applications would have the welcome effect of giving users the opportunity to "step into" a system gradually, while keeping costs reasonable. Users will only invest in what they use.

\section{Conclusions}

In view of the classical viewpoints expressed by Solow's productivity paradox (1987) and Moore's Law (1965), it is not surprising that online methods are proving slow to evolve in the distance education field. Educators can address this problem by helping to dispel the problems of technological adoption experienced by the student. Users of online audio-conferencing methods, for example, need opportunities to practise their use in a non-threatening environment where mistakes can be made - for example, small-group sessions. They must be given time to practise their audio setup skills, connection procedures, discussion skills, and moderator techniques. Educational institutions can add to the satisfaction level of student and faculty users by providing audio-conferencing servers that are not subject to the congestion problems of public third-party servers. The more practised a user becomes with a tool, the more satisfying the use of the tool becomes, and the more likely that person will become an advocate for the use of the application by others. On the part of the users, patience and perseverance is required. Previous technological revolutions have taken 50 to 60 years to mature, and to reach acceptable productivity gains. We 
may have to wait another decade or two before the full maturity of today's information technology is realised.

The next report in the series examines current international uses of the CanCore metadata system.

N.B. Owing to the speed with which Web addresses are changed, the online references cited in this report may be outdated. They are available, together with updates to the current report, at the Athabasca University software evaluation site: http://cde.athabascau.ca/softeval/. Italicized product names in this report can be assumed to be registered industrial or trademarks.

JPB. Series Editor, Technical Evaluation Reports

\section{References}

Anderson, T., Rourke, L., Garrison, D. R., and Archer, W. (2001). Assessing Teaching Presence in a Computer Conferencing Context. Journal of Asynchronous Learning Networks 5(2). Retrieved January 5, 2005 from: http://www.sloan-c.org/publications/jaln/v5n2/v5n2_anderson.asp

Baggaley, J. (2004). Personal communication (18 December). Athabasca University, Alberta.

Bates, A. W. (2000). Managing Technological Change. San Francisco: Jossey-Bass.

Carlson, C. (1975). A Financial Efficiency Model. East Lansing, MI.: Michigan State University Press.

The Economist (2000). Solving the paradox. September 21. Retrieved January 5, 2005 from: http://www.economist.com/displayStory.cfm?Story_ID=375522

Fahy, P. J. (1998). Reflections on the productivity paradox and distance education technology. Journal of Distance Education, 13(2). Retrieved January 5, 2005 from: http://cade.athabascau.ca/vol13.2/fahy.html

McLuhan, M. (1964). Understanding Media: the extensions of Man. New York: McGraw-Hill.

Moore, G. E. (1965). Cramming more components onto integrated circuits. Electronics 38(8) 114 $-117$.

Morningstar, B., Schubert, J., and Thibeault, K. (2004). WebCT: A major shift of emphasis. International Review of Research in Open and Distance Learning, 5(3). Retrieved January 5, 2005 from: http://www.irrodl.org/content/v5.3/technote6.html

Rappa, M. (2005). Business Models on the Web. Digitalenterprise.org. North Carolina State 
University. Retrieved January 5, 2005 from:

http://digitalenterprise.org/models/models.html

Silicon (2003). Research at Intel: Moore’s Law. Paper found at the Intel.com website. Retrieved January 5, 2005 from: http://www.intel.com/research/silicon/mooreslaw.htm\#

Solow, R. (1987). We’d better watch out. Book Review. New York Times, July 12, p. 36.

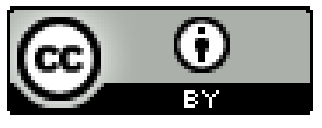




\title{
46. CanCore: in Canada and Around the World
}

\author{
Norm Friesen \\ CanCore Initiative \\ Athabasca University - Canada's Open University
}

\begin{abstract}
The current report provides an update on Report \#11 and Report \#40 in this series, describing the increasing range of international uses of the CanCore metadata for the indexing of learning objects.
\end{abstract}

\section{Introduction}

CanCore (http://www.cancore.ca) is a learning resource metadata initiative funded by Industry Canada and supported by Athabasca University, Alberta, and TeleUniversite du Quebec. CanCore is designed to facilitate the indexing of online educational resources or Learning Objects (LO), by assisting project implementers and catalogers in the development of highquality systems and indexing based on the IEEE Learning Object Metadata (LOM) standard. This standard specifies the ways in which descriptive data (metadata) about these educational resources can be formulated to simplify searching and information interchange between systems. The LOM standard is both complex and general in nature, however. It contains a broad range of elements, and leaves open many possibilities for interpretation. CanCore provides guidance on interpretation and implementation of the LOM at a level of detail much greater than the standard itself. In the words of one private sector implementer, "CanCore has supplied some of the best guides and best practices on how to apply learning object meta-data in the real world" (Recombo, 2004). As a result, the CanCore guidelines have been used in public and private-sector projects in many Canadian jurisdictions and provinces, in pan-Canadian initiatives, and in projects in the USA, France, the UK, and elsewhere. As a result of this work, CanCore and Canada generally have been widely recognized as providing leadership in e-learning metadata implementation. This article describes the range and character of CanCore implementations, illustrating the way CanCore is utilized, by focusing specifically on a number of developments currently underway in Ontario. 
CanCore has been working with an expanding community of implementers since November 2000. Its beginnings were in the context of collaborative initiatives involving several Canadian provinces: the LearnAlberta portal (http://learnalberta.ca/), the Campus Alberta Repository of Educational Objects (CAREO) project (http://www.careo.org/), and the Telecampus repository of online courses developed at the University by TeleEducation of New Brunswick. CanCore has subsequently been active in the pan-Canadian eduSource project sponsored by CANARIE. Most recently, CanCore's focus has returned to a number of localized private and provincial government implementations, with financial support by the Multimedia Learning Group of Industry Canada, and under the management of Athabasca University.

Among the provincial projects currently implementing CanCore are the BCcampus Learning Resources Centre, the LearnAlberta portal, the Centre for Distance Learning and Innovation (CDLI) Portal of Newfoundland and Labrador, and the normetric metadata profile work in Quebec. eduOntario is a further provincial project for which CanCore has been selected "as the key cataloging model" (Hannaford and Sutherland, 2004). This particular project, funded by the Ontario Knowledge Network for Learning (OKNL) and based at Ontario Institute for Studies in Education (OISE), is developing "a general-purpose repository prototype" to serve the needs of K-12 and other learners in Canada's most populous province (St. John, Hyman, Hannaford, and Sutherland, 2004). The project leaders are Avi Hyman (OISE) and Baiba St. John (OKNL); and project managers are Brian Sutherland and Julie Hannaford (OISE). As a part of this and other work, this initiative has also developed OnCore, a version of CanCore designed to meet the educational needs of Ontario. The adaptation of CanCore's classification elements allows each resource catalogued in OnCore to be indexed in relation to Ontario-specific educational outcomes and expectations. OnCore has also been used by Ontario's Bibliocentre to catalogue a number of TVOntario video resources. (TVO is a provincially-funded educational television network that reaches approximately 12 million Ontarians and subscribers to cable and satellite television across Canada.)

The OnCore group has also been exploring the possibility of further adapting CanCore to work alongside another successful metadata solution for online resources: Rich Site Summary or Real Simple Syndication (RSS). RSS is used as a way of syndicating or distributing news stories, annotated links, and other timely information from one location to many other locations quickly and easily. Combined with CanCore, RSS could be used as a way of alerting users and repositories to the availability of new and relevant learning objects and metadata records, thus increasing levels of resource sharing and reuse. As the OnCore group explains, "the goal is to piggyback LOM (CanCore) Learning Object metadata on RSS to energize the many Learning Object Repositories which are creating resources but not facilitating resource discovery" beyond their own collections (B. Sutherland, personal communication, November 2, 2004; Hannaford and Sutherland, 2004). A number of other CanCore and RSS implementers, as well as the CanCore initiative itself, are currently working together to find ways to accomplish this "piggybacking" or adaptation. 


\section{Other CanCore Implementations}

Other implementations of CanCore have been undertaken in a wide range of projects and educational contexts. A list of some of these projects, products and organizations, and their respective websites is provided below. In each case, a brief indication is provided of how the initiative has used CanCore.

- AD LIB Project (http://adlib.athabascau.ca/adlib/). CanCore has been used as a basis for defining the metadata creation interface for this project; CanCore documentation is used for help screens. Free registration is required to view the metadata interface.

- BC Campus (http://www.bccampus.ca). CanCore is being referenced and adapted in the Learning Object Repository Project of BC Campus: The goal of this project is to build the foundation for a comprehensive BC learning objects repository (LOR) for British Columbia K-12 and postsecondary education. It is the first phase of a larger goal of BCcampus, which is to provide a LOR model for the BC educational system across all disciplines (http://www.bccampus.ca/Page95.aspx).

- BC Open School. BC Open University (http://careo.prn.bc.ca/cgibin/WebObjects/CAREO.woa). CanCore's guidelines have been used to develop metadata records. BC School District \#60 Peace River North (http://careo.prn.bc.ca/cgibin/WebObjects/CAREO.woa). CanCore's guidelines have been used to develop new metadata records and to recapture metadata records that previously existed in the Scrapbook (http://scrapbook.prn.bc.ca) and the Learning Lab (http://tll.prn.bc.ca/newTLL/). XSLT was used to convert the MySQL based records from the Scrapbook and the ZOPE based records from the Learning Lab into CanCore based records in a localized version of CAREO.

- Canadian Heritage (http://www.pch.gc.ca/). CanCore's metadata approach plays a central role in this overall metadata strategy recommended for Canadian Culture Online Policy (http://mdlet.jtc1sc36.org/doc/SC36_WG4_N0075.pdf).

- CDLI Portal (http://www.cdli.ca/). In making its learning objects available through its portal, the Centre for Distance Learning and Innovation of the Department of Education in Newfoundland and Labrador is adhering to CanCore's guidelines.

- CELTS (China). CanCore metadata element subset is referenced in defining CELTS subset, "the core set of CELTS-3.1 is a subset of CanCore, which in turn is a subset of LOM" (http://mdlet.jtc1sc36.org/doc/SC36_WG4_N0059.pdf).

- CMEC Portal. As is explained in CMEC documentation: "proponents will be expected to meta-tag each multimedia learning object using the standard descriptors developed for use in the CMEC portal. These descriptors follow the CanCore standard" (http://dev.cdli.ca/developer/meta-tagging.htm).

- Desire2Learn (http://www.desire2learn.com). Desire2Learn is a full-featured learning management system which includes a learning object repository. "The D2L Learning Object Repository technology incorporates industry standards, such as SCORM, CanCore, IMS, and others ..." 
- Edusplash and Lionshare (http://www.edusplash.net). The eduSplash peer-to-peer metadata and object sharing software advertises itself as "powered by CanCore." This interface and tool are being incorporated in the international Lionshare project.

- Eisenhower National Clearinghouse (http://www.enc.org/). CanCore's guidelines documents and discussions have been used extensively in the development of metadata for this American project (http://www.dlib.org/dlib/september03/lightle/09lightle.html).

- Etraffic Solutions Inc. (http://www.etrafficsolutions.com). This is an international online learning content and applications developer that uses CanCore in creating and tagging its learning objects (http://www.etrafficsolutions.com/about/news/newsletters/apr2003.html).

- FLORE (http://www.pomme.ualberta.ca/french/french/a.html) is a free repository of French language educational resources. It is meant to help the user to find appropriate sites and specific learning objects for teaching or learning French. FLORE is designed for faculty and students in post-secondary institutions. It offers over 1,000 online resources with annotations such as content descriptions and peer reviews. CanCore is assisting FLORE with the alignment of its metadata to CanCore/LOM elements and mechanisms of exchange.

- Government of Canada Metadata Framework (Canadian Treasury Board). "Within the GoC, CanCore is the preferred interpretation of the IEEE LOM" (www.cio-dpi.gc.ca/imgi/mwg-gtm/ems-sml/docs/2004/meta-profil/meta-profil04_e.asp).

- LearnAlberta.ca (http://www.learnalberta.ca). "The metadata records used to locate and describe resources available at this portal have been developed using the CanCore guidelines as a central input."

- LLearn (http://www.llearn.net/project.php). "The LLEARN project is a private-public partnership . . . designed to bring together best practices in second language teaching/ learning and the capacity of broadband technology . . . LLEARN will be SCORM and CanCore compliant (www.llearn.net/_pdf/documents_papers_3pager.pdf).

- Magic Lantern (http://www.magiclantern.ca/index.asp). As a major supplier of video learning objects to Alberta Learning, Magic Lantern has created metadata records for a large number of its resources, using CanCore as a guide.

- ManUeL Metadata Application Profile and Metalab tool. CanCore is acknowledged as being the basis for this French application profile. (Documentation is under development). (http://minotaure.ulysse.ubordeaux.fr/area21/resource_manager_1.7/).

- National Science Digital Library (http://www.nsdl.org/). In developing and refining its Dublin Core-based metadata scheme, the NSDL has consulted with CanCore staff and utilized CanCore's guidelines.

- NORMETIC Quebec (http://www.profetic.org:16080/normetic) The CanCore element subset and guidelines has been used as central inputs in the development of the Normetic element subset (http://www.profetic.org:16080/normetic/article.php3?id article=53).

- Recombo (http://www.recombo.com/) has utilized CanCore in a number of its metadata tools.

- Peace River North School District's Resource Scrapbook (http://scrapbook.prn.bc.ca/). CanCore Guidelines has been used in updating this collection's metadata. 
- TeleCampus is a listing of 50,000 courses and course components used by CanCore to update its metadata. A version of this repository will be housed at Athabasca University.

- The Inclusive Learning Exchange (TILE) Project (http://barrierfree.ca/tile/project). "CanCore Metadata (with extensions)" has been used to mark up the content in this collection.

- TVOntario (http://www.tvo.org). "TVOntario recently adopted a version of CanCore to catalogue its video resources in relation to the Ontario Curriculum" (http://www.eduontario.ca/research/oncore/).

- UK LOM Core (http://www.cetis.ac.uk/profiles/uklomcore/). "Lorna Campbell, one of the UK LOM Core's initiators, felt that the depth of gratitude owed to the CanCore makers was well worth a name check, and also neatly indicated the similarity between the two adaptations (http://www.cetis.ac.uk/content/20030731165743/).

\section{References}

Hannaford, J. and Sutherland, B. (2004). OnCore. Retrieved January 5, 2005 from: http://www.eduontario.ca/research/oncore/

Recombo Inc. (2004). Resources, Learning Standards Meta-data. Retrieved January 5, 2005 from: http://www.recombo.com/resources_standards_meta.htm

St. John, B., Hyman, A., Hannaford, J., and Sutherland, B. (2004). Developing a Prototype for an Ontario Education Portal. (PowerPoint Presentation). Retrieved January 5, 2005 from: http://www.eduontario.ca/showcase2004.ppt

N.B. Owing to the speed with which Web addresses are changed, the online references cited in this report may be outdated. They are available, together with updates to the current report, at the Athabasca University software evaluation site: http://cde.athabascau.ca/softeval/. Italicized product names in this report can be assumed to be registered industrial or trademarks.

JPB. Series Editor, Technical Evaluation Reports

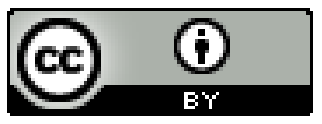

